FREDERIK MARTELL

\title{
The Protection of Consumers in Rest Homes - TIME FOR A CHANGE?
}

\author{
LLM DISSERTATION
}

LAWS 592: DISSERTATION

TE WHARE WĀNANGA O TE ŪPOKO O TE IKA A MĀUI

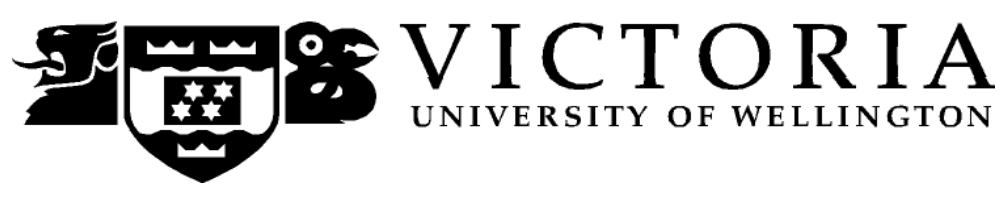

2012 / 2013

\section{Word length}

The text of this paper (excluding table of contents, abstract, footnotes, and bibliography) comprises approximately 36,342 words. 


\section{Table of Contents}

I

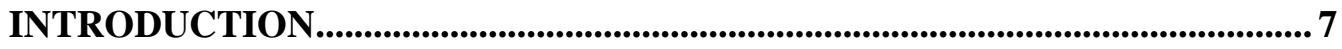

II IS REGULATORY INTERVENTION ON REST HOME CONTRACTS

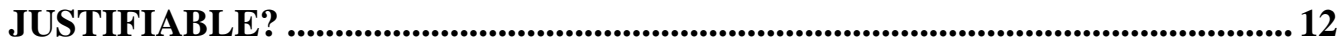

A Informational Asymmetries ..................................................................................... 14

B Providers Psychological Superiority ........................................................................ 18

C Economic Superiority of the Provider.......................................................................... 19

D Deterioration of the cognitive and intellectual, but also emotional, sensitive and social-communicative skills ............................................................................ 20

E Barriers to Consumer Access to Justice................................................................... 22

F Abstract Exposure of Physical Integrity, Health and Wealth................................. 24

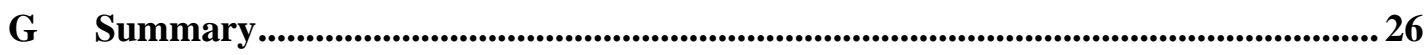

III STATUTORY REGULATIONS IN NEW ZEALAND, AUSTRALIA AND

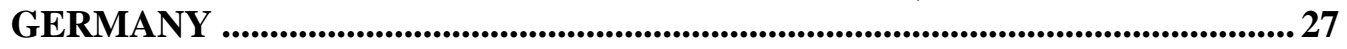

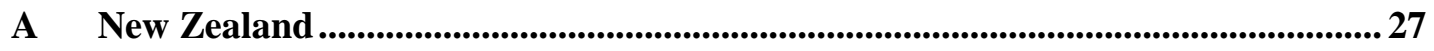

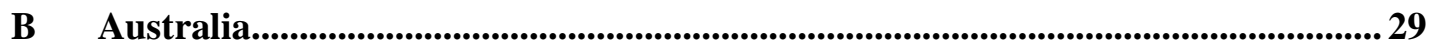

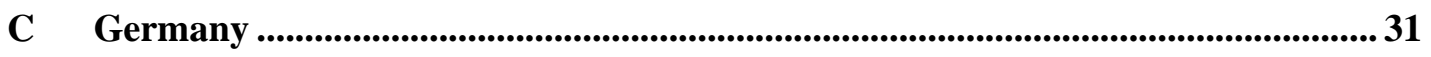

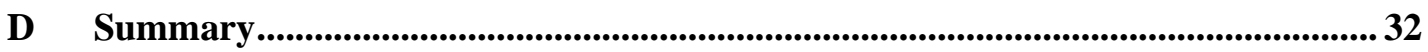

IV INFORMATION OBLIGATIONS AS A MEASURE TO PROTECT ELDERLY CONSUMERS IN REST HOMES ...................................................... 33

A Advantages of Consumer Protection by Information................................................. 33

B Existing Statutory Rules and Regulations ............................................................ 34

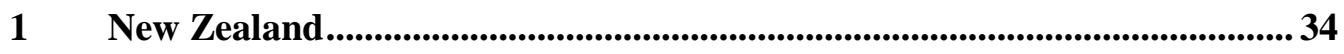

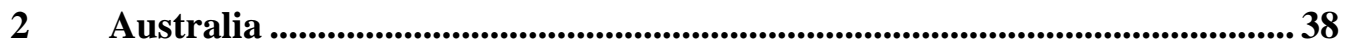

$3 \quad$ Germany ..................................................................................................................... 40

C Limitations of Consumer Protection by Information ............................................. 42

1 The Insights of Research into Consumer Behaviour ................................... 43

a. Limitations on Consumers’ Ability to Process Information.............. 43

b. Limited Benefit of Information .........................................................44

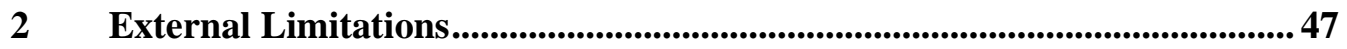

3 Point of Reference: The Average Consumer ....................................................... 48

4 Health Care Services as Credence Goods.....................................................49

5 Consequences for the Structuring of Information Obligations ...................50 50

D Proposals to Maximise the Positive Impact of Consumer Information .................. 51

$1 \quad$ Pros and Cons of the German Legislation....................................................... 52

$2 \quad$ Pros and Cons of the Australian Legislation................................................ 53

3 Pros and Cons of New Zealand's Legislation..................................................... 53

4 The Future Path for New Zealand .............................................................54

a. Obligation to Use Plain and Intelligible Language............................... 55 
b. Creation of a Legally Standardised Information Sheet ......................56

c. Information Sheet about Consumers’ Rights ......................................5 57

d. Defining the Way the Information is Provided................................... 58

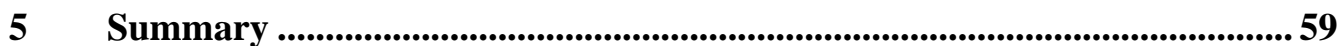

V THE PROTECTION OF THE CONSUMER DURING THE IMPLEMENTATION OF THE REST HOME CONTRACT .............................61

A Quality of Services Provided ..................................................................................... 61

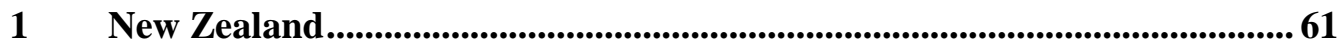

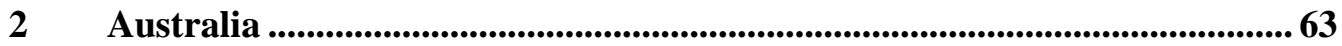

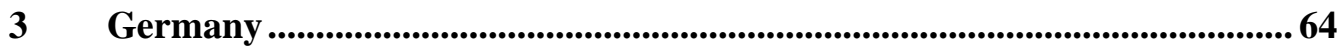

$4 \quad$ Lack of Mandatory Staffing Requirements.................................................... 65

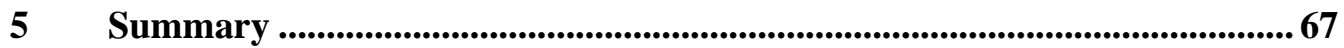

B Consequences of Improper Service Performance ....................................................... 67

1 Existing Statutory Rules and Regulations in New Zealand, Australia

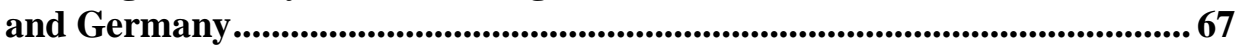

2 Proposals for Improvement ...............................................................................69 69

C Security of Place within the Rest Home .................................................................. 70

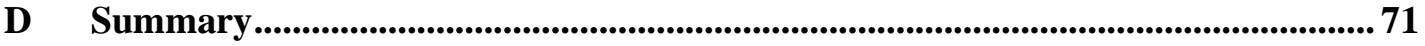

VI THE PROTECTION OF CONSUMERS AT THE TIME OF THE TERMINATION OF THE CONTRACT ................................................................. 72

A Consumer's and Provider's Right to Give Notice ................................................... 72

1 Existing Statutory Rules and Regulations in New Zealand, Australia and Germany............................................................................................................ 72

2 A Strict Regulation of Cancellation Options - A Future Way for New Zealand? ............................................................................................................ 75

B Providers' Obligations after the Termination of the Contract ............................. 78

1 Existing Statutory Rules and Regulations in New Zealand, Australia and Germany..................................................................................................... 78

2 Evaluation and Criticism - Does New Zealand Need Further Obligations on Providers?........................................................................................ 81

C Granting of a Cooling-off Period ............................................................................... 82

$1 \quad$ Existing Statutory Rules and Regulations .................................................... 83

2 Justification of Cooling-off Periods as a Measure to Protect the

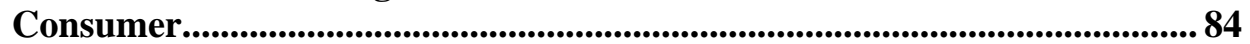

$3 \quad$ Structuring a Cooling-off Period in New Zealand ......................................... 87

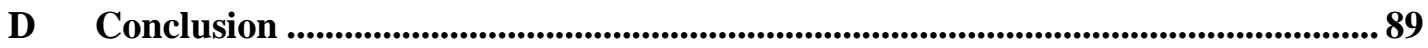

VII ACCESS TO JUSTICE FOR ELDERLY CONSUMERS IN REST HOMES .... 90

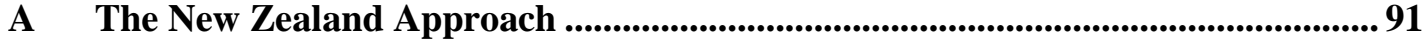

1 Internal Complaints Resolution Processes .....................................................91 91

2 The Health and Disability Commissioner....................................................... 92

3 The Advocacy Service...............................................................................96 
4 Complain to the District Health Boards ................................................................96

5 Complain to the Ministry of Health ..........................................................99

6 The Accident Compensation Corporation (ACC) ............................................99

7 Civil Law Proceedings and Disputes Tribunal........................................... 100

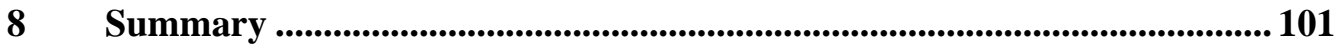

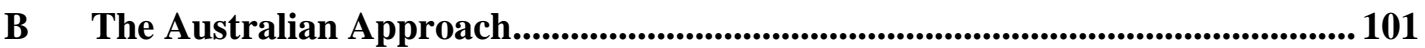

1 Australia's Complaint Scheme ....................................................................... 101

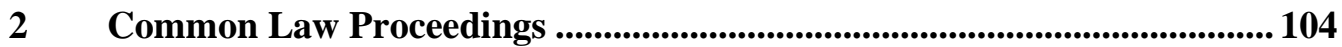

3 Enforcement of Obligations Stated in the Australian Consumer Law

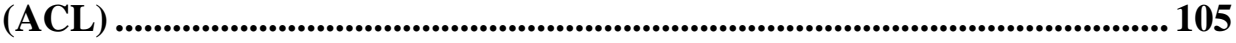

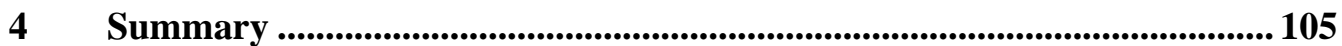

C The German Approach............................................................................................. 106

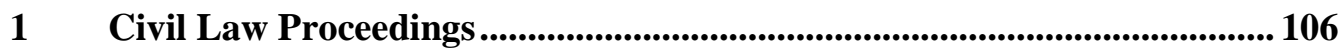

2 Out-of-Court Opportunities for Resolving Disputes in Germany.............. 106

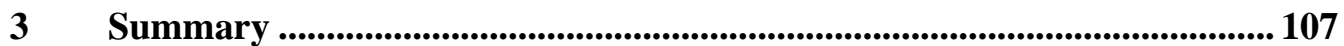

D Advantages and Disadvantages of New Zealand's Approach................................ 107

1 Advantages of New Zealand's Approach.................................................. 108

2 Proposals to Improve Consumers' Access to Justice..................................... 110

a. Establishment of a New Commissioner ............................................... 110

b. Introduction of a New Complaint Scheme ............................................. 111

c. Streamlining of the New Complaint Scheme ....................................... 113

d. Dramatic Decline in Disciplinary Proceedings ..................................... 114

e. Right to Appeal ................................................................................ 115

f. Lessons from the Retirement Village Act 2003 (RVA)...................... 116

g. Remaining Communication Barriers................................................ 118

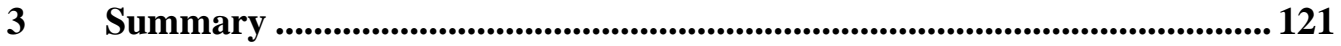

VIII IMPLEMENTATION OF THE DIFFERENT MEASURES ............................. 123

IX CONCLUSION............................................................................................................. 126

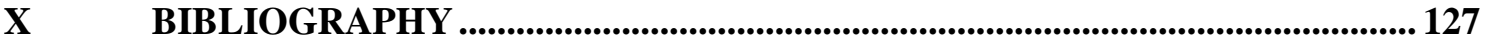

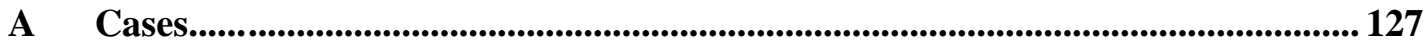

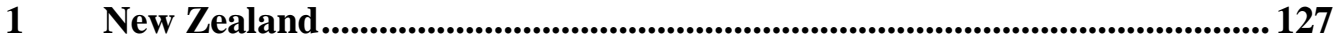

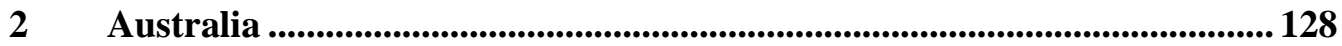

3 United Kingdom................................................................................................. 128

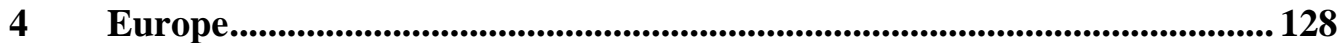

5 Germany ........................................................................................................ 129

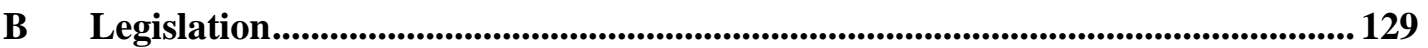

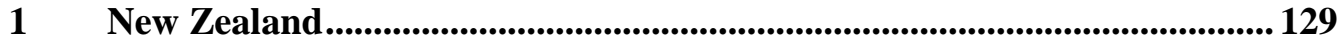

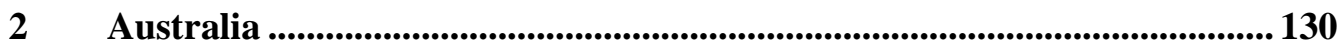

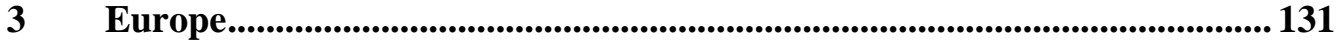

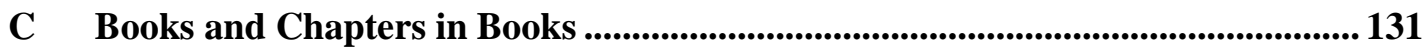




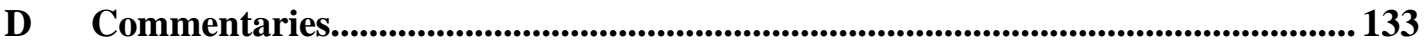

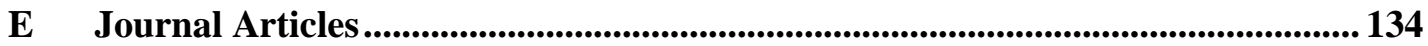

F Parliamentary and Government Materials ....................................................... 141

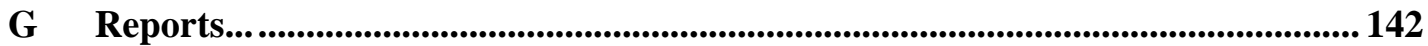

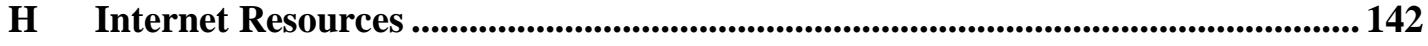

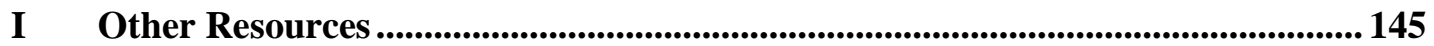




\begin{abstract}
This dissertation examines the statutory protection of elderly consumers in rest homes and makes several proposals of how to improve their protection. The dissertation compares New Zealand's legislation with the existing rest home related legislation in Australia and Germany to improve New Zealand's regulations.
\end{abstract}

At first, the dissertation characterises elderly consumers as a consumer group with special vulnerabilities. According to the dissertation several reasons can be identified, which justify regulatory intervention in favour of the elderly. Secondly, the dissertation gives an overview of the relevant rest home legislation in New Zealand, Australia and Germany.

In the later chapters the dissertation examines the existing information obligations, and the statutory protection of elderly consumers during the implementation and at the time of the termination of a rest home contract. The author argues that many of the existing consumer protection measures are not specifically tailored for consumers in rest homes and, therefore, do not ensure comprehensive protection. Furthermore, the author identifies several gaps in protection and proposes to introduce targeted new protection measures to close these gaps. Subsequently, the dissertation considers the access to justice for elderly consumers. The author states that the existing system offers some advantages but is far from being perfect. He speaks in favour of establishing a new Commissioner who is responsible for the issues of elderly consumers and the enhancement of their legal position.

Lastly and on the basis of the previous outcomes, the author recommends creating a new piece of legislation specifically tailored for the protection of elderly consumers in rest homes to implement all the proposed changes. In the author's opinion a new Act could build on the existing consumer protection measures but should also improve them to ensure the best protection possible. The author also outlines how a code of practice should be put in place, which sets out minimum requirements. 


\section{Introduction}

The population of New Zealand is getting older and it is, therefore, not surprising that New Zealand has a fast growth within the population of over 65 year olds. Since 1980 the number of people aged 65 and over has doubled to 600,000 in 2012 and it is likely that this number will double again to 1.2 million by 2036, and further rise to 1.5 million by 2061. ${ }^{1}$ This increase will be accompanied by a dramatic change in the age structure of New Zealand's population. It is to be expected that the proportion of the population aged 65 and over will increase from 14 per cent in 2012 to 23 per cent in 2036 and 26 per cent in $2061 .^{2}$ Statistics New Zealand also predicts that the median age ${ }^{3}$ of New Zealand will rise significantly from 37 years in 2012 to 41 years by the late 2030s and 44 years by $2061 .{ }^{4}$ Moreover, the elderly group itself is ageing as well. While in 2012 approximately 1 in 8 people aged 65 and over was older than 85 years, it is expected that by 2061 approximately 1 in 4 people in the age group of 65 and over will be older than 85 years. ${ }^{5}$ In volume terms, 76,000 people were aged 85 and over in 2012 and it is expected that the number will rise to $180,000-210,000$ in 2036, and 290,000 - 430,000 in 2061. ${ }^{6}$ These changes in proportion of the population are not unique for New Zealand. In most developed nations around the world the population of consumer aged 65 or over has been rising at an increasing rate. ${ }^{7}$

${ }^{1}$ Statistics New Zealand "National Population Projections: 2011(base)-2061” (19 July 2012) Statistics New Zealand <www.stats.govt.nz $>$ at 6.

${ }^{2}$ At 1 and 6; similarly Statistics New Zealand "How will New Zealand's ageing population affect the property market?” Statistics New Zealand <www.stats.govt.nz> at 6.

${ }^{3}$ Median age means that half the population is younger, and half the population is older, than this age. See Statistics New Zealand, above n 1, at 12.

${ }^{4}$ At 4.

${ }^{5}$ Statistics New Zealand, above n 2, at 7; Statistics New Zealand, above n 1, at 7.

${ }^{6}$ Statistics New Zealand, above n 1, at 7; for further worldwide statistics see Organisation for Economic Co-operation and Development Ageing, Housing and Urban Development (OECD, 2003) at 83.

${ }^{7}$ For Germany and the European Union see Statistisches Bundesamt "Ältere Menschen in Deutschland und der EU“ (June 2011) Statistisches Bundesamt < www.destatis.de> at 82 and 83 (translation: Aged People in Germany and the European Union); see Grant Thornton "Aged Residential Care Service Review" (September 2010) Grant Thornton <www.grantthornton.co.nz> at 7.5.; see Ümit Taş, Arianne P Verhagen, Sita MA Bierma-Zeinstra, Albert Hofman, Else Odding, Huib AP Pols and Bart W Koes "Incidence and risk factors of disability in the elderly: The Rotterdam Study” (2007) 44 Preventive Medicine 272 at 272; for Australia see Sharon Andrews-Hall, Anna Howe and Andrew Robinson "The dynamics of residential aged care in Australia: 8-year trends in admission, separations and dependency" (2007) 31 Australian Health Review 611; for Ireland Clodagh O’Dwyer and Desmond O'Neill "Developing Strategies for the Prevention, Detection and Management of Elder Abuse: The Irish Experience” (2008) 20 J Elder Abuse \& Neglect 169 at 170 . 
The ageing of the population is one main factor for an increased demand for residential care services including rest home care. ${ }^{8}$ With age the severity of disability increases significantly and, consequently, the need for care services increase as well. ${ }^{9}$ The older a person is, the more likely there will be a need for health and disability services. Even the rise in life expectancy does not alter this, because, regardless of the life expectancy, often severe disability occurs in the last two to four years of life. ${ }^{10}$ It has been stated that 25 to 30 per cent of people over 65 can expect to stay in long-term care before they die. ${ }^{11}$ Thus, when considering that there will be a fast growth in the population of people who are older than 65 years over the next decades it does not come as a surprise that there will be a growing demand for rest home care services. ${ }^{12}$ It has been outlined that numbers of older people in residential care will double by $2021 .{ }^{13}$ Therefore, more elderly consumers than ever before will face the question of whether they want to live at home or move into a rest home where it is easier to meet their specific needs. Overall, it can be said that the above statistics indicate clearly that the number of aged consumers in rest homes is very likely to increase significantly, which goes hand in hand with the difficult challenge of protecting their rights. ${ }^{14}$ New Zealand's legislature will not be able to turn away from these facts. The increasing rest home sector leads to the increasing importance of appropriate regulation of this area of law. However, horror stories of inadequate care, neglect and abuse ${ }^{15}$ and several Health and Disability Commissioner's decisions

\footnotetext{
${ }^{8}$ Grant Thornton, above $\mathrm{n} 7$, at 74 .

9 Ministry of Health "Health of Older People in New Zealand" (2002) Ministry of Health $<$ www.health.govt.nz> at 47; Grant Thornton, above n 7, at 74; Judith Davey, Virginia de Joux, Ganesh Nana and Mathew Arcus “Accommodation Options for Older People in Aotearoa/New Zealand" (June 2004) Institute for Governance and Policy Studies <igps.victoria.ac.nz> at 39.

${ }^{10}$ Warren P Hogan "Review of Pricing Arrangements in Residential Aged Care” (2004) Australian Government Department of Health and Ageing < www.health.gov.au> at 89.

${ }^{11}$ Jessica Wilson "Rest home roulette" (August 2009) Consumer < www.consumer.org.nz> at 27.

${ }^{12}$ Grant Thornton, above $n 7$, at 79 speaks of an additional 1,500 beds every year to keep up with the demand.

${ }^{13}$ Davey, de Joux, Nana and Arcus, above n 9, at 12 and 115.

${ }^{14}$ Michael Barnett and Robert Hayes "Not seen and not heard: Protecting elder human rights in aged care" (2010) 14 UWSLR 45 at 50.

${ }^{15}$ Marika Hill "Appalling plight of elderly revealed” (28 April 2013) Stuff <www.stuff.co.nz>; Geoff Cumming and Martin Johnston "Review: Rest home roulette" (11 August 2012) The New Zealand Herald $<$ www.nzherald.co.nz>; for a list of rest homes investigated see http://www.consumer.org.nz/reports/resthomes/list-of-homes-investigated; New Zealand Press Association "Nurse struck off for punching elderly man in mouth" (11 May 2010) The New Zealand Herald <www.nzherald.co.nz>; Shane Cowlishaw "Rest home tardy over referral to hospital” The Dominion Post (New Zealand, 20 September 2012); for details regarding Australia see Barnett and Hayes, above n 14, at 49; Aged Care Crisis "Elder Abuse" (10 February 2008) Aged Care Crisis <www.agedcarecrisis.com>; Rachel Browne "Alarm at violence in aged
} 
(hereinafter: the Commissioner) ${ }^{16}$ indicate that the rest home sector as it currently stands faces severe problems and that elderly consumers are not always well protected by the law. Some people state that these horror stories are only the tip of an iceberg and the sad reality is that such cases are not rare, but often not exposed to public scrutiny. ${ }^{17}$ This is supported by a publication of Age Concern that outlines “[o]ur elder abuse and neglect prevention services work with about 500 older people who have been abused or neglected every year." 18 Considering that abuse and neglect are only two examples of violating elderly person's rights and that a high number of incidents have gone unreported there is a demand for comprehensive protection of elderly consumers in rest homes.

Against this background, the scope of this dissertation is to answer the question whether New Zealand's legislation takes enough care of elderly consumers in rest homes. As a first step, this dissertation sheds light on the special vulnerabilities of elderly consumers and why they are in the need of special protection. Then it gives a brief overview of the existing regulations in the rest home sector not only in New Zealand but also in Australia and Germany. This is because in the further course of this work New Zealand's legislation is compared with the regulations in Australia and Germany. This is to improve New Zealand's regulations by using some of the best consumer protection measures from other countries. The dissertation considers the Retirement Village Act 2003 (hereinafter: the RVA) and other pieces of New Zealand's legislation where necessary and appropriate. The remaining chapters of the dissertation examine the effectiveness of the existing statutory protection of elderly consumers during the phase of entering into a rest home contract, as well as the phases of implementation and termination of the contract. It is shown that the existing regulations often do not focus on the special needs of aged consumers in rest homes and that the protection is designed inadequately and contains several gaps. To close the gaps that have been found every chapter will include several

care” (28 March 2010) The Age National <www.theage.com.au>; for the United States of America see Audrey S Garfield "Elder Abuse and the States' Adult Protective Service Response: Time for a Change in California” (1990-1991) 42 Hastings LJ 859 at 863 to 869.

${ }^{16}$ See Health and Disability Commissioner Decision 09HDC01641 (21 June 2012); Health and Disability Commissioner Decision 09HDC02110 (2 March 2012); Health and Disability Commissioner Decision 08HDC20957 (3 November 2010); Health and Disability Commissioner Decision 06HDC06457 (20 August 2009).

${ }^{17}$ New Zealand Nurses Organisation "Rest home "horror stories" will continue” (8 October 2009) New Zealand Nurses Organisation <www.nzno.org.nz>; It has been stated that there are approximately 100,000 unreported cases of elder abuse throughout Australia per year. See Lillian Jeter "Facts on Elder Abuse Australia” (February 2011) Office of the High Commissioner for Human Rights < www.ohchr.org> at 1.

${ }^{18}$ Age Concern "Respect Not Threats - Information about elder psychological abuse for resthome carers and managers” (2011) Age Concern New Zealand <www.ageconcern.org.nz> at 1. 
proposals to enhance the legal position of elderly consumers. The penultimate chapter examines whether consumers have an easy way to enforce their statutory rights against providers and proposes many changes to create consistent access to justice for aged consumers in rest homes. The last chapter proposes the introduction of a new piece of legislation tailored for rest home care to implement the different proposals into law.

However, to limit the scope of this dissertation, this paper will almost exclusively focus on the relationship of the provider and the consumer. Therefore, some aspects that also influence the contractual relationship will not be examined. This applies in particular to the areas of certification and audit of providers, the inspection of places and reporting requirements, but also to administrative and criminal enforcement remedies. Furthermore, some issues of a rest home contract, for example extra service charges and residential care subsidy, are not examined. This also applies to the proposed prohibition of unfair business terms in the Consumer Law Reform Bill 2011. ${ }^{19}$ A prohibition of unfair business terms could make a great contribution to protect consumers. However, to present hypothetical cases in which a term used by a provider would be unfair goes beyond the scope of this dissertation. Moreover, the proposed law is quite vague, whereas this dissertation will recommend specific targeted measures to protect elderly consumers in rest homes.

Some terms should be explained at this point. The term "rest home care" is not used uniformly in New Zealand, Australia and Germany. This dissertation takes the definition in New Zealand's regulation as a basis, especially the definition of rest home care in s 6 of the Health and Disability Services (Safety) Act 2001. Based on this definition rest home care is a form of "residential care provided for the care or support of, or to promote the independence of, people who are frail." ${ }^{20}$ In addition, it is necessary that the services are provided for 3 or more people unrelated by blood or marriage, and that the provider

\footnotetext{
${ }^{19}$ The proposed prohibition of unfair contract terms in the Consumer Reform Bill 2011 will not be a sufficient solution to this problem, because the existing rest home contracts regularly do not use an unfair contract term. However, that does not mean that further measures to protect elderly consumers are not justified. Regarding the Consumer Reform Bill 2011 and the prohibition of unfair business terms see Ministry of Consumer Affairs Consumer Law Reform: A Discussion Paper (Wellington, 2010) at 6.2.1; Ministry of Consumer Affairs Consumer Law Reform Additional Paper - Unfair Contract Terms (Wellington, 2010); for details about the justification of a prohibition on unfair business terms see Kate Tokeley "Introducing a Prohibition on Unfair Contractual Terms Into New Zealand Law: Justifications and Suggestions for Reform” (2009) 23 NZULR 419.

${ }^{20}$ Health and Disability Services (Safety) Act 2001, s 6(1)(a).
} 
principally runs a residence for elderly consumers and acts in consideration of payment. ${ }^{21}$ As rest home care is a long-term care service that is part of the superordinate term residential care, legislation that focuses more generally on the term residential care also applies to rest homes in the sense understood here. However, neither rest home care nor residential care includes living in a retirement village, because in contrast to the dependence of elderly consumers in rest homes, retirement villages are characterised by the independence of their residents.

For the purpose of this dissertation, the term "elderly consumers" is used to describe all consumers entering into a rest home contract with a provider, regardless of the extent to which they need care services. The term "provider" is used in accordance with s 3 of the Health and Disability Commissioner Act 1994 (hereinafter: the HDCA), but is limited to providers that run a rest home facility.

${ }^{21}$ Section 6(2). 


\section{Is Regulatory Intervention on Rest Home Contracts Justifiable?}

The question, whether and to what extent a legal intervention in favour of elderly consumers is justified, entails first dealing with the aims and the legitimation of consumer law and consumer regulation. Moreover, it is necessary to examine the different reasons for the need of protection for consumers and, in particular, elder consumers, as a special consumer group. This is an essential step, otherwise the examination if the existing measures to protect consumers in rest homes are effective and expedient would built on weak ground. In other words, this chapter will answer the fundamental questions of consumer law with a focus on the group of elderly consumers: How necessary are measures to legally protect consumers? To what extent are consumers disadvantaged? ${ }^{22}$

A further reason for examining the reasons for consumer protection is that any legislation in favour of consumers contravenes the freedom of contract principle. The freedom of contract principle states that the contract parties can freely negotiate the content of their contract. Therefore, everyone is, in principle, entitled to enter into legal relationships freely as long as the content of the contract corresponds with the common will of both parties. $^{23}$ Consumer protection legislation often overrides this principle by restricting what the parties can and cannot agree to.

To justify this contravention of the freedom of contract principle, some authors claim that in a free market equal strength between the contract parties is a fiction. ${ }^{24}$ These authors state that an inequality of bargaining power between consumers and providers exists with the consequence that consumers are generally in a weaker bargaining position. ${ }^{25}$ Therefore, the idea of a free bargain that underlies the freedom of contract principle no longer exists. For this reason, intervention in favour of the weaker party is necessary to restore the principle of freedom of contract. However, "the concept of inequality of

\footnotetext{
${ }^{22}$ Colin Scott and Julia Black Cranston's Consumers and the Law (3rd ed, Butterworths, London, 2000) at 1.

${ }^{23}$ Hein Kötz "Der Schutzzweck der AGB-Kontrolle - Eine rechtsökonomische Skizze” (2003) 43 JuS 209 at 209 (translation: The Protective Purpose of the Control of General Terms and Conditions - a Legal Economic Sketch).

${ }^{24}$ Jacob S Ziegel “The Future of Canadian Consumerism” (1973) 51 Can Bar Rev 191 at 191; John Goldring, Laurence W Maher and Jill McKeough Consumer Protection Law (4th ed, The Federation Press, Sydney, 1993) at 3; critical Duncan Kennedy "Distributive and paternalist motives in contract and tort law, with special reference to compulsory terms and unequal bargaining power” (1982) $41 \mathrm{Md}$ L Rev 563 at 614 to 615 .

${ }^{25}$ See Stefan Haupt “An Economic Analysis of Consumer Protection in Contract Law” (2003) 4 German L $\mathrm{J} 1137$ at 1137.
} 
bargaining power is in fact no more than an umbrella concept for those market and private-law failures which cause consumers to suffer economic detriment." ${ }^{26}$ It is, therefore, necessary to diagnose the particular sources of consumer detriment which lead to unequal bargaining power between the parties to the contract. As a consequence, the intention of this chapter is not to identify vulnerable consumers as such, but to point out the circumstances that lead to the vulnerability of elderly consumers in rest homes. ${ }^{27}$ Generally, vulnerability can be defined to be the dynamic interaction between a potentially vulnerable group and the specific situation they act in. ${ }^{28}$ Vulnerable consumer groups can be distinguished between visible characteristics (age, sex), states of mind (cognitive, emotional) and states of body (addiction, disability). ${ }^{29}$ Therefore, the main aim is to identify the detriments elderly consumers can suffer in connection with a rest home contract and which lead to unequal bargaining power of the contract parties.

It is certainly true that the concept of 'consumer detriment' is difficult to quantify and assess, ${ }^{30}$ especially because not all consumers share the same detriments. Even the members of the single consumer group 'elderly consumer' pursue different goals, and have different abilities, strengths and weaknesses. For example, rest home patients are not a homogenous block; they can be divided into two groups: "short-stayers" and "longstayers". ${ }^{31}$ Nevertheless, it is only possible to make suggestions to improve the protection of elderly consumers if one understands the multiple sources of consumer law ${ }^{32}$ and, therefore, realises why aged consumers are generally in the weaker negotiating position in comparison with providers when signing a rest home contract.

\footnotetext{
${ }^{26}$ Iain Ramsay Consumer Protection (Weidenfeld and Nicholson, London, 1989) at 57; Iain Ramsay “Consumer Law, Regulatory Capitalism and the 'New Learning' in Regulation” (2006) 28 Sydney L Rev 9 at 9.

27 Europe Economics "An analysis of the issue of consumer detriment and the most appropriate methodologies to estimate it” (July 2007) European Commission <ec.europa.eu> at 7.3.

${ }^{28}$ At 7.7.

${ }^{29}$ At 7.5 .

${ }^{30}$ Brian W Harvey and Deborah L Parry The Law of Consumer Protection and Fair Trading (6th ed, Butterworths, London, 2000) at 21.

${ }^{31}$ Emmett B Keeler, Robert L Kane and David H Solomon "Short- and Long-Term Residents of Nursing Homes” (1981) 19 Medical Care 363 at 363.

32 Paul O’Shea and Charles Rickett “In Defence of Consumer Law: The Resolution of Consumer Disputes” (2006) 28 Sydney L Rev 139 at 141.
} 
Some authors try to differentiate between two different forms of consumer detriment: structural and personal. 33 "Structural focuses on the loss of consumer welfare due to the market or regulatory failure, while personal focuses on the negative outcomes for consumers relative to a benchmark such as reasonable expectations." ${ }^{34}$ However, this distinction is more a theoretical than a practical one. It does not matter if one can sort the consumer detriments into different categories as long as it can be clearly shown that consumers as a group or a consumer as a single person are disadvantaged. Therefore, the following exposition will waive the differentiation.

Next, the main reasons for the disadvantaged position of elderly consumers are examined below.

\section{A Informational Asymmetries}

Information is an independent good, whose production and acquisition can be costly and which can be unequally distributed among consumers and providers. One main source for consumer detriment in all age groups is informational asymmetries between the contracting parties. Consumers are able to make an informed choice only if they have sufficient information about all services offered by the provider and, in addition, know about the different providers in the market. Only then are they able to assess their negotiating position realistically and determine and use their different possibilities in a proper way. ${ }^{35}$ More generally, it can be said that "[i]nformation is indeed necessary for consumers to participate successfully in the economy"36, not only but especially, because the goods and services become increasingly diverse.

However, the production and acquisition of information, as an independent good, can be costly and the information can be unequally distributed among consumers and providers. ${ }^{37}$ Moreover, in the situation at issue of consumers signing a rest home contract,

\footnotetext{
${ }^{33}$ See for example Ministry of Consumer Affairs "Consumer Law Reform Additional Paper - Consumer Information Standards” (February 2011) Consumer Affairs <www.consumeraffairs.govt.nz > at 25.

${ }^{34}$ At 25.

35 Rainer Kemper Verbraucherschutzinstrumente (Nomos, Baden-Baden, 1994) at 37 (translation: Consumer Protection Measures).

${ }^{36}$ See Geraint Howells “The Potential and Limits of Consumer Empowerment by Information” (2005) 32 BritJ Law \& Soc 349 at 354.

${ }^{37}$ Franziska Rischkowsky and Thomas Döring “Consumer Policy in a Market Economy: Considerations from the Perspective of the Economics of Information, the New Institutional Economics as well as Behavioural Economics” (2008) 31 JCP 285 at 287.
} 
it is likely that without regulatory intervention, such as information standards, consumers will have neither all the required nor perfect information. Characteristic of the situation of consumers is the fact that essential information is, due to its private character, frequently not available or is too expensive to collect, especially when consumers have to spend substantial search costs. ${ }^{38}$ Information normally comes as a by-product and is therefore costless to attain for providers, whereas consumers must search for the information and, therefore, spend time to obtain the necessary information. ${ }^{39}$ Hence, information processing costs can be defined as the costs for consumers to understand and apply the information in a special situation. ${ }^{40}$ However, the costs of collecting and analysing the information often exceed the benefits, particularly if the efforts to increase the supply of information are not linked with a better outcome for consumers or when it is difficult to obtain the necessary information. ${ }^{41}$ Rational consumers would, therefore, search for information only until the cost of the searching process outweighs the benefits. Consumers who reach that point would not spend more time and resources to gain and process information to make an informed choice. ${ }^{42}$ In other words, consumers sometimes behave rationally by not collecting and analysing the information, ${ }^{43}$ but make a costbenefit calculation regarding the amount of a search. ${ }^{44}$ For this reason, the outcome of an information search in a cost-benefit ${ }^{45}$ analysis may not lead to the information that is required. ${ }^{46}$ Consumers may rationally choose to make their decision on the basis of imperfect information. ${ }^{47}$

\footnotetext{
$\overline{38}$ Europe Economics, above n 27, at 8.90, 8.93; see for details George J Stigler "The Economics of Information" (1961) $69 \mathrm{~J}$ Pol Econ 213 - 225.

${ }^{39}$ See for details Stigler, above n 38, at 213 - 225; Rischkowsky and Döring, above n 37, at 287; see also in respect of standard business terms Johannes Köndgen "Grund und Grenzen des Transparenzgebots im AGB-Recht“ (1994) 42 NJW 943 at 947 (translation: Reason and Limitations of the Requirements of Transparency in Law on the General Terms of Business).

${ }^{40}$ Ramsay, above $\mathrm{n} 26$, at 46.

${ }^{41}$ Scott and Black, above n 22, at 30.

${ }^{42}$ Rossella Incardona and Cristina Poncibò "The average consumer, the unfair commercial practices directive, and the cognitive revolution” (2007) 30 JCP 21 at 35.

${ }^{43}$ Europe Economics, above n 27, at 8.91.

${ }^{44}$ Ramsay, above n 26, at 42.

${ }^{45}$ For a definition of the term cost-benefit analysis see Lewis A Kornhauser "On Justifying Cost-benefit Analysis" (2000) 29 JLS 1037 at 1039; Qi Zhou "What Can Contract Lawyers Learn from Law and Economics?” (2011) 30 U Tas LR 157 at 157; Barry Williams ”Cost-benefit analysis” (2008) 2 ELMR 67 at 67.

${ }^{46}$ Scott and Black, above n 22, at 31.

${ }^{47}$ Europe Economics, above n 27, at 6.9.
} 
Even if the information exists, consumers often do not adequately consider all the available information and, therefore, they may make decisions which do not correspond to their own interests. ${ }^{48}$ For many reasons, this particularly applies to the case of elderly people living in a rest home. Often elderly consumers are unwilling to abandon their existing social environment entirely. For this reason, from the beginning, consumers will consider and compare only a small sample of existing rest homes in their social environment. ${ }^{49}$ This means that the acquisition of information is limited from the outset.

Sometimes consumers are unable to search for the necessary information due to certain external circumstances. If, for example, the physical conditions of consumers change within a very short time, they are suddenly in a need of care and support services. In these circumstances it is a priority for consumers to find any, but not necessarily the best, provider for the required services. ${ }^{50}$ In these cases, consumers will often decide to put themselves in a weaker negotiating position, due to the fact that they are sometimes reliant or that they believe that they are reliant on the provider.

However, even if elderly consumers are not bound to the local environment, they still have to make a decision based on an array of providers. Consumers can hardly compare all existing providers, because, like every human, consumers are only able to process information up to a certain point. ${ }^{51}$ The capacity of the human mind is limited and cannot handle all complex information that is required for an objectively rational behaviour. ${ }^{52}$ Consumers who would try to compare all existing providers would be unable to distinguish between important and unimportant information and would probably not make a decision that would match best with their own interests. Therefore, the elderly consumer's decision is often based on a sample of incomplete information. This carries the risk that consumers will not make the best decision they could have made. ${ }^{53}$

Beyond that, consumers have no means of checking that the information given is correct; especially if they must experience the services or goods (sometimes called credence

\footnotetext{
${ }^{48}$ See below page 46.

${ }^{49}$ Kemper, above n 35, at 38.

${ }^{50}$ Generally regarding pressure of time as a factor of consumer detriment Kemper, above n 35, at 41.

51 Sandra Kind Die Grenzen des Verbraucherschutzes durch Information (Duncker \& Humblot, Berlin, 1998) at 467 (translation: The Limits of Consumer Protection by Information).

52 Richard Thaler “Toward a Positive Theory of Consumer Choice” (1980) 1 J Econ Behav \& Org 39 at 40; Herbert Simon Models of man (Wiley, New York, 1957) at 198; see below page 43.

${ }^{53}$ Kemper, above n 35, at 38; Scott and Black, above n 22, at 31.
} 
goods) ${ }^{54}$ before they can assess the value of the services or goods. ${ }^{55}$ Medical and health care services are credence goods, because the characteristics of the services are not apparent through their use alone. After signing the contract consumers do not know about the behaviour of the provider and with what quality the service will be carried out. ${ }^{56}$ Consequently, elderly consumers, regularly, cannot assess the quality of of most rest home services in advance; ${ }^{57}$ they need to experience the goods or services beforehand. ${ }^{58}$ This fact makes it easy for the provider to cheat in regards to the quality of the services provided and con consumers into services not necessarily needed. ${ }^{59}$ More generally, it can be said that consumers often do not lack full information about the prices of products, but have only poor information about the quality of service. ${ }^{60}$ This is because the latter information is more difficult to acquire. ${ }^{61}$ "Thus, a comparably high protection need for the consumer is derived from the information problems that go hand-in-hand with [...] credence goods.",62

In addition, elderly consumers are often unable to move from one rest home to the next, because of age and health status. Therefore, incomplete or incorrect information may have a particularly severe impact, because, most of the time, consumers have few to no opportunities to learn from their mistakes. ${ }^{63}$ This has the consequence that, even after a bad experience, the quality of the services is not ascertained and consumers can run into the same unfortunate situation again.

Furthermore, a rest home contract is often exceedingly sophisticated and very convoluted in its wording. Thus, elderly consumers or their relatives are often unable to understand every term of the contract, whether or not there are external circumstances which lead to pressure of time to make a decision about entering the contract. ${ }^{64}$ Moreover, the costs of understanding all the terms of the contract would be relatively high. Providers often

\footnotetext{
${ }^{54}$ Ministry of Consumer Affairs “Regulatory Impact Statement Consumer Law Reform” (December 2010) Consumer Affairs <www.consumeraffairs.govt.nz> at 4.

${ }^{55}$ Scott and Black, above n 22, at 30 - 31.

${ }^{56}$ Rischkowsky and Döring, above n 37, at 296.

57 See fundamentally and more generally Phillip Nelson "Information and Consumer Behaviour” (1970) 78 J Pol Econ 311; Phillip Nelson “Advertising as Information” (1974) 82 J Pol Econ 729.

${ }^{58}$ See Europe Economics, above n 27, at 8.145.

${ }^{59}$ At 8.163.

${ }^{60}$ Nelson, above $\mathrm{n} 57$, at 311 .

${ }^{61}$ At 311.

${ }^{62}$ Rischkowsky and Döring, above n 37, at 288.

${ }^{63}$ See Europe Economics, above n 27, at 8.149.

${ }^{64}$ See more generally Phil Evans “Accessing Consumer Detriment” (2007) 28 ECLR 26 at 29.
} 
prepare their contracts with the help of a lawyer and then use prepared standard business terms without giving consumers the chance to influence or negotiate them. Theoretically, consumers have the chance to influence the contract with legal assistance, but in reality providers do not give consumers the chance to negotiate or change the terms. Having said this, it is understandable that providers have an information advantage. They are better able to understand and oversee the consequences of the conclusion of a contract.

Overall, it can be said that the inequality of information is, to a greater or lesser extent, a natural feature of many consumer contracts ${ }^{65}$ and one of the main sources of consumer detriment. ${ }^{66}$ It is of particular concern in consumer contracts involving the elderly. Therefore, the provision of information is a key tool in the enhancement of consumer protection for consumers entering rest homes. ${ }^{67}$ However, informational asymmetries address only a particular problem of consumer detriment, but there are more reasons which justify governmental regulation in order to protect consumers.

\section{B Providers Psychological Superiority}

A further reason for consumer detriment in general is the psychological superiority of providers. This superiority can occur in many ways, such as when methods of modern marketing, sales strategies or in particular methods of selling (for example door to door sales $^{68}$, lay by sales ${ }^{69}$ ) by which consumers are surprised are used. This results in consumers not necessarily being aware of their rights and, on top of this, having less bargaining power. Thus, their contractual freedom is limited and they do not express their free consent. $^{70}$

The psychological superiority of the provider is less pronounced in the area of rest home contracts. However, even in this area modern marketing can strongly influence the decision-making process of consumers. ${ }^{71}$ The website of the provider, promotion flyers

\footnotetext{
${ }^{65}$ O'Shea and Rickett, above n 32, at 146.

${ }^{66}$ Stephen G Corones The Australian Consumer Law (Thomson Reuters, Sydney, 2011) at 2.20; Gillian K Hadfield, Robert Howse, Michael J Trebilcock "Information-Based Principles for Rethinking Consumer Protection Policy” (1998) 21 JCP 131 at 140.

${ }^{67}$ Howells, above $n$ 36, at 352.

${ }^{68}$ See Door to Door Sales Act 1967.

${ }^{69}$ See The Layby Sales Act 1971.

${ }^{70}$ Pamatia Rekaiti and Roger Van den Bergh "Cooling-off Periods in the Consumer Laws of the EC Member States” (2000) 23 JCP 371 at 373.

${ }^{71}$ Evans, above n 64, at 30.
} 
and information brochures, are often suitable enough in order to influence the consumers' decision-making processes on a subliminal level. ${ }^{72}$ If one considers advertising measures, these measures often try to arouse associations in an automatic, implicit and tacit way. ${ }^{73}$ Brochures and websites, for example, often contain pictures, which only have a small link to reality. ${ }^{74}$ Frequently, the advertising gives no information about the services themselves, but tries to affect consumers through their emotions by placing the lifestyle as the central point. ${ }^{75}$ Hence, the danger exists that elderly consumers will get the wrong impression of the rest home, especially because of the lack in understanding of marketing techniques particularly widespread to elderly consumers. ${ }^{76}$ In addition, modern marketing is suitable for exploiting the existing informational asymmetry, because it can obscure the lack of relevant information.

\section{Economic Superiority of the Provider}

Regularly, providers are not only in a psychologically but also in an economically superior position in comparison with consumers in general. This can exacerbate the imbalanced situation between the parties. It is a matter of fact that the parties to a contract generally pursue non-aligned interests. In other words, it is in the nature of a contract that both parties try to enforce their own aims and goals. On the one hand, consumers try to conclude a contract that corresponds with their needs and, on the other hand, providers try to enforce a contract with which they hope to have an optimal financial profit. It is not surprising that regularly the stronger party can better achieve its interests.

In a rest home contract the role of each party can clearly be identified. While elderly consumers regularly act as single persons in the market, providers, however, are in most cases a major commercial enterprise; sometimes acting on a nationwide basis. For this reason, the provider will regularly be successful in achieving its interests.

\footnotetext{
72 See generally Europe Economics, above n 27, at 7.16.

${ }^{73}$ At 7.17 .

${ }^{74}$ Regarding retirement villages see for example the report of the Retirement Commissioner "Retirement Villages Act 2003 Monitoring Project Residents’ Perspectives” (July 2011) Commission for Financial Literacy and Retirement Income <www.cflri.org.nz> at 4: "Use of photos depicting facilities that are not available in the village."

75 Generally Eike von Hippel Verbraucherschutz (3rd ed, Mohr, Tübingen, 1986) at 4 (translation: Consumer Protection).

${ }^{76}$ Europe Economics, above n 27, at 7.28.
} 
Moreover, the provider often does not depend on the formation of the contract and can therefore act with the principle "take it or leave it" in mind. ${ }^{77}$ As a result aged consumers often have no chance to influence the content of the contract; they can only decide whether or not to sign the contract. Thus, the freedom of contract principle is limited, because the freedom of content principle is, for consumers, more or less non-existent. Additionally, as mentioned before, ${ }^{78}$ consumers are sometimes in need of a particular product or service. In these cases, providers do not have to fear negative consequences, because consumers are dependent on signing a contract that provides the product or service. This imbalance is also because elderly consumers often do not have special business experience and, in addition, in most cases sign a rest home contract only once in their life. $^{79}$

Overall, it can be said that, due to the difference in economic power, providers have an advantage over consumers and can advance their interests with greater ease.

\section{Deterioration of the cognitive and intellectual, but also emotional, sensitive and social-communicative skills}

Elderly consumers will most often move to a rest home when in need of special medical, health care and social services. All of these services help to manage the need for assistance that occurs as a result of age, which is a strong predictor of future disability in older people, ${ }^{80}$ care dependency and disability. ${ }^{81}$ In other words, elderly consumers often move to a rest home if they are no longer able to live in their own houses. ${ }^{82}$ However, the elderly consumer group is heterogeneous and, therefore, the need for special healthcare and special services varies within this group. ${ }^{83}$ Consequently, the individual

\footnotetext{
${ }^{77}$ Kemper, above n 35, at 61; Kate Tokeley Consumer Law in New Zealand (Butterworths, Wellington, 2000) at 13 .

${ }^{78}$ See above page 18 .

${ }^{79}$ Similarly Evans, above n 64, at 29.

${ }^{80}$ Regarding disability see Ümit Taş, Ewout W Steyerberg, Sita MA Bierma-Zeinstra, Albert Hofman, Bart W Koes and Arianne P Verhagen “Age, gender and disability predict future disability in older people: the Rotterdam Study” (2011) 11 BMC Geriatr 22; Taş, Verhagen, Bierma-Zeinstra, Hofman, Odding, Pols and Koes, above $n 7$, at 276.

81 See Taş, Steyerberg, Bierma-Zeinstra, Hofman, Koes and Verhagen, above n 80, at 22 "Disability, especially in older people, is a common problem... Prevalence rates range from 30\% for people aged 75 or older to $40 \%$ for those aged 85 and older.”

${ }^{82}$ At 22.

83 Synneve Dahlin-Ivanoff, Gunilla Gosman-Hedström, Anna-Karin Edberg, Katarina Wilhelmson, Kajsa Eklund, Anna Duner, Lena Ziden, Anna-Karin Welmer and Sten Landahl "Elderly persons in the risk zone.
} 
consumer requires different professional support. Nonetheless, research in Australia has shown that about 70 per cent of the people in aged care had high care needs, ${ }^{84}$ and therefore are highly dependent on the services of the provider.

When analysing the consequences of age, care dependency and disability, it can be seen that these aspects are often linked with a deterioration of the cognitive and intellectual abilities. $^{85}$ Moreover, many elderly consumers will, increasingly, have some form of cognitive impairment as longevity rates increase. ${ }^{86}$ Generally, with increasing age the ability to perform routine daily tasks declines ${ }^{87}$ and, moreover, high age also decreases the likelihood of an improvement or recovery of function. ${ }^{88}$ Furthermore, there is an intellectual decline with advancing age. Consequently, elderly consumers are, on average, not able to understand and process as much information as younger consumers. Aged consumers are often significantly restricted and, therefore, unable to represent their own interests adequately. As pointed out above, they are able to apprehend the legal complexities and required information only to a limited extent. ${ }^{89}$ Moreover, the reduction of cognitive abilities can be accompanied by a threat to consumers' self-determination, because relatives will decide to interfere. From an empirical point of view the autonomy of elder and care-dependent consumers is deficient and imperfect. ${ }^{90}$ With this background in mind, elderly consumers are particularly vulnerable; this is, especially, because most of the factors mentioned are not modifiable and, hence, the detriments inevitably occur.

\footnotetext{
Design of a multidimensional, health-promoting, randomised three-armed controlled trial for "prefrail" people of 80+ years living at home” (2010) 10 BMC Geriatr 27.

${ }^{84}$ Barnett and Hayes, above n 14, at 55.

${ }^{85}$ See Ümit Taş, Arianne P Verhagen, Sita MA Bierma-Zeinstra, Else Odding and Bart W Koes "Prognostic factors of disability in older people: a systematic review" (2007) 57 Br J Gen Pract 319 at 322.

${ }^{86}$ Barnett and Hayes, above n 14, at 50.

87 See Dahlin-Ivanoff, Gosman-Hedström, Edberg, Wilhelmson, Eklund, Duner, Ziden, Welmer and Landahl, above n 83, at 27.

${ }^{88}$ Vincent Mor, Victoria Wilcox, William Rakowski, and Jeffrey Hiris "Functional Transitions among the Elderly: Patterns, Predictors, and Related Hospital Use” (1994) 84 Am J Public Health 1274 at 1274, 1277; Taş, Verhagen, Bierma-Zeinstra, Odding and Koes, abone n 85, at 322.

${ }^{89}$ See above page 14 .

90 Reinhard Damm "Medizinrechtliche Grundprinzipien im Kontext von Pflege und Demenz "Selbstbestimmung und Fürsorge" (2010) 13 MedR 451 at 460 (translation: Fundamental principles of medical law in the context of care and dementia - self-determination and welfare).
} 


\section{E Barriers to Consumer Access to Justice}

Access to justice is a fundamental requirement for adequate and effective consumer protection. $^{91}$ In addition to the above reasons, consumers often have difficulties in accessing out-of-court or legal justice ${ }^{92}$ and a limited ability to protect themselves. On the one hand, consumers sometimes are not cognisant or do not know about their own rights and remedies ${ }^{93}$ and, therefore, they are not aware that they have a legal right that they can exercise. ${ }^{94}$ Especially elderly consumers often have a knowledge level that is lower compared to the overall population. ${ }^{95}$ Even consumers who are aware sometimes do not know how to discover or formulate their claims or how to enforce the applicable rights. ${ }^{96}$ Elderly consumers may have mental or physical disabilities or problems with memory or communication and, therefore, face additional difficulties in finding avenues for complaint and investigation of possible complaints. ${ }^{97}$ Moreover, research has shown that elderly people are the most vulnerable consumer group, because they are less likely to take action in order to achieve satisfaction in regards to their complaint. ${ }^{98}$ This is because elderly consumers are often afraid of dependency or reprisal. ${ }^{99}$ Their whole position is often dominated by passivity, acceptance, and dependency. ${ }^{100}$ In addition, they have often no real power of exit and, therefore, are reluctant to criticise the services or individual

\footnotetext{
${ }^{91}$ Barnett and Hayes, above n 14, at 71.

92 Neil Vidmar “Seeking Justice: An Empirical Map of Consumer Problems and Consumer Responses in Canada” (1988) 26 Osgoode Hall LJ 757; see regarding complaints about late departures Kate Tokeley “Late Departures: Consumers' Rights Under the Consumer Guarantees Act 1993” (2001-2004) 10 Otago L Rev 411 at $417-419$.

93 Ramsay, above n 26, at 120; Scott and Black, above n 22, at 515.

94 Nicolas L’Heureux “Effective Consumer Access to Justice: Class Actions” (1992) 15 JCP 445 at 445 ; Tokeley, above n 77, at 376.

95 Israel Doron, Iddo Gal, Maya Shavit and Pnina Weisberg-Yosub “Unheard voices: complaint patterns of older persons in the health care system” (2011) 8 Eur J Ageing 63 at 70.

96 Tokeley, above n 92, at 418; L’Heureux, above n 94, at 445.

${ }^{97}$ Barnett and Hayes, above n 14, at 54.

${ }^{98}$ Ramsay, above n 26, at 125; Marie Magdaleen Bismark, Troyen A Brennan, David M Studdert, Ronald J Paterson and Peter B Davis "Relationship between complaints and quality of care in New Zealand: a descriptive analysis of complaints and non-complaints following adverse events” (2006) 15 QSHC 17 at 19, 21.

99 Linda Bauld, John Chesterman and Ken Judge "Measuring satisfaction with social care amongst older service users: issues from the literature” (2000) 8 Health Soc Care Community 316 at 320; for retirement villages see Retirement Commissioner, above $n$ 74, at 9.2.

100 Michael Calnan, Stephen Almond and Nick Smith “Ageing and public satisfaction with the health service: an analysis of recent trends” (2003) 57 Soc Sci Med 757 at 758.
} 
workers. ${ }^{101}$ However, even if they know and are convinced about their claims, they are often unwilling to bring their claims to court or they are too embarrassed to take legal action or even too disempowered to make an initial complaint. ${ }^{102}$ This is often because there is a gross power disparity between the individual consumer and the provider. ${ }^{103}$ Additionally, without any cynicism, it can be said that sometimes consumers will not live to see the end of the legal proceedings, because they die beforehand. ${ }^{104}$ On the other hand, providers regularly have more experience in handling consumer complaints, because they have been through the procedure before. ${ }^{105}$

Another barrier is the financial cost of litigation. Consumers sometimes cannot afford to hire a lawyer in order to take their claim to court or the excessive costs of the legal action might be too high. Especially when the monetary value of the claim is low, consumers may not want to spend the necessary amount of time and money to take legal action. ${ }^{106} \mathrm{In}$ addition, consumers often do not want to spend the necessary amount of time and effort to complain, because if the provider does not remedy the problems, consumers have to take further steps, which are, for most of them, an unrealistic option. ${ }^{107}$ Linked to this is the phenomenon that consumers are often reluctant to change the provider, because they tend to prefer the status quo (status quo bias) and show therefore an inappropriate loyalty. ${ }^{108}$ This difficulty is even more severe for elderly consumers in rest homes. They regularly rely on the services of the provider and caregivers. Additionally, elderly consumers have often changed their place of residence completely and, therefore, do not want to leave the rest home, even if there are reasons to complain. They are afraid of losing their new-found social contacts and relationships and prefer to keep the status quo.

${ }^{101}$ Bauld, Chesterman and Judge, above n 99, at 320; Sandra McCullough "Aged Care - A Victorian perspective on complaints handling and the enforcement of consumer rights” (2002) 27 Alternative LJ 57 at 60.

${ }^{102}$ Leib Leventhal "The role of understanding customer expectations in aged care” (2006) 21 IJHCQA 50 at 55; Tokeley, above n 77, at 376; see Cowan Ertine "Consumer Redress for Misleading and Aggressive Practices” (2011) 15 Edin LR 448 at 449; McCullough, above n 101, at 60.

${ }^{103}$ Stephen Goldberg, Eric Green and Frank Sander Dispute Resolution (Little Brown, Boston, 1985) at 389.

104 See John A Pearce II, John J O’Brien and Derek A Rapisarda "Protecting Nursing Home Residents From Attacks on Their Ability to Recover Damages” (2008-2009) 61 Rutgers L Rev 705 at 718; McCullough, above n 101, at 61.

105 Tokeley, above n 77, at 376.

106 At 377; Bill Bevan, Bob Dugan and Virginia Grainer Consumer Law (LexisNexis NZ, Wellington, 2009) at 1.6.

${ }^{107}$ Tokeley, above n 92, at 418.

${ }^{108}$ Rischkowsky and Döring, above n 37, at 301. 
Furthermore, consumers often fear that they will suffer further detriments or be victimised if they complain. ${ }^{109}$ This is because sometimes the people they complain about are those who continue to provide the services required. Hence, it is likely that elderly consumers will complain to their friends, other residents or relatives about the poor services, but will not make a direct complaint to the provider. ${ }^{110}$ Finally, consumers may have no social contacts and therefore may not have the adequate resources in order to report an issue or to contact a lawyer. ${ }^{111}$

Some of these concerns that rest-home residents have might be inappropriate or ungrounded. Nevertheless, they hinder consumers from making a complaint. Overall, it can be said that elderly consumers in rest homes are unlikely to have the skills, abilities, financial resources or opportunity to complain or access justice without a great deal of assistance; a problem which is exacerbated by the advanced age of elderly consumers. ${ }^{112}$

\section{F Abstract Exposure of Physical Integrity, Health and Wealth}

In terms of rest home contracts, consumers are dependent on the provider in many different ways. The provider grants accommodation to the consumers and, in addition, provides care and support services. Therefore, it can be said that in the execution of the contract a relationship of particular proximity between the consumer and the provider and its employees exists. In addition, unlike health care services, aged care residential services are permanent residential arrangements and with that comes more extreme intimate issues such as home, security and emotional support." ${ }^{113}$ Thus, the provider is regularly able to breach various legal protected rights of elderly consumers. In particular, due to the consumers' fragility, they have very specific needs; sometimes this requires permanent care and, as a consequence, in most cases, they are unable to manage everyday routine tasks. ${ }^{114}$ Furthermore, elderly consumers in rest homes often suffer from some form of dementia ${ }^{115}$ and, therefore, have further problems managing their own needs and special issues regarding information and access to justice. This means the provider not

\footnotetext{
${ }^{109}$ New Zealand Labour, Green Party of Aotearoa and Grey Power New Zealand “A Report into Aged Care: What does the future hold for Older New Zealanders?”(October 2010) Labour <www.labour.org.nz> at 8 .

110 See in a different context Tokeley, above $\mathrm{n}$ 92, at 418.

${ }^{111}$ Pearce, O’Brien and Rapisarda, above n 104, at 718.

112 Similarly Barnett and Hayes, above n 14, at 72.

113 Leventhal, above n 102, at 55 - 56.

114 See New Zealand Labour, Green Party of Aotearoa and Grey Power New Zealand, above n 109, at 6.

115 At 6.
} 
only provides the care services, but also ensures that the daily meals, the living area and medical services are provided, if required. Overall, it can be said that the provider is responsible for most of the consumers' needs. ${ }^{116}$ For this reason, the execution of the contract is regularly characterised by a specific vulnerability and dependency of consumers $^{117}$ whose physical integrity, therefore, is subject to particular risks. These special risks increase the more consumers lose contact with relatives, social contacts and familiar environment, because they lose contact with people who could protect their interests. ${ }^{118}$ Furthermore, consumers often feel dependent on the provider and its employees and, therefore, rely on a favourable relationship to the provider. With this background in mind, it is likely that elderly consumers are often willing to put their own interests aside and accept detrimental situations, even if they could complain.

Moreover, a rest home contract is linked with the bond of a significant part of consumers' assets. Often consumers have to pay so much money for the services that there remains barely any freely disposable money. Therefore, there is a threat of considerable financial losses, if consumers, due to the previously described detriments, agree to excessive payments when signing the contract. The same danger also applies when the provider or its employees do not provide the services flawlessly.

All in all, it can be said that the rest home contract is, in many ways, characterised by a dependent situation on the part of consumers. It is certainly true that this fact alone cannot justify legal intervention, because the dependency is not always linked with detriment to consumers. However, as the House of Lords pointed out, ${ }^{119}$

experience shows that in the case of ... nursing homes, old people's homes, geriatric wards, and other residential homes for ... vulnerable, there is an inherent risk that indecent assaults on the residents will be committed by those placed in authority over them, particularly if they are in close proximity to them and occupying a position of trust.

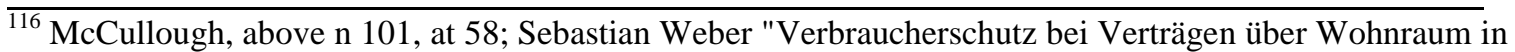
Verbindung mit Pflege- und Betreuungsdienstleistungen” (2010) 13 NZM 337 at 338 (translation: Protection of Consumers in Contracts for Living Space in Conjunction with Nursing and Care Services).

${ }^{117}$ According to New Zealand Labour, Green Party of Aoteaora and Grey Power New Zealand, above n 109, at 6, 56\% of residents in Auckland rest homes and private hospitals had high dependency in 2008, compared with just $36 \% 20$ years ago.

${ }^{118}$ At 24.

${ }^{119}$ Lister v Hesley Hall Ltd [2002] 1 AC 215 at 250.
} 
The quote refers only to one type of abuse, but many different types can occur in rest homes. Statistics for Australia say about 4.6 per cent of elderly consumers are victims of physical, sexual or financial abuse. ${ }^{120}$ Therefore, New Zealand's Aged Care Association correctly warns $^{121}$

... despite everyone's best endeavours, there will always be cases of poor care, and while one case is one too many, we must accept we are dealing with people and not every one of the sector's 35,000 caregivers and nurses are going to act appropriately at all times.

\section{G Summary}

The analysis in this chapter has shown that elderly consumers have special vulnerabilities and can suffer various detriments at the time of the signing and implementation of the contract that make comprehensive and effective legal protection essential. ${ }^{122}$ On an individual basis, the possible detriments may not be enough to justify intervention to protect the interests of consumers. However, on the whole, the above reasons have shown that it is likely that consumers will be the inferior contracting party, not only at the moment of signing but also during the implementation and termination of the contract. Therefore, a rest home contract between the consumer and the provider cannot be expected to meet the interests of both parties equally. Moreover, the notion of freedom of contract can explain many of the consumer detriments, because - without intervention it is likely that the superior contracting party, in this case the provider, will use its freedom to the detriment of the inferior contracting party, in this case the consumer. ${ }^{123}$

For this reason, measures to protect consumers and restore their sovereignty are necessary. Hence, the following chapters will answer the question of whether the currently existing measures effectively protect consumers of rest home services against possible detriments.

\footnotetext{
${ }^{120}$ See Barnett and Hayes, above n 14, at 49.

${ }^{121}$ Quoted from New Zealand Labour, Green Party of Aotearoa and Grey Power New Zealand, above $n$ 109 , at 8 .

${ }^{122}$ Likewise Barnett and Hayes, above n 14, at 45.

123 Scott and Black, above n 22, at 516.
} 


\section{Statutory Regulations in New Zealand, Australia and Germany}

Rest home contracts are often directly or indirectly influenced by more than one piece of legislation. This chapter will first give a brief overview of the different regulations concerning rest homes in New Zealand, Australia and Germany and state the differences of the regulations. The current laws will then be discussed in more detail in the following chapters.

\section{A New Zealand}

New Zealand does not have a single statute that deals with rest home contracts, but rather it has several regulations and statutes that apply to rest home contracts.

The Health and Disability Services (Safety) Act 2001 applies to all health care services and, therefore, includes rest home care for frail consumers. ${ }^{124}$ This Act focuses mainly on the certification of providers and the auditing process, ${ }^{125}$ including the inspection of registered rest homes. On top of this, it also contains a power for the Minister of Health $^{126}$ to approve and establish safe and reasonable levels for providing health and disability services and reduce the risk to elderly consumers brought on by these services. ${ }^{127}$ Using this basis in regards to authorization, the Health and Disability Standards 2001 initially came into force, but was replaced by the Health and Disability Services Standards 2008, which came into effect on 1 June 2009. These standards cover many aspects of service provision and include several consumer rights. They promote the current accepted good practice and they are mandatory for services that are subject to the Health and Disability Services (Safety) Act 2001. ${ }^{128}$ The NZS 8134.1:2008 Health and Disability Services (Core) Standards 2008, especially, determine detailed consumer rights "to enable consumers to be clear about their rights and providers to be clear about their responsibilities for safe outcomes."129

The standards also assist the providers to meet their standards under the Code of Health and Disability Services Consumers’ Rights 1996 (hereinafter: Code of Rights), a further source that influences the relationship between consumers and providers. The Code of

\footnotetext{
${ }^{124}$ See Health and Disability Services (Safety) Act 2001, ss 5(1)(a)(iii) and 6(2).

${ }^{125}$ Additional regulations in terms of audits can be found in the Auditor Regulation Act 2011.

${ }^{126}$ Health and Disability Services (Safety) Act 2001, s 13.

${ }^{127}$ See Health and Disability Services (General) Standard 2008, s 1.

128 Sections 1 and 4.

${ }^{129}$ Foreword of NZS 8134.1:2008 Health and Disability Services (Core) Standards 2008.
} 
Rights covers a wide range of providers (whether public or private) including rest home providers. It gives various rights to all consumers (for example the Right to Complain and the Right to be Fully Informed) and places obligations on providers. ${ }^{130}$ The Code came into force based on the provisions of ss 19 and 20 of the HDCA which entitled the Commissioner to introduce the Code of Rights under certain conditions described in the aforementioned sections. Furthermore, the HDCA governs the consumers' right to complain and the complaint procedure.

The Social Security Act 1964 also influences the relationship between the consumers and the provider, but serves a different purpose. The Act does not affect the relationship of the contract parties directly, but, rather, it specifies circumstances in which elderly consumers are required to pay for their own long-term residential care and in which they can apply for Residential Care Subsidy. ${ }^{131}$ It contains the details of the Residential Care Subsidy application procedure; especially the financial means assessment ${ }^{132}$ and the needs assessment, ${ }^{133}$ which aims to find out if a consumer requires long-term residential care in a rest home. The needs assessment is conducted by the District Health Boards (hereinafter: DHBs). The DHBs were established by the New Zealand Public Health and Disability Act 2000 and have, among other things, the objective to promote effective care or support for those in need of personal health services or disability support services. To do so, the DHBs do not only conduct the needs assessment, but also negotiate service agreements with providers. Under which the DHBs agree to give money to the providers in return for the provision of care services. ${ }^{134}$ This has further consequences, because consumers who get Residential Care Subsidy can choose only a residential care provider that has a contract with a DHB. ${ }^{135}$ The so called Aged Related Residential Care Services Agreement also determines numerous obligations for providers that they have to fulfil in connection with the contractual relationship with consumers to receive the payments from the DHBs.

\footnotetext{
${ }^{130}$ Code of Health and Disability Services Consumers’ Rights 1996, s 1. A further source of consumer rights is the Code of Residents’ Rights and Responsibilities of the New Zealand Aged Care Association. However, this Code does not contain enforceable rights and is not a governmental regulation in the proper sense.

131 Social Security Act 1964, p 4.

132 Section 144.

133 Section 137.

${ }^{134}$ New Zealand Public Health and Disability Act 2000, s 25.

135 Social Security Act 1964, s 138(1)(a).
} 
Finally, the obligations of the Consumer Guarantees Act 1993 (hereinafter: the CGA) apply to the contractual relationship between consumers and provider; especially, the guarantee that services will be carried out with reasonable care and skill. ${ }^{136}$ The definition of the term "service" in s 2(1) is exhaustive and covers health and disability services. ${ }^{137}$ However, the Act is not a code, and the rights and remedies provided in the Act are in addition to any other right or remedy under any other Act or rule of law. ${ }^{138}$ Against the background that the CGA is not especially tailored for rest home contracts, more specific and stricter provisions of other Acts are not affected by the provisions of the CGA. ${ }^{139}$

\section{B Australia}

In Australia, the Aged Care Act 1997 (Cth) contains, more or less, a comprehensive regulation of aged care. The Act aims to provide funding for a high quality of aged care, accommodation for frail consumers and also aims to protect elderly consumers who receive aged care services; additionally, the Act covers different types of aged care, including residential care. ${ }^{140}$ Moreover, the Act introduces standards to regulate the quality of care provided. ${ }^{141}$ Therefore, the Act heavily influences the rest home contract between elderly consumers and providers. The Aged Care Act 1997 (Cth) comprises regulatory provisions of the approval, ${ }^{142}$ the allocation ${ }^{143}$ of the aged care providers and the certification of residential care services. ${ }^{144}$ Approval and allocation are necessary for the provider to receive residential care subsidy for providing residential care to care recipients. ${ }^{145}$ Detailed procedural regulations of granting residential care subsidy are not only set out in ss 41-1 to 44-32 of the Aged Care Act 1997 (Cth), but also in the Residential Care Subsidy Principles 1997 (Cth). Further details about the allocation of places can be found in the Allocation Principles 1997 (Cth) which deals with the distribution of places.

\footnotetext{
${ }^{136}$ Consumer Guarantees Act 1993, s 28.

${ }^{137}$ For a comprehensive description of the term see Tokeley, above $n$ 77, at $133-135$.

138 Consumer Guarantees Act 1993, s 4(1).

${ }^{139}$ Section 40(a); Tokeley, above n 77, at 132.

140 Aged Care Act 1997 (Cth), s 2-1.

${ }^{141}$ Barnett and Hayes, above n 14, at 51.

${ }^{142}$ Aged Care Act 1997 (Cth), pt 2.1.

143 Part 2.2.

144 Part 2.6.

145 Section 41-1.
} 
Moreover, the Aged Care Act 1997 (Cth) determines a number of responsibilities for approved providers. A particularly important aspect within a rest home contract is the responsibilities related to the quality of care ${ }^{146}$ and to elderly consumers. ${ }^{147}$ Details about the care quality are defined in the Quality of Care Principles 1997 (Cth). Providers must act in accordance with several user rights mentioned in s 56-1 of the Aged Care Act 1997 (Cth); especially the User Right Principles 1997 (Cth). ${ }^{148}$ In addition, s 96-1(1) states that the Minister may, by legislative instrument, make principles for user rights. ${ }^{149}$ Using this basis, the User Rights Principles 1997 (Cth) were created. The principles set out various rights and responsibilities, which directly influence the contractual relationships of consumers and providers. If a provider fails to meet its responsibilities pt 4.4 of the Aged Care Act 1997 (Cth) imposes several sanctions.

The Aged Care Act 1997 (Cth) also deals with matters of social welfare. It regulates the approval of care recipients to receive residential care subsidy ${ }^{150}$ and the classification of care recipients according to the level of care they need. ${ }^{151}$ These regulations are complemented by the Approval of Care Recipients Principles 1997 (Cth) that define the eligibility to receive residential care. Details about the classification of elderly consumers are set out in the Classification Principles 1997 (Cth). Furthermore, the Aged Care Act 1997 (Cth) contains an enabling clause to introduce complaint principles, ${ }^{152}$ and also set out the general baselines for the complaint scheme. ${ }^{153}$ Based on the enabling provision, the Complaint Principles 2011 were introduced. The principles regulate, in detail, how to make, deal with and solve a complaint. On top of this, the Aged Care Act 1997 (Cth) established an Aged Care Commissioner, ${ }^{154}$ which examines the effectiveness of the Complaint Principles 2011, in theory and in practice. Lastly, in order to help approved providers comply with all the responsibilities under the Aged Care Act 1997 and the Aged Care Principles the Australian government has published a Residential Care Manual. $^{155}$

\footnotetext{
${ }^{146}$ Section $54-1$.

${ }^{147}$ Sections 55 and 56-1.

${ }^{148}$ Section $56-1(\mathrm{~m})$.

${ }^{149}$ Section 96-1(1) item 23.

${ }^{150}$ Part 2.2.

${ }^{151}$ Part 2.4.

152 Section $96-1$.

153 Section 94A-1.

${ }^{154}$ Section 95A-1.

155 The manual can be found on the internet at http://health.gov.au/internet/main/publishing.nsf/Content/ 1CC3ACD213466762CA256F19000FC9A5/\$FilF/RCMUpdates.pdf.
} 
However, the aged care legislation in Australia is made more complex by Federal State consumer protection regulations that can be relevant to aged care facilities. ${ }^{156}$ Exploring each of these individual regulations would go beyond the scope of this dissertation, because it would require exploring each piece of legislation on a case by case basis. ${ }^{157}$ For this reason, this paper will focus on the propositions of the Aged Care Act 1997 (Cth).

\section{Germany}

In Germany, a wide range of different laws directly or indirectly affect the contractual relationship between consumers and providers, in terms of rest homes. Firstly, the Wohnund Betreuungsvertragsgesetz 2009 (hereinafter: the WBVG) ${ }^{158}$ is a civil law that regulates the main parts of the civil law contract. More specifically, it is a special consumer protection law outside of the German Civil Code (hereinafter: the BGB) ${ }^{159}$ and it is the fundamental law that protects consumers in rest homes. It aims to protect older, care-dependent or disabled adults against disadvantages when entering into and throughout the duration of a rest home contract, which grants accommodation to the consumer and, in addition, provides care and support services. ${ }^{160}$ Moreover, the law aims to support these people, at most, in an independent and self-determined way of life. ${ }^{161}$

This protection is matched by the social regulations of the Eleventh Code of Germen Social Law (hereinafter: the SGB XI) ${ }^{162}$ and Twelfth Code of German Social Law (hereinafter: SGB XII). ${ }^{163}$ The SGB XI aims to reduce the risk of requiring long-term nursing care due to age and care dependence. In terms of the content, the law regulates

\footnotetext{
$\overline{{ }^{156} \text { For an overview see Peter Hanks and Lisa de Ferrari "Regulation of Residential Aged Care. Review of }}$ Legislation: Commonwealth, State and Territory” (30 April 2003) Australian Government Department of Health and Ageing <www.health.gov.au>; Barnett and Hayes, above n 14, at 52.

${ }^{157}$ At 52.

158 The law is accessible on the internet at www.gesetze-im-internet.de/wbvg/.

${ }^{159}$ The law is accessible on the internet at www.gesetze-im-internet.de/bgb/.

160 Drucksachen des Deutschen Bundestages “Gesetzentwurf eines Gesetzes zur Neuregelung der zivilrechtlichen Vorschriften des Heimgesetzes nach der Föderalismusreform“ (24 March 2009) BT-Dr 16/12409 at [10] (translation: Bill of a Revision of the Civil Law Rules of the Amended Nursing Home Act (HeimG) after the Reform of the Federal System).

${ }^{161}$ At [10].

162 See Sozialgesetzbuch XI 1994 (Germany). The law is accessible on the internet at www.gesetze-iminternet.de/sgb_11/.

${ }^{163}$ See Sozialgesetzbuch XII 2003 (Germany). The law is accessible on the internet at www.gesetze-iminternet.de/sgb_12/.
} 
the Social Care Insurance and includes several provisions, which affect the contractual relationship between the consumer and the provider. If a consumer is insured by the Social Care Insurance, the dual relationship between the consumer and the provider changes to a triangular relationship that includes the care insurance as the social benefit institution. ${ }^{164}$ The nature and level of benefits depends on the level of care dependency and which type of care is used. ${ }^{165}$ Moreover, key points of the civil law contract (for example the payment and the provided services) are replaced by the social welfare regulations, because the German Nursing Care Insurance, which provides the payment, negotiates these key points directly with the provider in accordance with paras 72, 75, 85 of the SGB XI.

On top of this, further protection is granted by the regulatory framework of the individual federal states. ${ }^{166}$ These regulatory provisions primarily regulate the requirements to register a rest home. They often do not provide direct protection of consumers, but indirectly ensure a certain level of protection by removing regulatory abuses.

\section{Summary}

The overview has shown that a wide range of regulations, especially in New Zealand and Australia, can influence the contractual relationship between consumers and providers, while in Germany mainly two Acts define their legal positions. However, there is a significant difference between Australia and New Zealand. While Australia has a piece of legislation that focuses on aged care services alone, New Zealand's regulations are piecemeal. The existing Acts relate primarily to health and disability services in general, without a special focus on aged related services.

\footnotetext{
${ }^{164}$ Federal Supreme Court (of Germany) [2001] III ZR 14/01, 8 November 2001, (2002) 55 NJW 507 at [508]; Drucksachen des Deutschen Bundestages "Entwurf eines Gesetzes zur Absicherung des Risikos der Pflegebedürftigkeit“ (24 June 1993) BT-Dr 12/5262 at [168] (translation: Bill of a Law Against the Risk of Requiring Long Term Nursing Care).

${ }^{165}$ See Sozialgesetzbuch XI 1994 (Germany), para 4(1).

${ }^{166}$ See in detail in terms of the federal states: Baden-Württemberg, Landesheimgesetz (LHeimG); Bavaria, Pflege- und Wohnqualitätsgesetz (PfleWoqG); Berlin, Wohnteilhabegesetz (WTG); Brandenburg, Brandenburgisches Pflege- und Betreuungswohngesetz (BbgPBWoG); Bremen, Bremisches Wohn- und Betreuungsgesetz (BremWoBeG); Hamburg, Wohn- und Betreuungsqualitätsgesetz (HmbWBG); Mecklenburg Western Pomerania, Einrichtungenqualitätsgesetz (EQG); Lower Saxony, Niedersächsisches Heimgesetz (NHeimG); Northrhine-Westphalia, Wohn- und Teilhabegesetz (WTG); Rhineland Palatinate, Landesgesetz über Wohnformen und Teilhabe (LWTG); Saarland, Landesheimgesetz Saarland (LHeimGS); Saxony-Anhalt, Wohn- und Teilhabegesetz (WTG LSA); Schleswig-Holstein, Selbstbestimmungsstärkungsgesetz (SbStG).
} 


\section{Information Obligations as a Measure to Protect Elderly Consumers in Rest Homes}

This chapter will first show the existing regulations in New Zealand, Australia and Germany, as well as the advantages and limitations of information obligations as a measure to protect consumers in general. Following up and in the light of the foregoing, this chapter will make various proposals to improve the existing measures in New Zealand.

\section{A Advantages of Consumer Protection by Information}

Information obligations are often favoured as a measure to protect consumers by the government, providers and consumers alike. ${ }^{167}$ They are a response to the asymmetries of information between consumers and providers. ${ }^{168}$ Information requirements lie at the heart of many legislative approaches to protecting consumers and are often seen as the most efficient approach. ${ }^{169}$ The aim is to ensure that all parties of a contract have access to important information and to help consumers to make informed choices. ${ }^{170}$ It is supposed that information obligations can enhance transparency and ensure equivalence between providers and consumers, as long as the latter is sophisticated enough. Furthermore, consumers often wish to have more information about the products and services of providers. ${ }^{171}$ Moreover, information obligations are less interventionist in comparison to other measures to protect consumers. The market mechanism remains nearly untouched; as well as the private autonomy of consumers and providers. ${ }^{172}$ Consumers, on one hand, will only be encouraged to help themselves, while providers, on

\footnotetext{
167 See Howells, above n 36, at 352; Julia Black “Decentring Regulation: Understanding the Role and Regulation and Self-Regulation in a 'Post-Regulatory' World” (2001) 54 CLP 103 at 126; Department of Trade and Industry "Extending Competitive Markets: Empowered Consumers, Successful Business” (June 2005) Department for Business Information \& Skills <www.bis.gov.uk> at 5.1; Better Regulation Executive and the National Consumer Council "Warning: Too Much Information Can Harm” (November 2007) Department for Business Information \& Skills <www.bis.gov.uk> at 3, 6.

168 See Howells, above n 36, at 354; see also above page 14.

169 Even courts often show a preference for information rules. See Case 178/84 Commission v Germany [1987] ECR 1227; Case C-362/88 GB-INNO-BM v Confédération du commerce luxembourgeois [1990] ECR I-667.

${ }^{170}$ Better Regulation Executive and the National Consumer Council, above n 167, at 6.

171 Department of Trade and Industry "Extending Competitive Markets: Empowered Consumers, Successful Business” (July 2004) Department for Business Information \& Skills <www.bis.gov.uk> at 4.25 .

172 Rischkowsky and Döring, above n 37, at 292.
} 
the other hand, will not suffer from restrictive, compulsory regulatory controls. ${ }^{173}$ However, this does not mean that there is no intervention in the free market. The affected providers cannot behave as they please and have to disclose mandatory information, which they may have preferred not to pass on to consumers. ${ }^{174}$ In addition, implementing information requirements is not costless. For example, the National Consumer Council stated "that information requirements in the consumer policy area alone now cost UK business $£ 1.5 b n ” .{ }^{175}$ Nevertheless, duties to provide information do not influence the contents of the contract directly and the "limitation of the autonomy of the [provider] is minimal compared to the potential growth in autonomy of the consumer who can make an informed choice of [the] service.”176

Overall, it can be said that information obligations affect the free market. Thus, precontractual information duties must be appropriate and necessary to enable selfdetermined decisions by consumers. Additionally, the obligations must aim to ensure that the contracts meet the requirements of the freedom of contract of both parties. In other words, the measures to protect consumers must consider the interests and balance the legal positions of both parties of the contract, consumers and providers. The focus is therefore to restore the private autonomy of consumers by restricting the private autonomy of providers.

\section{B Existing Statutory Rules and Regulations}

Before comparing the existing information standards and considering whether improvements can be made, it is necessary to present the current legal situation in New Zealand, Australia and Germany.

\section{New Zealand}

In New Zealand, pre-contractual information duties can be found in the Code of Rights, the Health and Disability Service Standards 2008, the Health and Disability Services (Safety) Act 2001 and the Social Security Act 1964. The Code of Rights contains ten

\footnotetext{
${ }^{173}$ Howells, above $\mathrm{n} 36$, at 350 .

174 See Chris Willett “Autonomy and Fairness: The Case of Public Statements” in Geraint G Howells, Andre Janssen and Reiner Schulze (ed) Information Rights and Obligations - A Challenge for Party Autonomy and Transactional Fairness (Ashgate, Aldershot, 2005) 1 at 6, 10; Kind, above n 51, at 95; Howells, above n 36, at 355.

${ }^{175}$ Better Regulation Executive and the National Consumer Council, above n 167, at 6 .

${ }^{176}$ Howells, above n 36, at 355; see also Willett, above n 174 , at $1-15$.
} 
different rights to promote and protect the consumers. In terms of information duties, three rights ensure that consumers obtain the necessary information. The Code of Rights sets out the right for consumers to effective communication (right 5), to be fully informed (right 6) and to make an informed choice and give informed consent (right 7). ${ }^{177}$

The right to be fully informed is defined as: "[e]very consumer has the right to the information that a reasonable consumer, in that consumer's circumstances, would expect to receive." ${ }^{178}$ This includes an explanation of the consumer's condition, the options available and any other information, which is required by other legal, professional, ethical and relevant standards. This information must be given to consumers before they make a choice or give their consent. ${ }^{179}$ Moreover, if consumers ask for one, they have to receive a written summary of the provided information. ${ }^{180}$ The term "reasonable consumer" is not entirely objective, although it is, on the other hand, unclear to what degree the term is subjective. $^{181}$ However, a completely subjective assessment would cause legal uncertainty, because the provider would have to examine case-by-case how much information the individual consumer need. Therefore, the term must be objectified. ${ }^{182}$

The right to make an informed choice and give informed consent (right 7) includes, among other things that services can only be provided to consumers if they make an informed decision, ${ }^{183}$ but also that consumer can refuse a service or withdraw their consent. $^{184}$

The right to effective communication tries to ensure that elderly consumers can understand and process the given information. In doing so, the right contains the obligation to communicate "in a form, language, and manner that enables consumers to understand the information provided." ${ }^{185}$ Moreover, the provider has to consult a competent interpreter for consumers where necessary and practical and, additionally, has

\footnotetext{
${ }^{177}$ Code of Health and Disability Services Consumers’ Rights 1996, rights 5 - 7.

178 Right 6.

${ }^{179}$ Right 6(2).

${ }^{180}$ Right 6(4).

181 Tokeley, above n 77, at 159.

182 Similarly at 159.

${ }^{183}$ Code of Health and Disability Services Consumers’ Rights 1996, right 7(1).

${ }^{184}$ Right 7(5).

${ }^{185}$ Right 5(1).
} 
to create an environment that enables consumers "to communicate openly, honestly, and effectively." 186

It is not necessary for a breach of the Code of Rights that the failure to comply with the obligations in rights 6 and 7 causes an injury or other harm, because the Code of Rights entitles consumers to make an informed choice and give informed consent. ${ }^{187}$ Therefore, a breach already exists, if a provider does not give consumers sufficient information. ${ }^{188}$

A further source of information for consumers and providers are the explanations written down in the mandatory Health and Disability Services (Core) Standards 2008 Consumer Rights. ${ }^{189}$ These explanations put the general rights of the Code of Rights in concrete terms and aim to clarify consumers about their rights and to assist providers to give effect to the Code of Rights. ${ }^{190}$ The consumers' rights need not be individually described here, but the most important standards related to information duties are listed briefly. Standard 1.2 states that consumers have to be informed about their rights by displaying the Code of Rights in the rest home and by providing information about the code as early as possible "in language and formats suited to the needs of consumers who use the service." ${ }^{191}$ According to Standard 1.9, the provider has the obligation to communicate effectively with consumers, which includes, among other things, full and frank information, enough time for discussions and assistance where needed. ${ }^{192}$ Standard 1.10 gives a detailed list of how to ensure that consumers give informed consent. A fact particularly worthy to note is the duty to provide all the information consumers need to have ${ }^{193}$ in an appropriate format and in a timely manner. ${ }^{194}$ To meet the requirements of the aforementioned standard, it is necessary that consumers are "provided with understandable, written and verbal information on the potential benefits, adverse effects, alternatives, costs, and predictable inconvenience associated with a particular treatment

\footnotetext{
${ }^{186}$ Right 5(2).

${ }^{187}$ Tokeley, above $\mathrm{n} 77$, at 161.

${ }^{188}$ At 161; see in contrast the law of negligence Rogers $v$ Whitaker (1992) 175 CLR 479 (HCA); Smith $v$ Auckland Hospital Board [1964] NZLR 241; from the literature Karen Tickner "Rogers v Whitaker Giving Patients a Meaningful Choice" (1995) 15 OJLS 109; James Cockayne "Roger v Whitaker: still crazy after all these years?” (2007) 36 HIMJ 30.

${ }^{189}$ For the legal basis of these standards see above on page 27.

${ }^{190}$ NZS 8134.1:2008 Health and Disability Services (Core) Standards 2008 - Consumer Rights at 6.

${ }^{191}$ At 7.

192 At 13.

${ }^{193}$ At 1.10.2.

${ }^{194}$ At 1.10.3.
} 
or therapy." ${ }^{195}$ Moreover, the provider has to create a system to check if consumers are able to understand the given information. ${ }^{196}$

Further information obligations for providers are stated in the Aged Related Residential Care Services Agreement between the provider and the DHBs. ${ }^{197}$ These duties focus on information about the provided services, so that the elderly consumers know about the details of the offered services (for example: location, hours accessibility).

The Health and Disability Services (Safety) Act 2001 does not contain any further information obligations in respect to the contractual relationship between consumers and providers. It only includes various obligations of providers for the certification of its services. The Act, specifically, mentions certain information that providers have to give the Director-General of the Ministry of Health. ${ }^{198}$

The Social Security Act 1964, lastly, comprises numerous information obligations of the provider, but these liabilities are also related to the contractual relationship between the provider and the Director-General. First and foremost, s 11 of the Act describes the Director-General's power to obtain information. ${ }^{199}$ However, the purpose of the commitment to provide the Director-General with all requested and necessary information is to determine whether a person who is receiving, or has received, or made a claim for a benefit or payment was or is entitled to receive that benefit or payment. ${ }^{200}$ Therefore, the information obligations mentioned in the Social Security Act 1964 are more related to the social law and less related to consumer law and rest home contracts.

Taken as a whole, New Zealand has established several information duties but none of them is specifically tailored for rest home contracts alone.

\footnotetext{
195 At G 1.10.2.

${ }^{196}$ At G 1.10.3.

197 For an example see Section D 11 of the contract used by the Canterbury District Health Board (http://www.cdhb.govt.nz/planning/documents/Health\%20of\%20Older\%20People/ARRC\%20Base\%20Do cument\%202012.pdf).

198 See Health and Disability Services (Safety) Act 2001, ss 4 and 31.

199 Social Security Act 1964, s 11.

200 Section 11(2)(a).
} 


\section{Australia}

In Australia, the main information responsibilities are established by ss 56-1, 59-1 and 96-1(1) of the Aged Care Act 1997 (Cth), ss 23.12 and 23.14 of the User Rights Principles 1997 (Cth) and the Charter of Residents’ Rights and Responsibilities (Cth). In the future, more rest home related information obligation may be introduced on the basis of sch 2, ss 134 and 135 of the Competition and Consumer Act 2010 (Cth).

Section 56-1 Aged Care Act 1997 (Cth) contains many different obligations for the provider, but no special information duties regarding rest home contracts, which in Australia are called resident agreements. A resident agreement is a legal agreement between the consumer and the aged care home, which sets out the rights and obligations of the elderly consumer (sometimes called the resident) and the aged care home. Providers have among other the obligations to act in accordance with any rights and responsibilities of consumers that are specified in the User Right Principles 1997 (Cth) ${ }^{201}$ and other responsibilities specified in the User Right Principles 1997 (Cth). ${ }^{202}$

The User Rights Principles 1997 (Cth) contains, in s 23.14, information that has to be given to elderly consumers about their rights and obligations. ${ }^{203}$ Contrary to the heading of the section, s 23.14 User Rights Principles 1997 (Cth) itself comprises of no specific information duties, but refers to the Charter of Residents' Rights and Responsibilities (Cth) ${ }^{204}$ and s 59-1(1)(b) to (h) of the Aged Care Act 1997 (Cth). ${ }^{205}$ However, s 23.14(2) of the User Rights Principles 1997 (Cth) obliges the provider to assist consumers to understand the information. ${ }^{206}$ Further information obligations are stated in s 23.14A of the User Rights Principles 1997 (Cth) regarding the eligibility of reduction in resident fees, s 23.28 of the User Rights Principles 1997 (Cth) regarding information about accommodation bonds ${ }^{207}$ and s 23.81C of the User Rights Principles 1997 (Cth) regarding information about accommodation charges. ${ }^{208}$

The most detailed and important information duties are laid down in s 23.85 of the User Rights Principles 1997 (Cth). This section describes, in detail, the requirements for a

\footnotetext{
${ }^{201}$ Aged Care Act 1997 (Cth), s 56-1(l).

${ }^{202}$ Section 56-1(m).

${ }^{203}$ User Rights Principles 1997 (Cth), s 23.14.

${ }^{204}$ Section 23.14(1)(a)(i).

${ }^{205}$ Aged Care Act 1997 (Cth), s 59-1(1)(b) to (h).

${ }^{206}$ User Rights Principles 1997 (Cth), s 23.14(2).

${ }^{207}$ This obligation is linked with Aged Care Act 1997 (Cth), s 57-2.

${ }^{208}$ Section 57A-2.
} 
resident agreement. The agreement must specify the care and services to be provided, the fees, charges and any further matters to be negotiated and, on top of this, the consumer's rights and obligations. Of particular importance are the obligations to help consumers to understand the terms of the contract ${ }^{209}$ and, moreover, that the contract must be expressed in plain language and be readily understandable. ${ }^{210}$ In this way, s 23.85 of the User Rights Principles 1997 (Cth) puts s 59-1 of the Aged Care Act 1997 (Cth) in concrete terms. In other words, s 59-1 of the Aged Care Act 1997 (Cth), on the one hand, describes in detail the compulsory contents of a rest home contract ("A resident agreement ... must specify”), ${ }^{211}$ while s 23.85 of the User Rights Principles 1997 (Cth), on the other hand, regulates the formal aspects of the contract signing ("A resident agreement must comply with the following requirements”). ${ }^{212}$ Moreover, s 59-2 of the Aged Care Act 1997 (Cth) states that a resident agreement must comply with any requirements specified in the User Rights Principles, especially the way in which, and the process by which, the agreement is to be entered into. ${ }^{213}$

In addition to these information liabilities, the Charter of Residents' Rights and Responsibilities mentions that every consumer has "to have access to information about his or her rights, care, accommodation, and any other information which relates to him or her personally."214 This right exists irrespective of the home the elderly consumer chooses, which means that consumers always have the same information rights. However, the Charter has no enforcement or compliance mechanisms and is therefore only exhortatory. ${ }^{215}$ Thus, consumers cannot require providers to comply with the Charter.

Furthermore, the Australian law contains several information duties, which do not have a pre-contractual character but determine information that has to be given to the consumers as the compulsory content of the contract. Providers have to consider further information duties, if they charge an accommodation charge for the entry of elderly consumers into their rest home. Sections 57A-3(1) and 57A-12(1)(c) of the Aged Care Act 1997 and ss 23.81M and 23.81N of the User Rights Principles 1997 set out essential information in

\footnotetext{
${ }^{209}$ User Rights Principles 1997 (Cth), s 23.85(e).

210 Section 23.85(i).

${ }^{211}$ Aged Care Act 1997 (Cth), s 59-1(1).

${ }^{212}$ User Rights Principles 1997 (Cth), s 23.85.

${ }^{213}$ Aged Care Act 1997 (Cth), s 59-2 (2)(a).

214 Australian Government Department of Health and Ageing “The Charter of Residents' Rights and Responsibilities” Department of Health and Ageing <www.health.gov.au> at 1 .

215 Barnett and Hayes, above n 14, at 57.
} 
accommodation charge agreements. If consumers have to sign an accommodation bond agreement the provider has to fulfil the information duties mentioned in s 57-9 of the Aged Care Act 1997 and pt 4(5) of the User Rights Principles 1997.

Similar to the legislation in New Zealand, the Australian Aged Care Act 1997 also quotes certain information the provider has to accompany with its application to register as an approved provider ${ }^{216}$ and a further obligation to give information when the provider is already approved. ${ }^{217}$

Overall, the Australian legislation contains several different information obligations for providers and aims to ensure that consumers are fully informed.

\section{Germany}

In Germany, information provisions are regulated in detail in paras 3 and 6(3) of the WBVG. ${ }^{218}$ Paragraph 3 of the WBVG states pre-contractual information duties, whereas para 6(3) of the WBVG regulates the minimum content of the contract.

The first sub-para of para 3 describes, in a general way, when and in what form the providers must fulfil their information obligations. The provider must allocate content to include information about its general range of services and the services which come into consideration for the individual consumer. This information must be passed to consumers in a timely manner and in writing before they sign the contract. Moreover, the information must be given to consumers in plain and intelligible language. The provision of this information is a legally enforceable right. Therefore, consumers can judicially enforce its fulfilment.

The second sub-para contains more detailed information provisions regarding the providers' general service range. Consumers must, among other things, be informed about the facilities and the location of the rest home and, on top of this, the services according to content, type and scope. In other words, the second sub-para aims to provide consumers with information about the whole service portfolio of the provider, so that they can compare the services with the services of other providers. However, this does

\footnotetext{
${ }^{216}$ Aged Care Act 1997 (Cth), s 8.

${ }^{217}$ Section 9.

218 The law is accessible on the internet at www.gesetze-im-internet.de/wbvg/BJNR231910009.html.
} 
not have to take place on a case-by-case basis, but can be given through a general information brochure. ${ }^{219}$

In addition, the third sub-para requires providers to give a comprehensive explanation of all services which can be considered by the consumer. These details must cover the interests of the individual consumer and can therefore not being granted in the form of a general brochure. The information has to be tailored to the situation of the consumer. This does not necessarily mean, however, that the information has to be linked with an actual offer of a contract. Very briefly described, the provider has to give information about the rooms and their equipment, the care and catering services, the service concept, the remuneration to be paid by the consumer, the conditions for change of services and remuneration when the care needs of the consumer change. ${ }^{220}$ Furthermore, the third subpara contains the obligation that the provider has to inform the elderly consumer, in a highlighted form, about when an adjustment of the contract is precluded, if the provider wants to stipulate such terms.

Lastly, the fourth sub-para regulates the legal consequences, if the provider does not fulfil the information obligations described above. In this case, the consumer is entitled to terminate the contract without previous notice. Further civil law claims, especially claims for compensation because of culpa in contrahendo, ${ }^{221}$ are also possible as long as the requirements of the claim are fulfilled.

In addition to these pre-contractual information duties, para 6(3) of the WBVG contains further legal prerequisites regarding the content of the rest home contract. The norm describes the minimum compulsory content of the contract. In particular, the contract has to contain a detailed description of the providers' services regarding scope and execution, ${ }^{222}$ the charges and their individual components (separated into residential accommodation, care services and where applicable catering) ${ }^{223}$ and the pre-contractual information and any deviation from the pre-contractual information. ${ }^{224}$ The latter obligation is the most important one for consumers because the provider has to set down

\footnotetext{
$\overline{219}$ Frederik Martell Der Schutz des Verbrauchers im Heimrecht (Dr. Kovač, Hamburg, 2012) at 201 (translation: The Protection of the Consumer in the Area of Law Governing Homes for the Elderly).

${ }^{220}$ Wohn- und Betreuungsvertragsgesetz 2009 (Germany), para 3(3).

${ }^{221}$ See Bürgerliches Gesetzbuch 2002 (Germany) para 311(2) read in conjunction with paras 241(2) and 280(1).

${ }^{222}$ Wohn- und Betreuungsvertragsgesetz 2009 (Germany), para 6(3)(1).

${ }^{223}$ Paragraph 6(3)(2).

${ }^{224}$ Paragraph 6(3)(3).
} 
in written form the pre-contractual information as a basis of the transaction and has to mark every modification of this information. ${ }^{225}$ The reason for this regulation is to ensure that consumers can easily see if there is a change concerning the expected contents of the contract. Overall, it can be said that the spirit of the norm is a clear explanation for consumers and that the total monthly payment of the contract is understandable.

These prerequisites are not information obligations in a strict sense, but they ensure that consumers know about the services of the provider and the contents of the contract.

\section{Limitations of Consumer Protection by Information}

The previous part has shown that, although New Zealand, Australia and Germany consider information obligations as an essential component of the consumer protection law that pertains to elderly consumers, there are serious differences in the structuring of these obligations. This is no surprise if one considers that it is almost indisputable that information can make an essential contribution to consumer protection. ${ }^{226}$ Ideally, information enables consumers to protect themselves, so that a further intervention in the market in favour of consumers is no longer required, but still leaves consumers free within the market to make their own choices. ${ }^{227}$

However, despite the general acceptance of the goal to redress information asymmetry, analysis of how to efficiently provide consumer information has lagged behind. ${ }^{228}$ Furthermore, it is often overlooked that there are limitations on consumer protection through information. These limitations are often underestimated, even though they limit the efficacy of this consumer protection instrument from its beginning. The following section will show some of the limitations. They often apply to every consumer, but some of the limitations are specifically applicable to elderly consumers in rest homes. Priority should be given to behavioural economics, which applies insights from psychology and focuses on the effects of social, emotional, and cognitive factors on the economic behaviour of the consumer. ${ }^{229}$

\footnotetext{
${ }^{225}$ Walter Weidenkaff in Otto Palandt Bürgerliches Gesetzbuch (71 ed, CH Beck, München, 2012), para 6 WBVG, at 4 (translation: Commentary on the German Civil Code).

${ }^{226}$ Howells, above $n$ 36, at 352; see above page 14 .

227 Howard Beales, Richard Craswell and Steven C Salop “The Efficient Regulation of Consumer Information” (1981) 24 J L Econ 491 at 513.

${ }^{228}$ Beales, Craswell and Salop, above n 227, at 491.

${ }^{229}$ Corones, above n 66, at 2.25 .
} 


\section{The Insights of Research into Consumer Behaviour}

The behavioural economics movement shows that, in opposition to the assumptions of some traditional law and economics approaches, ${ }^{230}$ consumers are subjected to specific constraints. $^{231}$

\section{a. Limitations on Consumers’ Ability to Process Information}

Consumers have severe limitations on the amount of information that they are able to receive, understand, process and remember. ${ }^{232}$ They cannot remember everything and cannot calculate every possible option. ${ }^{233}$ Due to this, consumers are sometimes unable to "run through" all the possible alternatives. ${ }^{234}$ Moreover, the human brain can process information only up to a certain point; to be more precise, research has shown that people who break the information down into manageable chunks are able to handle, on average, five to seven chunks at one time ${ }^{235}$ (although this number can certainly vary depending on the individual consumer). ${ }^{236}$ This has the consequence that it does not necessarily help to supply consumers with more information, if this information washes over them.

\footnotetext{
${ }^{230}$ For further sources see Horst Eidenmüller Effizienz als Rechtsprinzip (Mohr Siebeck, Tübingen, 2005) at 28 (translation: Efficiency as an Essential Principle of Law). See regarding the difference between the traditional economic analysis and the rational choice theory Jules L Coleman "The Rational Choice Approach to Legal Rules” (1989) 65 Chi L Kent Rev 177 at 181; regarding the behavioural law and economics approach see Christine Jolls, Cass R Sunstein and Richard Thaler "A Behavioral Approach to Law and Economics" (1998) 50 Stan L Rev 1471 at 1471, 1476; regarding the modifications of the behaviour assumptions of the neoclassical standard theory see Dragan Miljkovic "Rational choice and irrational individuals or simply an irrational theory: A critical review of the hypothesis of perfect rationality" (2005) 34 J Socio-Econ 621; Vernon L Smith "Behavioral economics research and the foundations of economics” (2005) 34 J Socio-Econ 135.

${ }^{231}$ Alan M White "Behavior and Contract” (2009) 27 Law \& Ineq J 135 at 135, 149; Rischkowsky and Döring, above n 37, at 308; Howells, above n 36, at 349, 358; Evans, above n 64, at 32.

${ }^{232}$ George A Miller "The Magical Number Seven, Plus or Minus Two: Some Limits on Our Capacity for Processing Information” (1956) 63 Psychological Rev 81 at 95; Howells, above n 36, at 359.

${ }^{233}$ Evans, above n 64, at 31; Russell Korobkin "Bounded Rationality, Standard Form Contracts, and Unconscionability” (2003) 70 U Chi L Rev 1203 at 1206.

${ }^{234}$ Stefan Schneider "Homo economicus - or more like Homer Simpson?” (29 June 2010) DB Research $<$ www.dbresearch.in> at 15.

${ }^{235}$ See Miller, above n 232, at 81 - 96; White, above n 231, at 155; critical Alan Baddeley "The Magical Number Seven: Still Magic After All These Years?” (1994) 101 Psychological Rev 353 - 356; Howells, above $\mathrm{n}$ 36, at 360 .

${ }^{236}$ Korobkin, above n 233, at 1227.
} 
Furthermore, too much information makes it more difficult for consumers to be attentive and to select the most important features for consideration. ${ }^{237}$

Complex information can also induce an "information overload". ${ }^{238}$ An overload of information has the consequence not only that consumers can only partially process the information, but also that the consumers" "hit rate” will first stagnate and then drop off again. ${ }^{239}$ This means that consumers will process less information, although provided with more (necessary) information and, furthermore, it will become more difficult for consumers to distinguish between relevant and unimportant information. Besides that, stress reactions can occur, as well as, distortion of information, forgetfulness, partial considerations or erroneous weighting of important information, ${ }^{240}$ which also influence the amount of information transferred. The worst case scenario is that consumers are completely overstrained with all the given information and are unable to use any of the given information. ${ }^{241}$ However, even if consumers take notice of less information, consumers will think that they made the best decision concerning their own interests. Sometimes too much information can also have a paralyzing effect on consumers. When too many options are presented, consumers may feel overwhelmed and completely unable to make a decision. ${ }^{242}$ Overall it can be summarized that wrongly supplied information can have a negative effect in terms of protecting consumers.

This problem is made worse by the fact that the ability to understand and process information strongly depends on the cognitive skills (intelligence, memory and concentration ability) but also educational attainment, social background and linguistic competence $^{243}$ of the single consumer. It was shown above ${ }^{244}$ that with increasing age the cognitive skills decline and, therefore, elderly consumers, particularly, suffer restrictions in their ability to understand information. However, limitations of those skills often do not become perceptible and evident during the first conversations with consumers. For

\footnotetext{
${ }^{237}$ Incardona and Poncibò, above n 42, at 32.

238 At 32; Jacob Jacoby "Perspectives on information overload” (1984) $10 \mathrm{~J}$ Consum Res 432; David Bawden, Clive Holtham and Nigel Courtney "Perspectives on information overload" (1999) 51 Aslib Proceedings 249.

239 See Kind, above $\mathrm{n}$ 51, at 467.

${ }^{240}$ Markus Rehberg Der Versicherungsabschluss als Informationsproblem (Nomos Verlag, Baden-Baden, 2003) at 58 - 59 (translation: The Conclusion of an Insurance Contract as a Problem of Information).

${ }^{241}$ Kind, above $n$ 51, at 468, 474.

${ }^{242}$ White, above $\mathrm{n} 231$, at 153.

243 See Scott and Black, above n 22, at 34.

${ }^{244}$ See above page 20 .
} 
this reason, it is difficult for a rest-home provider to assess whether or not consumers understand all, or only a selection, of the information.

Beyond that, further research into consumer behaviour has shown that the way information is presented (for example the language of the presentation or the nature of the display) has a major impact on how consumers perceive and react to it. ${ }^{245}$ In other words, the way information is framed influences the decision of consumers. ${ }^{246}$ This means that even if consumers have stable preferences and these preferences match best with their needs, these preferences can change if other options are presented in a convincing way. ${ }^{247}$ For example, a provider can try to induce a shift of preference by presenting its additional services as "gain" or the consumers will "lose" these services if they waive them, because people dislike losses significantly more than they like gains. ${ }^{248}$ In other words, the way information and choices are presented can be used to direct consumers towards outcomes that the provider desires. ${ }^{249}$ It has also been identified that consumers tend to select alternatives that are favourably evaluated by other consumers, even when consumers know that those other consumers do not have special knowledge regarding the pending decision. ${ }^{250}$ Furthermore, rational deliberation can be overridden by the influence of visceral factors. ${ }^{251}$

As a further point, most of the providers know about these insights, especially because the science of marketing is essentially based on the "weaknesses" of consumer behaviour. Therefore, it is likely that providers will use various marketing strategies to exploit consumers' frailties. ${ }^{252}$ In addition, situational factors highly influence consumers' preferences and consumers are, thus, readily subject to provider manipulation. ${ }^{253}$ For

\footnotetext{
${ }^{245}$ Howells, above $n$ 36, at 361 .

${ }^{246}$ Schneider, above n 234, at 9.

247 See for example Daniel Kahnemann and Amos Tversky “Choices, Values, and Frames” (1984) 39 Am Psychologist 341 at $343-344$,

${ }^{248}$ Matthew Rabin "Psychology and Economics” (1998) J of Economic Literature 11 at 11; Derek E Bambauer "Shopping Badly: Cognitive Biases, Communications, and the Fallacy of the Marketplace of Ideas” (2006) 77 U Colo L Rev 649 at 694.

${ }^{249}$ Howells, above n 36, at 355.

${ }^{250}$ Itamar Simonson “Choice Based on Reasons: The Case of Attraction and Compromise Effects” (1989) $16 \mathrm{~J}$ of Consumer Research 158 at 171.

${ }^{251}$ See for details George Loewenstein "Out of Control: Visceral Influences on Behavior" (1996) 65 Organizational Behavior and Human Decision Processes 272 at 274.

${ }^{252}$ See White, above n 231, at 158.

${ }^{253}$ At 150; Amos Tversky and Daniel Kahnemann “Rational Choice and the Framing of Decisions” (1986) $59 \mathrm{~J}$ Bus 251 at $254-255$.
} 
example, consumers often have to set their original preferences aside after an accident. In these cases, aged consumers often have to move from a hospital straight to a rest home, because they cannot return to their home to live there without external help. In these circumstances, decisions that need to be made take place under enormous time pressure and the main preference is to find a rest home as soon as possible.

\section{b. Limited Benefit of Information}

Even if information duties would consider all the limitations of the consumers' ability to process information, the effectiveness of information obligations would still be limited. This is because consumers do not behave completely rationally. ${ }^{254}$ The consumers' judgment often departs from perfect rationality, even if they are completely informed and know what their preferences are. Consumers sometimes do not choose the alternative that best matches their own preferences, but make irrational decisions on the basis of cognitive errors. ${ }^{255}$ Hence, it is better to assume that the rationality of human nature is imperfect. ${ }^{256}$ It is therefore likely that even perfectly developed information obligations cannot ensure, in all cases, that consumers make the "right” decision.

Another problem is a natural propensity of consumers to choose only information that coincides with their pre-existing opinion, whereas facts that disprove that opinion are ignored. ${ }^{257}$ This means that consumers are often biased and search only for information that strengthens their first impression rather than challenges its validity. ${ }^{258}$ They show a clear tendency to justify their desired conclusion, even if new input logically negates the original opinion and, therefore, objectively, a different outcome would be a better match

\footnotetext{
${ }^{254}$ See Daniel Kahnemann and Amos Tversky "Prospect Theory: An Analysis of Decision und Risk" (1979) 47 Econometrica 263; Corones, above n 66, at 2.25; Rabin, above n 248, at 24; Schneider, above n 234, at 8; for a critique of this traditional view see Richard A Posner "Rational choice, behavioral economics, and the law” (1998) 50 Stan L Rev 1551; Cass R Sunstein "Behavioral analysis of law” (1997) 64 U Chi L R 1175.

${ }^{255}$ Europe Economics, above n 27, at 6.47; see in detail Bambauer, above n 248, at 673 to 696.

${ }^{256}$ Herbert A Simon “A Behavioural Model of Rational Choice” (1955) 69 Q J Econ 99 at 100; Zhou, above $\mathrm{n}$ 7, at 171.

${ }^{257}$ Kind, above n 51, at 471 - 472; Howells, above n 36, at 360; Bambauer, above n 248, at 678 to 679.

258 Lee Ross, Mark R Lepper and Michael Hubbard "Perseverance in Self-Perception and Social Perception: Biased Attributional Processes in the Debriefing Paradigm” (1975) $32 \mathrm{~J}$ of Personality and Social Psychology 880 at 889; Charles G Lord, Lee Ross and Mark R Lepper "Biased Assimilation and Attitude Polarization: The Effects of Prior Theories on Subsequently Considered Evidence” (1979) 37 J of Personality and Social Psychology 2098 at 2098.
} 
for their needs. ${ }^{259}$ Consumers tend to behave in accordance with their personal impressions and social perceptions and, hence, do not process the information impartially. ${ }^{260}$ For this reason, contradictory evidence has far less impact than it would have if consumers behaved completely rationally or logically. ${ }^{261}$ Consumers have a tendency to dismiss empirical evidence if it contradicts with their expectations and initial views. ${ }^{262}$ Furthermore, consumers are often inattentive to the possibility that information which supports their own opinion may be invalid or unreliable. ${ }^{263}$

In addition, empirical studies have shown that consumers sometimes do not use, or only to a limited extent, the information available, independently of their form of presentation. ${ }^{264}$ Moreover, consumers will only consider additional information when they are motivated to receive and process further information. This crucially depends on, whether the information gains the consumers' attention. ${ }^{265}$ Information that is too complex or presented in an unappealing way consumers will not assimilate the information. ${ }^{266}$ Furthermore, the consumers' attention depends on their knowledge and whether they have previous experience with rest home contracts. ${ }^{267}$ Overall, a rational decision is linked to some serious constraints from the beginning. Thus, consumers make irrational decisions which they would not make if they were able to ponder all available information rationally. ${ }^{268}$

\section{External Limitations}

Apart from the insights of behavioural economics, there are often external limitations, which can reduce the effectiveness of information duties.

\footnotetext{
${ }^{259}$ Ross, Lepper and Hubbard, above n 258, at 880.

${ }^{260}$ Lord, Ross and Lepper, above n 258, at 2099.

${ }^{261}$ Ross, Lepper and Hubbard, above n 258, at 880.

${ }^{262}$ Lord, Ross and Lepper, above n 258, at 2099.

263 Ross, Lepper and Hubbard, above n 258, at 889.

264 See Rischkowsky and Döring, above n 37, at 294.

265 Incardona and Poncibò, above n 42, at 32.

${ }^{266}$ Better Regulation Executive and the National Consumer Council, above n 167, at 4.

${ }^{267}$ Incardona and Poncibò, above n 42, at 23.

268 Deborah Stone "Shopping for Long-Term Care” (2004) 23 Health Affairs 191 at 192 has convincingly stated: "It's fairy-tale magic, this market story with Wise Consumer as its hero, and it revolves around fairy-tale characters. I don’t know any real people, especially frail elders, who are motivated or think much like homo economicus."
} 
Elderly consumers are often influenced by time or spatial preferences. Sometimes they favour a rest home next to their previous residence, for family reasons. In addition, younger relatives also strive to find a rest home next to their own residence, so that they can easily visit and take care of the elderly. In practice, time preferences occur as well. Frequently, elderly consumers have to move to a rest home abruptly, because of spontaneously emergent factors (for example, due to a fall or a disease). Consumers and their relatives then do not have enough time to compare a lot of rest homes, but have to try to find any rest home that has space available.

It is certainly true that factors such as family and timing are important for the decision making, but these factors often lead to a limited information search. Sometimes they might not have enough time to read all the given information; sometimes consumers or their relatives will only search for information that coincides with their pre-existing opinion to convince themselves that their first opinion was right. Therefore, external limitations often lead to the situation that consumers and their relatives will not ponder all the given information equally.

\section{Point of Reference: The Average Consumer}

The efficacy of information duties can further be limited if the government takes the average consumer as a basis for regulatory action. This is because consumers who are below the average would then not be addressed by the regulation ${ }^{269}$ and unable to understand the given information. This problem can be exacerbated if the legislature refers to a concept of consumers that do not include the insights of the research in consumer behaviour and, as a result, assumes that consumers are able to understand and process any information. This would set an overly demanding standard and consumers would be "falsely deemed to be ever reasonably circumspect and attentive." problem can occur, if the government considers vulnerable consumers as atypical consumers, which must not benefit from the protection measures. ${ }^{271}$ Consequently,

\footnotetext{
${ }^{269}$ Actually consumer policy regimes were often modelled around the needs of the average consumer. See Department of Trade and Industry "Comparative Report on Consumer Policy Regimes" (October 2003) Department for Business Information \& Skills <www.bis.gov.uk> at 10; Case C-210/96 Gut Springenheide GmbH and Rudolf Tusky v Oberkreisdirektor des Kreises Steinfurt - Amt für Lebensmittelüberwachung [1998] ECR I-4657; Incardona and Poncibò, above n 42, at 22; see also Geraint Howells and Christian Twigg-Flesner "What sort of Europe do consumers want" (2005) 15 CPR 169 at 170.

${ }^{270}$ Incardona and Poncibò, above n 42, at 23.

${ }^{271}$ Howells, above n 36, at 359.
} 
consumers who do not meet the requirements of the law would not be protected and the norm would not achieve its objective. ${ }^{272}$

A consumer law policy that focuses around the needs of the average consumer would particularly harm the interests of elderly consumers. Elderly people are more likely to have no formal or less educational qualifications in comparison to other age groups. ${ }^{273}$ They often have difficulties when looking after themselves and more likely suffer some cognitive deficits. ${ }^{274}$ Elderly consumers are a particularly vulnerable consumer group and would, therefore, due to their limitations, frequently not be covered by information obligations that aim to inform the average consumer.

However, information duties can hardly address each consumer group in a different way and provide tailored information obligations. This is because the law phrases the duties in an abstract form in order to cover all relevant situations. Nevertheless, in the specific case of a rest home contract consumers are in nearly all cases part of a particularly vulnerable consumer group: the elderly. Thus, the government should design obligations that take the special deficits of the elderly into account, ${ }^{275}$ or at least target the average consumer in relation to the identified group of elderly consumers. ${ }^{276}$ The government should establish targeted legislation specific to the rest home situation and try to mirror consumer behaviour more faithfully. ${ }^{277}$ Otherwise, most elderly consumers would not be protected by the law, because they could not understand and process the given information.

\section{Health Care Services as Credence Goods}

A further limitation of information duties is linked with the fact that medical and health services are credence goods. Regulations to reduce information asymmetries between consumers and providers can ensure that the former will have information about the

\footnotetext{
${ }^{272}$ Barbara Grunewald “Aufklärungspflichten ohne Grenzen?” (1990) 190 AcP 609 at 614 (translation: Duty to Give Information without Borders?).

${ }^{273}$ For the United Kingdom see Ramil Burden "Vulnerable consumer groups: quantification and analysis" (April 1998) Office of Fair Trading < www.oft.gov.uk> at 25 "probably a reflection of past educational and cultural trends".

${ }^{274}$ Burden, above n 273, at 26.

${ }^{275}$ Similarly Better Regulation Executive and the National Consumer Council, above n 167, at 13 "design for all approach".

${ }^{276}$ Similarly Incardona and Poncibò, above n 42, at 29.

${ }^{277}$ At 36.
} 
services itself, but cannot ensure that the services will be performed in a proper and appropriate manner. ${ }^{278}$ However, the provider can become subjected to other consumer protection measures to make sure that the services' correspond with an appropriate quality standard. ${ }^{279}$ This will be especially the subject of the next chapter. ${ }^{280}$

\section{Consequences for the Structuring of Information Obligations}

Information obligations are important as a powerful tool to protect consumers, but the tool is neither perfect nor costless. ${ }^{281}$ The limitations shown above do not principally call into question the effectiveness of information, even if these limitations cannot be corrected through learning processes. ${ }^{282}$ However, the limitations have consequences in regards to the design of the information duties. This means, when structuring information obligations to protect consumers, one has to keep in mind the limitations because "[i]nformation is only useful if it can be acted upon it." 283 As a consequence, an ambitious consumer information strategy should not merely focus on the amount of information provided, ${ }^{284}$ but provide appropriate and targeted information for elderly consumers. Policy makers should shift their emphasis from the quantity to the quality of the information supplied, especially the presentation format. ${ }^{285}$ To optimise the outcomes the government should also focus on the situation in which the information is provided and the consumers' attention.

However, with information obligations alone, the legislature cannot ensure that consumers will process the information and use it to their advantage. Extensive information and instructions, for example, might confuse elderly consumers and cannot guarantee that they will understand the economic or legal consequences of the rest home contract. The provision of additional information can miss its target, elderly consumers. Therefore, the legislature has to focus on a realistic comprehension of the consumers' behaviour, ${ }^{286}$ also because the amount of information processed depends on the existing

\footnotetext{
${ }^{278}$ Rischkowsky and Döring, above n 37, at 288 - 289; Howells, above n 36, at 362.

279 At 289.

${ }^{280}$ See below on page 61 .

${ }^{281}$ Likewise Better Regulation Executive and the National Consumer Council, above n 167, at 7.

${ }^{282}$ Rischkowsky and Döring, above n 37, at 301.

${ }^{283}$ Howells, above n 36, at 358.

${ }^{284}$ At 353.

${ }^{285}$ Rischkowsky and Döring, above n 37, at 306; Ramsay, above n 26, at 41; similarly Bambauer, above n 248 , at 709 .

${ }^{286}$ Similarly Kind, above n 51, at 546.
} 
abilities in the specific situation. ${ }^{287}$ For this reason, it can be effective to show restraint concerning the information obligations. The manner of presentation is more important than the amount of information. ${ }^{288}$ In any case, the legislature has to ensure that the law does not expect too much of elderly consumers. Information is a dangerous good that can, in the worst case, thwart the purpose of consumer protection.

Overall, it can be said in accordance with Rischkowsky and Döring “the consumer's cognitive abilities to reach rational decisions, as well as the independence of individual information search and procession of situational, motivational and emotional factors should be considered."289 Consumers will tend to act rationally when the presented information is clear and transparent, but will more likely behave irrationally when the information is opaque. ${ }^{290}$ It is therefore necessary to understand and consider the framework on which consumers and providers base their decision-making behaviour ${ }^{291}$ and to design tailored information requirements. ${ }^{292}$ However, it is also clear that information duties alone cannot ensure comprehensive consumer protection. This is because consumers, in particularly the elderly have, and act upon, their cognitive biases; for example, a systematic tendency to misinterpret or ignore information or to repress unwanted information. ${ }^{293}$ Due to these biases, they will make an irrational decision from time to time, but it is neither the task of the legislature nor is it possible to make provisions to protect the consumers against their own irrationality. ${ }^{294}$ Nevertheless, the legislator can introduce further measures to protect consumers, for example, allow elderly consumers to cancel their contract short term ${ }^{295}$ or give them the opportunity to reframe their decision for limited time after the contract was signed. ${ }^{296}$

\section{Proposals to Maximise the Positive Impact of Consumer Information}

If one looks on the current legal situation in New Zealand, Australia and Germany, on the basis of the criteria aforementioned, all legislation has some advantages and

\footnotetext{
${ }^{287}$ At 468.

${ }^{288}$ Rischkowsky and Döring, above n 37, at 306.

${ }^{289}$ At 295.

${ }^{290}$ Evans, above n 64, at 32.

${ }^{291}$ Similarly Rischkowsky and Döring, above n 37, at 286.

${ }^{292}$ See Incardona and Poncibò, above n 42, at 32; similarly Bambauer, above n 248, at 698.

${ }^{293}$ Kennedy, above n 24, at 627.

${ }^{294}$ Similarly White, above n 231, at 172.

${ }^{295}$ See below on page 75 .

${ }^{296}$ See below on page 82 .
} 
disadvantages. However, none addresses all the limitations. Therefore, it is most valuable to combine the pros, as best as possible, of all the different laws and avoid the cons.

\section{Pros and Cons of the German Legislation}

The German legislation has the advantage of clearly describing all information obligations. This ensures legal certainty and benefits providers because they know precisely what information must be provided to consumers. However, if one looks closer, it becomes clearer that the WBVG does not adequately take into consideration the research around behavioural economics. The pre-contractual information duties, as required by para 3 of the law, threaten to result in an information overload. Often the basic information about the location and the facilities alone can extend across multiple pages and therefore all the needed information can fill a whole book. Thus, more often than not providers find themselves with a dilemma. On one hand, they have to provide a large amount of information, and, on the other hand, they know that all this information can overwhelm and confuse consumers. To fulfil the information obligations adequately is, therefore, to try to square the circle. ${ }^{297}$ Thus, the German law is not a good example for a particularly well-designed consumer protection measure. It tries to provide a onesize-fits-all compromise and thereby makes it difficult to provide specificity in regards to the interests of a single consumer.

This said, another aspect of the measure is promising. The German law shows efficiency when specifying that the information must be provided in plain and intelligible language, as the WBVG states in para 3(1). This liability ensures that the provider is not allowed to use complicated law terms, but must explain the information so that consumers will understand them without legal advice. Furthermore, the law requires that the design, structuring and extent of the information allow consumers to find the relevant information without a long search. ${ }^{298}$ The law also includes the obligation to choose an understandable, lively language, which is concrete rather than abstract terms, and short sentences. ${ }^{299}$ In addition, font size, colour, spacing of titles and lines should also be used to promote the comprehensibility of the handed information. ${ }^{300}$ Overall, the legal term ensures enhanced transparency and understanding.

\footnotetext{
${ }^{297}$ See Martell, above n 219, at 219.

${ }^{298}$ See Kind, above n 51, at $484-485$.

${ }^{299}$ Weber, above n 116, at 340.

${ }^{300}$ Sascha Iffland and Markus Düncher Kommentar zum Wohn- und Betreuungsvertragsgesetz (Vincentz, Hannover, 2011) at [3.5] (translation: Commentary on the Residential Care Contract Law).
} 


\section{Pros and Cons of the Australian Legislation}

The Australian information obligations are very comprehensive. However, due to the large number of laws and regulations, they can be confusing for both providers and consumers. Nevertheless, the Australian government has created the Residential Care Manual 2009 (Cth), which acts as a plain English guide to Australian Governmentsubsidised residential aged care, legislated under the Aged Care Act 1997 (Cth) and the User Rights Principles 1997 (Cth). ${ }^{301}$ It is without a doubt beneficial to make this manual available to providers and give them an understandable overview of their duties, to therefore reduce mistakes and improve the understanding of the law. However, due to the substantial number of obligations, the manual requires 348 pages to explain all of the different obligations in plain English. Therefore, providers have to make a considerable effort to know and fulfil their duties.

In addition, consumers are unable to fully comprehend whether or not they understand the pre-contractual information in its entirety without legal assistance. In other words, the extent of the duties is detrimental to clarity and comprehensibility. Moreover, the Australian law shares the same problem as the German regulation. The provider has to pass a lot of information to consumers, which can overwhelm them and lead to an information overload.

Nevertheless, the Australian approach has some clear advantages, especially the providers' obligation to assist consumers in understanding the information. ${ }^{302}$ This can make a valuable contribution to protecting elderly consumers. This is because the obligation requires the provider to focus on the abilities of the individual consumer, rather than providing information based on the abilities of the average consumer. Similar to the German approach, the provider has to use plain language and to ensure that the contract is readily understandable. ${ }^{303}$ As stated above, this obligation is beneficial, because it ensures that all consumers have the chance to understand the contract terms.

\section{Pros and Cons of New Zealand's Legislation}

Similarly to the Australian regulations New Zealand describes the information duties of providers in several different laws. Therefore, it is difficult for providers to fulfil all their duties completely and difficult for the elderly consumers to know their rights.

\footnotetext{
${ }^{301}$ Residential Care Manual 2009 (Cth) at 3.

${ }^{302}$ User Rights Principles 1997 (Cth), ss 23.14(2) and 23.85(e).

${ }^{303}$ Section 23.85(i).
} 
It is commendable that New Zealand, using the Health and Disability Services (Core) Standards 2008 - Consumer Rights, tries to cast more light on this issue. However, the information duties are often general in nature and do not describe particular information that should be provided to consumers. For example, the information duties do not particularly focus on the financial matters of a rest home contract or the location and the facilities of providers. This lack of information within the information duties could be detrimental to consumers on entering into a contract.

Most of the fundamental elements of the contract are negotiated between the DHB and the provider in the Age Related Residential Care Services Agreement and therefore, most consumers have very limited opportunity to influence the contract. However, that does not mean that the consumers' right of self-determination does not demand comprehensive information about the contract details. In this context it is important to bear in mind that not all consumers receive a full Residential Care Subsidy, but often have to pay for some of the services.

Apart from this criticism, it is generally expedient that consumers have the right to receive the information based on what reasonable consumers would expect, in a language and format that is suited to their needs and therefore allowing them to make an informed choice. Nevertheless, these regulations do not adequately consider the limitations of consumer protection by information. The term reasonable consumer obviously aligns to the average consumer. Therefore, it cannot be expected that consumers below the average can understand all the information they need. Moreover, it is generally presumed that elderly consumers are competent to make an informed choice. ${ }^{304}$ This can lead to serious problems if the frailties of consumers are not obvious. As stated above, elderly consumers often have limited cognitive and intellectual abilities and, therefore, it cannot generally be assumed that consumers are able to make an informed choice.

\section{The Future Path for New Zealand}

This investigation has shown that the current information obligations are partly inappropriate to ensure an effective consumer protection. The question now is how to reshape the existing duties to improve the consumer protection through information.

$\overline{304}$ Code of Health and Disability Services Consumers’ Rights 1996, right 7(2). 
Generally, elderly consumers should have as much information available as possible when making the important decision whether or not moving to a rest home. ${ }^{305}$ This requires that New Zealand joins Australia and Germany in providing a law that is tailored for elderly consumers who are in need of long-term residential care; especially, but not only, in rest homes. The current regulations do not focus on rest home contracts but rather on health and disability services in general. Therefore, they do not consider the special situation and the special vulnerability of aged consumers adequately. To improve the existing regulations, New Zealand should - among other things - create more specific information obligations. The existing duties could be used as a starting point, but it is also necessary to make the adjustments mentioned below. Although often relatives sign the contract for the elderly consumers the information obligations should be directed to elderly consumers. They have often more difficulties to understand and process information. Therefore, only if the tailored information duties are addressed to the weakest consumers, can it be ensured that as many consumers as possible will benefit from the information given.

However, it is somewhat surprising that it is not alien to New Zealand to create special information standards. The RVA and the Retirement Villages Code of Practice 2008 (hereinafter: Code of Practice), ${ }^{306}$ which came into force on the basis of s 89 of the RVA and set out minimum requirements to meet the obligations under the RVA 2003, contain several information obligations that only apply for consumers and providers that intend to conclude a retirement village contract. ${ }^{307}$ Of particular importance is the obligation laid down in s 30 of the RVA, which ensures that consumers receive the most important information before they sign the contract and that the providers have to prove that the consumer has received the information. A similar regulation is desirable for the area of rest home contracts.

\section{a. Obligation to Use Plain and Intelligible Language}

Firstly, it can be recommended that New Zealand should - similar to Australia and Germany - create an obligation for the provider to use plain and intelligible language. As already shown, ${ }^{308}$ this measure has a whole array of advantages, especially, that the

\footnotetext{
305 Similarly Kathryn Hensiak “Abuse in Nursing Homes: Consumers Are Being Left in The Dark” (20022003) 4 Elder’s Advisor 73 at 76.

${ }^{306}$ For details regarding the Retirement Villages Code of Practice 2008 see Michelle Burke and John Greenwood Retirement Villages - the full impact of the Act (New Zealand Law Society, 2007) at 37.

${ }^{307}$ See Retirement Village Act 2003, ss 30, 33; Retirement Villages Code of Practice 2008, pt 3.

${ }^{308}$ See above on page 40 .
} 
presentation format gives consumers a better chance to understand the information presented in the documentation that they receive. ${ }^{309}$ So far the regulations and standards in New Zealand only contain an obligation to pass the information to consumers in age appropriate, spoken and written English. Therefore, providers have to consider the particular deficits of elderly consumers to ensure a high quality of information processing. ${ }^{310}$ Although this measure is to be welcomed, New Zealand should introduce a duty to use plain and intelligible language. Indeed, the Health and Disability Services (Core) Standards 2008 imply that providers have to use plain English to fulfil their duties, but they do not state a firm commitment.

\section{b. Creation of a Legally Standardised Information Sheet}

To ensure that providers do not overstrain elderly consumers and assure that providers can fulfil their duties, New Zealand should implement a standardised information sheet. $^{311}$ The sheet should contain most important information only, because often some pieces of information are more important to consumers than others. The information sheet could list the most important key information; for example the size and features of the accommodation, the food and care services. In addition to this it should outline the cost of the services and accommodation and any additional features that this cost covers. With this information, consumers would get a short, transparent overview of the main content of the contract, without the danger of an information overload. Elderly consumers would always receive the information without any distraction or redundant promotional information. Moreover, the key information should also be designed in an activating and highlighted form. All of these measures would enhance the capacity of consumers to process the information and facilitate the comparison of the different offers for consumers. ${ }^{312}$ Likewise, this measure would ensure that unimportant information can be filtered out and faster and more reliable decisions can be made.

309 See regarding the presentation of information as a factor to improve consumers' understanding of information Rischkowsky and Döring, above n 37, at 306; Ramsay, above n 26, at 41. Critical in terms of plain language in laws Rabeea Assy "Can the Law Speak Directly to its Subjects? The Limitation of Plain Language” (2011) 38 Brit J Law \& Soc 376.

310 In this sense Markus Roth "Die Rechtsgeschäftslehre im demographischen Wandel, Stärkung der Autonomie sowie Schutzkonzepte bei Älteren und Minderjährigen” (2008) 208 AcP 451 at 476 (translation: The Legal Doctrine in Demographic Change, Strengthening of the Autonomy and Protection Concepts for Elders and Minors).

${ }^{311}$ See for Germany Martell, above n 219, at 211 - 222.

312 Solveig Wikström "Bringing Consumer Information Systems Down to Earth, Experiences from a Swedish Experiment” (1984) 7 JcP 13; Ingrid Gottschalk and Iris Schneider “The Intelligibility of Supplier Information” (1983) 6 JcP 161. 
The information sheet should also be branded with a government label, so that it is evident for consumers that the legislator considers this information as particularly important. This would create a foundation of trust, due to most people trusting government information over the sales promotion of providers.

Prima facie, the creation of an information sheet is a severe intervention into the principle of freedom of contract, ${ }^{313}$ but on closer inspection the duty does not progress much further than the existing ones. The information sheet only contains the most important information that is necessary for consumers to be fully informed and, thus, has to be given to consumers due to Right 6 of the Code of Rights and standard 1.9.1 of the Health and Disability Services (Core) Standards 2008 - Consumer Rights. Therefore, the information sheet would only add an obligation regarding the way the information is provided, but would not influence the quantity of information that has to be passed to consumers. Furthermore, a compulsory information sheet has the advantage that the provision of the information is less prone to errors and misunderstanding.

\section{c. Information Sheet about Consumers' Rights}

Similarly to the introduction of a legally standardised information sheet ${ }^{314}$, a further standardised information sheet should be developed that clearly lists the different consumers' rights. The sheet should not only include the Code of Rights, but also state the relevant sections of the CGA, the consumers' termination rights and, most importantly, name the different contact points for elderly consumers when they seek for help and assistance. The pamphlet should be written in simple, easily understandable words. Such an information sheet would improve transparency and access to justice and ensure that consumers have the chance to know about their rights.

However, the question arises whether the pamphlet should be given to the consumer preor post-contractually. On one hand, consumers often do not really make use of precontractual information, because they often have enough to do with the information regarding the contract itself. ${ }^{315}$ As long as no dispute arises there is no need for consumers to read corresponding information. Consumers will therefore more likely use the information at the post-contractual phase, when they need to exercise the rights they

\footnotetext{
313 See Kind, above n 51, at 533.

${ }^{314}$ See above page 56.

315 Similarly Chris Willett "The functions of transparency in regulating contract terms: UK and Australian approaches” (2011) 60 ICLQ 355 at 376; for Germany see Martell, above n 219, at 419.
} 
have. ${ }^{316}$ On the other hand, even if most consumers do not read the information in advance that does not mean that none will. It is very likely that some consumers will understand the information and take advantage of it when a dispute arises. ${ }^{317}$ Furthermore, transparency would be enhanced as early as possible and, therefore, an informed decision making promoted. However, if the consumer is under legal supervision the provider should have the obligation to give the information sheet to the consumer's welfare guardian.

Ultimately, it seems to be most effective to give consumers the information before the contract is signed, but also in case consumers seek for further information. To ensure the latter two different measures seem to be appropriate. Firstly, the Commissioner should try to promote the information sheet and, similarly to the Code of Rights, the information sheet should be accessible in every rest home. It will be shown later that the implementation of this measure should be part of new legislation. ${ }^{318}$ Secondly, the standard 1.9 of the Health and Disability Services (Core) Standards 2008, which puts an obligation on providers to communicate effectively with consumers, should be amended. A new criterion for the standard should be introduced that states that effective communication requires giving consumers the information sheet immediately when a dispute arises.

\section{d. Defining the Way the Information is Provided}

In addition, to the information sheet the legislator should also ensure that the whole effort to provide tailored information for consumers is not counteracted by providers. To do so, it is necessary to establish a further obligation, which aims to restrict the amount of information given to consumers, because providers are often inclined to cover their backs by oversupplying consumers with information. ${ }^{319}$ It is certainly true that consumers should have the right to make an informed choice and be fully informed. ${ }^{320}$ However, "[a]s the amount of relevant information increases, decisions increase in complexity and demand higher levels of cognitive effort." 321 Therefore, both rights are worthless if providers can pass unlimited amount of information to consumers. This is because

\footnotetext{
316 Thomas A Durkin “Credit Card Disclosures, Solicitations, and Privacy Notices: Survey Results of Consumer Knowledge and Behavior” (2006) 92 Fed Res Bull 355.

317 Similarly Willett, above n 315, at 376.

318 See below page 123 .

${ }^{319}$ Howells, above n 36, at 363.

${ }^{320}$ Code of Health and Disability Services Consumers' Rights 1996, right 6 and 7.

${ }^{321}$ Korobkin, above n 233, at 1226.
} 
beyond a certain point, consumers are unable to process the information. Therefore, it should be clarified that providers must waive all redundant details and focus on the necessary information. Additional information should only be provided, if a consumer wishes to receive more information.

Furthermore, New Zealand should add a duty for providers to help consumers to understand the information. Indeed, New Zealand's law contains similar rights for elderly consumers, ${ }^{322}$ but does not clearly state an obligation for providers. Therefore, this right would go further than the existing right to make an informed choice by clearly stating an obligation on the provider. Moreover, the future law should ensure that as much of the information as possible is provided and explained by face-to-face means, because of the physical and cognitive disabilities of many elderly consumers. ${ }^{323}$

Due to the fact that the services provided are credence goods, consumers should also have the right to visit the rest home before signing the contract. Elderly consumers would have the opportunity to ask current residents and their families for their opinion and experiences. $^{324}$

\section{Summary}

New Zealand should shift away from a one-size-fits-all compromise solution, because this solution makes it difficult to consider the interests of a single consumer and to include all different services. It is necessary to focus on the situation of elderly consumers in rest homes and the related services by creating tailored information obligations. Thus, New Zealand can partly orientate itself to the existing duties in Australia and Germany, but also it should partly create new ones. More specifically, standardised information sheets could help to ensure that consumers receive all the information in an appropriate manner, with as little influence by third parties as possible.

However, it would be an erroneous assumption that all consumer detriments could be compensated by information obligations. Information duties are important but alone they cannot provide adequate protection for consumers. Often information is not exercised by

\footnotetext{
$\overline{{ }^{322} \text { See Code of Health and Disability Services Consumers' Rights 1996, right 5(1) and NZS 8134.1:2008 }}$ Health and Disability Services (Core) Standards 2008 - Consumer Rights at 1.10.2.

${ }^{323}$ Barnett and Hayes, above n 14, at 82.

${ }^{324}$ See Hensiak, above n 305, at 77.
} 
consumers despite all major efforts of the government. ${ }^{325}$ This is one reason why a wide range of regulatory options to protect elderly consumers are necessary.

$\overline{325}$ For an example see W Kip Viscusi "Individual Rationality, Hazard Warnings and the Foundations of Tort Law” (1996) 48 Rutgers L Rev 625 at 632; Howells, above n 36, at 356 - 357. 


\section{$V$ The Protection of the Consumer during the Implementation of the Rest Home Contract}

This chapter will focus on issues concerning the implementation of the rest home contract. First of all, the issue of whether the current law adequately ensures that elderly consumers receive a good standard and quality of care will be considered. The legal right to an acceptable quality and consistency of care is of vital importance to rest home residents. As one commentator points out, "[f]or vulnerable elderly residents the extent of their rights to receive a continuing standard or quality of care in a familiar environment is a matter of grave concern. ${ }^{\text {"326 }}$ They are often dependent on the provider, need permanent care and, therefore, they are reliant on a good quality of care. Secondly, this chapter will focus on the different remedies for consumers in case services have not been provided of an appropriate standard. Thirdly and lastly, the issue of whether elderly consumers have a secure place within the rest home will be discussed.

To limit the scope of this dissertation only these three issues are discussed here, although they provide only a small selection of the problems that can occur during the implementation of the contract. However, they give an overview over the major problems that may arise.

\section{A Quality of Services Provided}

As mentioned above, comprehensive consumer protection can only be achieved if regulations exist that ensure a good quality of the services provided. For example, care services are an essential part of the contract and consumers have the legitimate expectation that these services will be carried out to an appropriate standard. Moreover, the question whether the quality of care was acceptable is often a preliminary question regarding the liability of providers.

\section{New Zealand}

In New Zealand, the Code of Rights set out rights and responsibilities for consumers and providers of health and disability services within a clear framework. ${ }^{327}$ However, a

\footnotetext{
${ }^{326}$ Ellie Palmer "Current Developments - Residential care: rights of the elderly and the Contracts (Right of Third Parties) Act 1999” (2000) 22 J Soc Wel \& Fam L 461 at 461.

${ }^{327}$ Ron Paterson “Protecting Patients’ Rights in New Zealand” (2005) 24 Med Law 51 at 51.
} 
breach the Code of Right does not lead to any criminal liability. ${ }^{328}$ An important obligation in the Code is the providers' duty to provide services of an appropriate standard. ${ }^{329}$ This does not only mean that the services have to be provided with reasonable care and skill, but they also have to comply with legal, professional, ethical, other relevant standards and the consumers' needs. ${ }^{330}$ Overall, it can be said that the clause takes a holistic view on the consumers' needs to ensure the best possible outcomes. ${ }^{331}$ However, the rights are not absolute. Providers can avoid liability by proving that they took reasonable actions in the relevant circumstances including the consumer's clinical circumstances and the provider's resource constraints. ${ }^{332}$

In addition, s 28 of the CGA contains a guarantee that services will be carried out with reasonable care and skill. Conversely, this means that providers have to exercise their services with a standard appropriate to its professional status to avoid a liability based on negligent behaviour. Whether this was the case is a decision made by the courts. ${ }^{333}$

Furthermore, on the basis of s 13 of the Health and Disability Services (Safety) Act 2001, the Health and Disability Services Standards 2008 came into effect on 1 June 2009. ${ }^{334}$ These standards are designed to establish safe services of an appropriate standard for consumers and reduce the risk of harm. They are minimum standards and as such, some providers exceed them. The standards have to be reviewed regularly. ${ }^{335}$ They also apply to hospitals and other residential disability care services and, therefore, they are sometimes not tailored to the area of rest homes. Generally, in assessing whether the appropriate standard of care was applied is a question for the court that deals with the

\footnotetext{
${ }^{328}$ Peter Skegg “A Fortunate Experiment? New Zealand's Experience with a Legislated Code of Patients' Rights” (2011) 19 Med L Rev 235 at 240.

${ }^{329}$ Code of Health and Disability Services Consumers' Rights 1996, right 4; see also standard 1.8 of the Health and Disability Services (Core) Standards 2008 - Consumer Rights.

${ }^{330}$ Right 4(1)(2)(3).

331 Tokeley, above n 77, at 158.

332 Code of Health and Disability Services Consumers’ Rights 1996, s 3.

333 Sulco Limited v E S Redit and Company Limited and Another [1959] NZLR 45 (SC) at 88; McLaren Maycroft \& Co Ltd v Fletcher Development Ltd [1973] 2 NZLR 100 (CA) at 107-108.

334 See NZS 8134.0:2008 Health and Disability Services (General) Standard; NZS 8134.1:2008 Health and Disability Services (Core) Standards; NZS 8134.2:2008 Health and Disability Services (Restraint Minimisation and Safe Practice) Standards; NZS 8134.3:2008 Health and Disability Services (Infection Prevention and Control) Standards.

335 Health and Disability Services (Safety) Act 2001, s 24.
} 
single case and not a question for the experts to determine themselves. ${ }^{336}$ The court cannot base its judgment on the general practice of the profession alone, although it can seek expert advice where necessary and appropriate. ${ }^{337}$

The Medicines Care Guides for Residential Aged Care provide rest home providers with further assistance. This non-compulsory guide was developed in a collaborative initiative and aims to provide a quick medicine management reference tool. ${ }^{338}$

\section{Australia}

In Australia, details about the care quality are defined in the Quality of Care Principles 1997 (Cth), especially s 18.6(1) and the items in Schedule 1 of the Principles. The services listed in Schedule 1 have to be provided in a way that meets the accreditation standards set out in Schedule 2. ${ }^{339}$ This ensures that providers have to fulfil the standards not only on, but also after the day of accreditation. ${ }^{340}$ The subjects of the Schedules contain standards for care services and for all other services carried out by rest homes, for example furnishings, meals and daily living activities assistance.

Further provisions are to be found in the Charter of Residents Rights and Responsibilities, which states that every consumer has the right to quality care appropriate to his or her needs. ${ }^{341}$ The term is not very precise, but can be understand as meaning that providers have to fulfil their duties stated in the Quality of Care Principles 1997 (Cth). This follows from ss 54-1(a)(c), 56-1(l) of the Aged Care Act 1997 (Cth) that introduce responsibilities related to the quality of care provided. ${ }^{342}$

Finally, the Australian Consumer Law (hereinafter: the ACL) guarantees that services to consumers will be rendered with due care and skill. ${ }^{343}$ In addition and under certain

${ }^{336}$ Ambros v Accident Compensation Corporation HC Auckland CIV 2004-404-3261, 21 March 2005 at [29].

337 Sulco Limited v E S Redit and Company Limited and Another [1959] NZLR 45 (SC) at 88; Ambros v Accident Compensation Corporation, above n 336, at [29]

338 See Ministry of Health "Medicines Care Guides for Residential Aged Care” (May 2011) Ministry of Health <www.health.govt.nz $>$.

${ }^{339}$ Quality of Care Principles 1997 (Cth), s 18.6(1A).

340 This conclusion already follows from Quality of Care Principles 1997 (Cth), s 18(7). Therefore, s 18.6(1A) of the Quality of Care Principles 1997 (Cth) only has an explanatory function.

${ }^{341}$ User Right Principles 1997 (Cth), ss 23.12, 23.14 and schedule 1.

342 Barnett and Hayes, above n 14, at 51.

${ }^{343}$ Competition and Consumer Act 2010 (Cth), sch 2, s 60. 
circumstances, the services must reasonably fit the consumer's needs, achieve desired result and be supplied in a reasonable time. ${ }^{344}$ These guarantees are mandatory by force of law and cannot be excluded from a contract. ${ }^{345}$ They apply to every consumer contract, written or verbally, in which provision is made for the delivery of services. ${ }^{346}$ Therefore, these duties apply even if no written rest home contract exists.

\section{Germany}

In Germany, para 7(1) of the WBVG states that care and support services have to be provided in accordance with the generally accepted state of professional specified knowledge. Generally accepted is a level of knowledge that reflects the relevant social areas of life, refers to care services in rest homes and leads to outcomes, which could not be seriously questioned. ${ }^{347}$ This, in turn, requires considering medical-nursing, gerontological psychiatric and healthcare knowledge. ${ }^{348}$ However, that does not mean that there is only one possibility of skilled service provision. Often several different approaches are generally accepted.

Overall, it can be said that the norm contains a determination regarding the quality of care. The term is a vague legal concept and subject to dynamic developments. ${ }^{349}$ This is necessary, because it is the only way to consider that care and support standards constantly change. To define the term more precisely some expert standards came into force. The expert standards intend to guarantee the protection and development of the care quality. The standards are the outcome of an expert guided and consensus-oriented discussion process. Their primary aim is the utilisation of theoretical knowledge, so that the knowledge can be used in practice in rest homes. ${ }^{350}$

\footnotetext{
344 Schedule 2, s 61 - 63.

345 Schedule 2, s 64.

${ }^{346}$ Rodney Lewis “An alternative to the resolution of aged care disputes” (31 January 2013) Aged Care Crisis <www.agedcarecrisis.com>.

347 Otto Dahlem, Dieter Giese and Gerhard Igl Heimrecht des Bundes und der Länder (looseleaf ed, Wolters Kluwer) at para 3, note 11 (translation: The Federal and State Law Governing Homes for the Elderly).

348 See Drucksachen des Deutschen Bundestages, above n 160, at [20].

${ }^{349}$ Martell, above n 219, at 282.

350 Gerhard Dalichau Pflegeversicherung, Kommentar und Rechtssammlung (looseleaf ed, Luchterhand) at para 113a, note II. 1. (translation: Nursing Care Insurance, Commentary and Collection of Laws).
} 
Generally, it can be said that a service, which does not comply with the generally accepted state of professional specified knowledge, leads to liability of the provider. The compliance with the standards indicates that there is no liability, while the noncompliance indicates a liability. ${ }^{351}$ However, several other aspects have to be taken into account. Sometimes a standard is no longer relevant, because new developments have overtaken the standard. ${ }^{352}$ Furthermore, providers always have to consider the consumer's fundamental rights, especially the right to self-determination and the human dignity. ${ }^{353}$ Efficiency principles can also lead to a reduction of liability in individual cases. $^{354}$

\section{Lack of Mandatory Staffing Requirements}

New Zealand, Australia and Germany try to ensure a good quality of services provided for consumers. With good reason: care and support services lie at the heart of every rest home contract and elderly consumers are often dependent on these services. However, it is one thing to state obligations but another thing to ensure that the obligations will be implemented. One main factor for the provision of a good quality of care is the staffing of rest homes. ${ }^{355}$ In New Zealand, no mandatory staffing requirements for rest homes exist. $^{356}$ The providers can decide on their own how many staff they will employ. ${ }^{357}$ Indeed, the standard contract between a DHB and a provider defines minimum staffing requirements, ${ }^{358}$ but they are lower than the minimum staffing levels outlined in the New Zealand Standards Handbook “Indicators for Safe Aged-care and Dementia-care for

\footnotetext{
${ }^{351}$ Higher Regional Court Naumburg [2003] 1 U 97/03, 14 September 2004, (2005) 23 MedR 232.

352 Klaus Theuerkauf "Zivilrechtliche Verbindlichkeit von Expertenstandards in der Pflege" (2011) 29 MedR 72 at 75 (translation: Civil Liability of Expert Standards in the Care Sector).

353 Federal Supreme Court (of Germany) [2004] III ZR 399/04, 28 April 2005, (2005) 58 NJW 1937 at [1938]; likewise Higher Regional Court München [2008] 20 U 3322/08, 12 November 2008, (2009) 13 PflR 142 at [143].

${ }^{354}$ At [143]; Theuerkauf, above n 352, at 75.

355 Aged Care Crisis "Staffing issues” (18 December 2012) Aged Care Crisis <www.agedcarecrisis.com>; Wilson, above n 11, at 28.

${ }^{356}$ See New Zealand Nurses Organisation "Submission to the Health Select Committee On the Report from the Controller and Auditor-General on the effectiveness of arrangements to check the standard of services provided by rest homes” (April 2010) New Zealand Parliament <www.parliament.nz $>$ at 7, 8, 10, 17 and 18.

${ }^{357}$ New Zealand Labour, Green Party of Aotearoa and Grey Power New Zealand, above n 109, at 19.

358 See for example Section D 17 of the contract used by the Canterbury District Health Board: http://www.cdhb.govt.nz/planning/documents/Health\%20of\%20Older\%20People/ARRC\%20Base\%20Doc ument\%202012.pdf.
} 
Consumers". ${ }^{359}$ Although the handbook was prepared by a cross-sector committee, no legislative action followed the recommendation. ${ }^{360}$ It remained as a voluntary standard. Therefore, many rest homes face a significant under-staffing in comparison with the minimum staffing requirements of the Handbook. ${ }^{361}$ This holds true both for nurses as well as untrained staff such as care-givers. A glance into Australia's legislation provide no further help. The Aged Care Act 1997 (Cth) only states that providers have the responsibility "to maintain an adequate number of appropriately skilled staff to ensure that the care needs of care recipients are met." ${ }^{362}$ This lack of a minimum staff to resident ratio places vulnerable elderly consumers at risk and can lead to dramatic consequences for the consumers affected. ${ }^{363}$

The situation in Germany differs significantly. Federal state regulations ${ }^{364}$ and contracts between associations of providers and the medical advisory service of the German association of statutory health insurance funds set out detailed staffing requirements for rest homes, to ensure that providers can fulfil their duty to provide an appropriate standard of care. Furthermore, in other areas of law New Zealand has already established staffing requirements. For example, the Education (Early Childhood Services) Regulations 2008 established staffing levels in early childhood centres. ${ }^{365}$ Considering that both groups, young children and elderly consumers in rest homes, are especially vulnerable, there is no valid reason to deny elderly consumers a similar protection. A legally codified staff-to-consumer ratio would ensure that rest homes have enough staff to carry out their services with reasonable care and skill. For this reason, New Zealand should introduce mandatory staffing requirements for rest homes. ${ }^{366}$ The baselines should be set out in a special Act tailored for rest homes, whereas the details could be introduced as a new service standard for providers. ${ }^{367}$

\footnotetext{
${ }^{359}$ Standards New Zealand New Zealand Handbook: Indicators for Safe Aged-care and Dementia-care for Consumers (NZ Standards Council, Wellington, 2005); Wilson, above n 11, at 28.

${ }^{360}$ New Zealand Nurses Organisation, above n 356, at 26.

${ }^{361}$ New Zealand Nurses Organisation “A snapshot of staffing levels in aged care services” (September 2005) New Zealand Nurses Organisation <www.nzno.org.nz> at 4 and 5.

362 Aged Care Act 1997 (Cth), s 54-1(1)(b).

363 See David Schout "Staff cuts faulted in nursing home death” (6 August 2012) The Dandenong Journal $<$ www.dandenongjournal.com.au>; Jeter, above n 17, at 2.

${ }^{364}$ See for example the Bavarian Verordnung zur Ausführung des Pflege- und Wohnqualitätsgesetzes, paras 11 to 17 .

${ }^{365}$ Education (Early Childhood Services) Regulations 2008, s 44 and schs 1 and 2.

${ }^{366}$ For the concrete implementation of these proposals see below page 123.

${ }^{367}$ For details see below page 123.
} 


\section{Summary}

It is somewhat surprising that the existing regulations in New Zealand and Australia place an obligation on providers to perform their services to an appropriate standard and with reasonable care and skill, but do not support mandatory staff levels. As a consequence many rest homes are understaffed. This puts consumers unnecessarily at risk and could be changed by introducing mandatory staffing requirements.

\section{B Consequences of Improper Service Performance}

Even the best statutory regulations cannot ensure that every provider will carry out its services to an appropriate standard or with reasonable care and skill. To ensure comprehensive consumer protection requires, therefore, that consumers can draw consequences in case of a bad service performance. The question of whether consumers can draw legal consequences is certainly linked with the question of whether consumers have adequate access to justice, because to answer the former question requires presenting different remedies to consumers. Although the latter question is answered in a later chapter, ${ }^{368}$ the former question is answered here to link it directly with the illustration of the existing statutory rights of elderly consumers regarding the quality of services provided. However, this chapter only illustrates the existing remedies for consumers, but do not show how consumers can enforce their rights. Therefore, access to justice via complaint schemes, advocacy services and court proceedings are not illustrated here.

\section{Existing Statutory Rules and Regulations in New Zealand, Australia and Germany}

In New Zealand, the CGA contains several remedies against providers of services if the provider fails to comply with the guarantee that services will be carried out with reasonable care and skill. ${ }^{369}$ This also applies for services carried out in rest homes. The different remedies are set out in s 32 of the CGA. Elderly consumers can ask the provider to remedy the failure within a reasonable time if the failure can be remedied. ${ }^{370}$ If the provider refuses or neglects to remedy the failure or does not succeed to remedy the failure within a reasonable time, the aged consumers can have the failure remedied elsewhere and recover all reasonable costs incurred from the provider or they can cancel

\footnotetext{
${ }^{368}$ See below page 90 .

${ }^{369}$ Consumer Guarantees Act 1993, s 28.

${ }^{370}$ Section 32(a)(i).
} 
the contract. ${ }^{371}$ However, consumers can only take advantage of these rights if they have given the provider at first the chance to remedy the failure. ${ }^{372}$ It is likely that these rights will only be rarely used by elderly consumers, because they often do not want leave the provider's rest home and, moreover, rely on good relations with the provider. If a failure is of a substantial character ${ }^{373}$ or cannot be remedied elderly consumers are entitled to cancel the rest home contract in accordance with s 37 of the CGA ${ }^{374}$ or they can obtain compensation for any reduction in value of the service. ${ }^{375}$ The latter entitlement is of particular practical importance for elderly consumers. The poor performance of health and disability services is often a failure of a substantial character, because a reasonable consumer would not have acquired the rest home services if they had known about the failures. ${ }^{376}$ This has the consequence that consumers can claim for compensation for any reduction in value of the service, but can also stay in the providers' rest home. In addition to the remedies set out in s 32(a) and (b) of the CGA, elderly consumers can claim damages for any loss that was reasonably foreseeable. ${ }^{377}$

Under certain circumstances elderly consumers can also cancel the contract under the provisions of the Contractual Remedies Act $1979,{ }^{378}$ which operates alongside with the CGA, ${ }^{379}$ and claim for remedies. ${ }^{380}$

Elderly consumers in Australia have similar rights to their counterparts in New Zealand. Schedule 2 ss 267 to 271 of the Competition and Consumer Act 2010 (Cth) set out several different remedies available not only but also for elderly consumers. ${ }^{381}$ Especially s 267(2) to (4) of the Competition and Consumer Act 2010 (Cth) largely coincides with the statutory rights of s 32 of the CGA and s 268 of the Competition and Consumer Act 2010 (Cth) corresponds with s 36 of the CGA to a great extent. Indeed, the different

\footnotetext{
${ }^{371}$ Section 32(a)(ii).

${ }^{372}$ For the corresponding provision regarding goods see Cooper v Ashley \& Johnson Motors Ltd (1997) 6 NZBLC 102, 108, (1996) 7 TCLR 407, [1997] DCR 170.

${ }^{373}$ For a definition of the term “substantial character” see Consumer Guarantees Act 1993, s 36.

374 The effects of the cancellation are set out in s 38(1) of the Consumer Guarantees Act 1993.

375 Section 32(b)(i) and (ii).

376 See generally Section 36(a).

${ }^{377}$ Section 32(c).

${ }^{378}$ Contractual Remedies Act 1979, s 7.

379 Section 15(ga), see Consumer Guarantees Act 1993, s 4(1).

380 Sections 6, 9, 10.

${ }^{381}$ For details see Corones, above n 66, at 15.130 to 15.185 .
} 
regulations often use different expressions, but the area of application is consistent in major areas.

In Germany, the situation for elderly consumers is significantly different. Elderly consumers are entitled to reduce their fees to a reasonable extent where the provider does not perform or improperly performs its services or the services show a defect that is not only insignificant. ${ }^{382}$ Consumers can exercise this right for the past and the future. On one hand, the elderly consumers can claim a reasonable reduction of the total gross remuneration for the future until the failure is remedied ${ }^{383}$ and, on the other hand, reclaim overpaid fees if they have already paid the fees. ${ }^{384}$ Consumers can assert the claim for up to six month retroactively. The six month deadline is a limitation period with the consequence that consumers cannot assert the claim even if the defect exists over a longer period. ${ }^{385}$ For the future, consumers have a right to withhold the payment (partly) until the defect is remedied. ${ }^{386}$ In terms of the accommodation provided it is necessary that consumers notify the provider in order to reduce their fees. ${ }^{387}$ This is because consumers live in the place of residence and the provider is, therefore, only to a limited extent able to determine a defect. However, consumers can exercise this right independently of further claims for compensation. ${ }^{388}$

\section{Proposals for Improvement}

To improve the legal position of elderly consumers it could be worth looking at the German approach. The different statutes in New Zealand, Australia and Germany allow elderly consumers to obtain compensation if services have not been carried out to an appropriate standard and, therefore, the value of these services was reduced. However, the German law grants further remedies for consumers. Elderly consumers can reduce their fees to a reasonable extent for a poor performance of the services even for the future. Therefore, to introduce a similar right for elderly consumers in New Zealand could enhance their legal position. Elderly consumers could easily enforce their rights

\footnotetext{
${ }^{382}$ Wohn- und Betreuungsvertragsgesetz 2009 (Germany), para 10(1).

383 Federal Supreme Court (of Germany) [2005] VIII ZR 347/04, 20 July 2005, (2005) 58 NJW 2773 at [2774].

${ }^{384}$ See Bürgerliches Gesetzbuch 2002 (Germany), para 812(1).

${ }^{385}$ Weidenkaff, above n 225, para 10 WBVG, at 3.

${ }^{386}$ At 3.

${ }^{387}$ Wohn- und Betreuungsvertragsgesetz 2009 (Germany), para 10(2).

${ }^{388}$ For details regarding compensation claims in Germany see below page 106.
} 
and would have leverage to encourage providers to perform their services properly from the beginning.

However, there are not only advantages. The German regulation harbours considerable potential for conflict if the contract parties have different opinions. In a worst case scenario the enforcement of a fee reduction would lead to silent, bitterness and in the end most likely to a termination of the contract. On the other hand, Australia and New Zealand already allow consumers to claim compensation for reduction in value. To allow consumers to partly withhold their fees if it is foreseeable that the provider will not perform its services to the necessary standard of care would therefore be a logical step to ensure comprehensive consumer protection. Furthermore, there is no good reason why providers should benefit from poor service provision. Providers should be able to understand that they can claim for total payment only if they carry out their own services faultlessly. Moreover, the potential for conflict would not go beyond the existing one. Elderly consumers can already claim for compensation. The new right would simplify their law enforcement.

The proposed new provision could be added to the CGA but be also part of new legislation for the area of rest homes. The details of the implementation are discussed later. $^{389}$

\section{Security of Place within the Rest Home}

A further problematic issue is the consumers' security of place within the rest home. Consumers expect that they can stay in the same room or apartment, which is often their new shelter of life, for the whole time they live in the rest home. Consider, for example, an elderly consumer who signed a contract that gives the provider the right to move the consumer following prior announcement, but without a reason. ${ }^{390}$

New Zealand's rest home related legislation does not contain any legislation that secures consumers a specific place within a rest home. Only when the rest home contract specifies a single room, would consumers be able to stay in this room. However, residents in retirement villages receive protection based on s 27 and schedule 3 s 1(a)(iv) of the Retirement Villages Act 2003 and s 24 of the Code of Practice. The Code of Practice regulates in detail the requirements for a transfer within the retirement village.

\footnotetext{
389 See below page 123.

${ }^{390}$ For further examples see Palmer, above n 326, at 461 - 462.
} 
In Australia, several restrictions on moving consumers within a rest home exist. Section 23.15 of the User Right Principles 1997 (Cth) allows to move consumers only under certain circumstances, for example the move is a consumer's request or the consumer has agreed to move. In Germany, it is nearly impossible to move consumers within a rest home. It is a necessary part of every contract that consumers receive a detailed description of their living space and the exact number of their room. The specific accommodation is, therefore, part of the contract and can only be changed with consumers' consent.

It cannot be stressed enough that it is a valid concern for consumers to stay in the room or apartment they moved into. The new accommodation is their centre of life, which they adapt to their own requirements. Furthermore, elderly consumers are often frail and care dependent and can hardly move into the rest home. For these consumers it would be a significant burden if they have to move to another room without an objective reason. Therefore, New Zealand should ensure that consumers have to move only to another room within the facility if there is a valid reason for such a dramatic change. In doing so, New Zealand should not adopt its own regulation, because the Code of Rights focuses on a different situation. The German regulation is different from New Zealand's approach and is difficult to integrate into the existing system. However, s 23.15 of the User Right Principles 1997 (Cth) contain convincing standards. The Australian legislation found a good balance between the different interests. Consumers can generally stay in their room but have to move for medical reasons, if they agree, request to move or the move is necessary to carry out repairs or improvements.

\section{Summary}

The protection of elderly consumers during the implementation of rest home contracts is only partially guaranteed. Although more than a few measures try to protect consumers several gaps were recognized. To improve the existing consumer protection it is necessary to focus directly on the situation of elderly consumers in rest homes. Mandatory minimum staff levels, an entitlement for consumers to reduce their fees for the future to a reasonable extent in the case of a poor performance of the services and the guarantee of security of place within a rest home would substantially improve the legal position of consumers in rest homes. 


\section{The Protection of Consumers at the Time of the Termination of the Contract}

Moving into a rest home is often a significant event for consumers, which is usually associated with huge burdens to consumers. Comprehensive protection for consumers should therefore aim to make it possible for them to stay in one rest home as long as possible. Consumers have the expectation that they do not have to make a considerable effort to adapt a second time, but can stay in the rest home as long as they want to stay. Nevertheless, it must be possible for consumers to leave the facility when difficulties are encountered or they are dissatisfied with the services or the accommodation. However, the interests of providers have to be taken into consideration as well, because consumer protection cannot be introduced one-sidedly to the detriment of providers. There must always be a consideration of all pros and cons of the consumer protection measures. Against this background, this chapter will examine whether or not New Zealand's government protects elderly consumers against all forms of contract terminations and enables them to live in the chosen rest home as long as choose to live there. The Australian and German models will be used to critically assess the current situation in New Zealand.

\section{A Consumer's and Provider's Right to Give Notice}

It is no surprise that the unexpected termination of a rest home contract is a matter of grave concern for consumers, because they expect it to be a shelter for life. ${ }^{391}$ Therefore, this part will examine whether or not the existing regulations in New Zealand protect consumers adequately, but also considers the interests of both contracting parties at the same time.

\section{Existing Statutory Rules and Regulations in New Zealand, Australia and Germany}

New Zealand's legislation contains several rights of cancellation for consumers, but no specific standards relating the area of rest homes. The Contractual Remedies Act 1979 (hereinafter: CRA) allows the contracting parties to cancel the contract only under certain circumstances, ${ }^{392}$ especially allows the cancellation on the substantiality of the breach. ${ }^{393}$ The CGA contains in ss 32(b), 35 to 39 several provisions relating to cancellation. The provisions are mainly borrowed from the CRA and allow consumers to cancel the

\footnotetext{
${ }^{391}$ Palmer, above n 326, at 461 .

${ }^{392}$ Contractual Remedies Act 1979, s 7.

${ }^{393}$ Bevan, Dugan and Grainer, above n 106, at 2.5.
} 
contract in case the services do not comply with the guarantees of the CGA, ${ }^{394}$ but only if the failure is of substantial character. ${ }^{395}$ However, both pieces of legislation does not contain a comprehensive regulation regarding the period of notice, the reasons for dismissal or the ordinary right to terminate the rest home contract. For this reason, the contracting parties can freely negotiate the conditions under which a cancellation is possible in essential respects. ${ }^{396}$ This is in contrast to the standards set out in the Code of Practice for retirement villages. Consumers in retirement villages are by law entitled to terminate for any reason and at any time. The period of notice can be specified in the occupation right agreement, but is at least a one month's notice in writing. ${ }^{397}$ Providers, on the other hand, are only entitled to terminate the contract under the conditions stated in s 48 of the Code of Practice and have to follow a specific process for exercising their right to terminate. ${ }^{398}$

Elderly consumers in Australia, however, are by law entitled to terminate a rest home contract on a seven days written notice of their intention. According to s 23.85(d) of the User Rights Principles 1997 (Cth) the rest home contract must contain a corresponding provision for the benefit of consumers. To ensure the effectiveness of this cancellation right providers are not allowed to derogate from this provision to the consumers' detriment. ${ }^{399}$ To guarantee the security of tenure the provider is allowed to terminate the contract only under specific conditions. ${ }^{400}$ Section 23.5 of the User Rights Principles 1997 contains an exhaustive list ${ }^{401}$ of six different reasons for dismissal. ${ }^{402}$ The provider can ask the consumer to leave the rest home if the facility is closing, the facility can no longer provide adequate accommodation and care for the long-term assessed needs of the consumer, the consumer does no longer need the services, the consumer has not paid any agreed fee to the provider within 42 days after the due date, the consumer has intentionally caused serious damage or injury to the provider or its staff, or the consumer left the rest home for a continuous period of at least seven days without a permission or an emergency. Furthermore, the provider has to give the consumer a written notice,

\footnotetext{
${ }^{394}$ See for services Consumer Guarantees Act 1993, s 28 and the presentation on page 61.

${ }^{395}$ For details see Bevan, Dugan and Grainer, above n 106, at 4.99 - 4.112.

${ }^{396}$ For an example see http://switzer.co.nz/uploads/file/007\%20Admission\%20Agreement.pdf at 7.

${ }^{397}$ Retirement Villages Code of Practice 2008, s 46(1).

398 Section 49(1).

399 See Aged Care Act 1997 (Cth), s 59-1(3).

400 See Section 56-1 and User Rights Principles 1997 (Cth), s 23.5.

401 Section 23.5(1).

402 Section 23.5(2) and (3).
} 
which has to contain a number of compulsory information, ${ }^{403}$ and at least 14 days before the consumer is to leave. ${ }^{404}$ However, even after this period has expired the provider is not entitled to make the consumer leave the facility, but has to wait until suitable alternative accommodation is available that meets the consumer's needs. ${ }^{405}$

A further right to terminate the rest home contract is stated in sch 2, s 269 of the Competition and Consumer Act 2010 (Cth). Consumers are entitled to terminate contracts for the supply of services, which includes rest home contracts, without a period of notice if the provider fails to meet the guarantees stated in the ACL and the guarantee cannot be remedied or is a major failure. ${ }^{406}$

The German law, lastly, allows consumers to cancel the contract within the first three business days of a calendar month to the end of the same month. ${ }^{407}$ Furthermore, consumers can terminate the contract without any period of notice, if the continuation of the contract is unreasonable for them. ${ }^{408}$ The question of whether or not a continuation is unreasonable is assessed solely on the basis of the consumer's interests. ${ }^{409}$ Consumers are also entitled to terminate the contract, if the provider wants to increase the remuneration. In this case, consumers can declare the termination for the point in time when the markup becomes effective. ${ }^{410}$

The provider, however, can terminate the contract only for an important reason. Paragraph 12(1) of the WBVG describes in a non-exhaustive list ("An important reason shall particularly exist if ...”), four important reasons, which allow the provider to terminate the contract under certain circumstances. ${ }^{411}$ Further reasons can justify a termination as an important reason only if the seriousness of misconduct is consistent with the reasons stated in the law. ${ }^{412}$ Similarly to the Australian law, the provider must give the consumer a written notice and has to name the reasons for the termination. An

\footnotetext{
${ }^{403}$ See for details Section 23.6(1).

404 Section 23.6(2).

405 Section 23.6(3).

${ }^{406}$ Competition and Consumer Act 2010 (Cth), sch 2, ss 267(3), 269(2).

407 See Wohn- und Betreuungsvertragsgesetz 2009 (Germany), para 11(1)(1).

${ }^{408}$ Paragraph 11(3).

${ }^{409}$ Weidenkaff, above n 225, para 11 WBVG, at 3.

${ }^{410}$ Wohn- und Betreuungsvertragsgesetz 2009 (Germany), para 11(1)(2).

${ }^{411}$ Paragraph 12(1) to (4).

${ }^{412}$ Martell, above n 219, at $364-365$.
} 
ordinary termination, however, is not possible for the provider and also, due to para 16 of the WBVG, cannot be agreed to on an individual basis. ${ }^{413}$

\section{A Strict Regulation of Cancellation Options - A Future Way for New Zealand?}

It has been shown above ${ }^{414}$ and in the previous chapters ${ }^{415}$ that there some good reasons to protect aged consumers in general and also against all forms of arbitrary and ordinary cancellation of a rest home contract, but allow them to cancel the contract short-term.

Generally easier to justify is a termination right in cases in which the provider does not perform the services of an appropriate standard. This would be tantamount to a breach of right 4 of the Code of Rights, but also a breach of s 28 of the CGA. There is no doubt that consumers must be able to cancel the contract if the provider breaks a term of the contract. New Zealand's legislature shared this opinion. Therefore, consumers can cancel the contract if there is a failure of substantial character. ${ }^{416}$ This corresponds with the ACL and existing German legislation and ensures that consumers are not bound to a contract that is not respected by the provider.

A consumer's right to cancel the contract within a short period of time, even if there is no breach of the contract or the guarantees of the CGA, can be justified in the particular relationship of trust between the contracting parties. The provider is often responsible for most of the consumer's needs, ${ }^{417}$ even for those related to the private sphere of the consumer. ${ }^{418}$ Therefore, it is difficult to justify a consumer's having to stay in the provider's facility, when they no longer want to receive the care services of the provider. For this reason, it would be a significant burden and unreasonable for consumers to stick to the contract for a long time.

It should also be considered that in nearly all cases consumers do not move to another rest home in order to pay less. Most of the elderly consumers receive a Residential Care Subsidy with the consequence that consumers and providers cannot freely negotiate the remuneration for the services, but are determined in the Age Related Residential Care

\footnotetext{
$\overline{413}$ Martell, above n 219, at $412-414$.

${ }^{414}$ See above page 72 .

${ }^{415}$ See above page 12.

${ }^{416}$ Consumer Guarantees Act 1993, s 36; Contractual Remedies Act 1979, s 7(3)(b).

${ }^{417}$ This point was made by New Zealand Labour, Green Party of Aotearoa and Grey Power New Zealand, above $n 109$, at 6 .

${ }^{418}$ See Weber, above n 116, at 338.
} 
Services Agreement. ${ }^{419}$ Consumers will, therefore, only move to another rest home if they have serious problems with or lost all confidence in the provider or its staff. This is supported by the facts that most consumers in rest homes are 85 years and over, ${ }^{420}$ often unable to leave their room without help and, moreover, consider the quality of the care services and not the price as the most important factor. ${ }^{421}$ Therefore, elderly consumers will consider carefully if they really want to leave the facility.

However, it must also be considered that the shorter the period of notice the more likely providers will suffer economic harm, because it will become more difficult for them to rent out the place of residence immediately following the termination. Nevertheless, the advantages for consumers outweigh the costs for providers. The whole contractual relationship is based on trust and confidence. ${ }^{422}$ If this contractual basis no longer exists, it is not justified under any circumstances to keep consumers to the contract. The provider's economic interests can be taken into account when thinking of the length of the termination period.

These reasons can also be used to restrict the provider's cancellation right. Without some limitations it cannot be ensured that elderly consumers can live in the provider's facility permanently and satisfy their strong need for security. ${ }^{423}$ On the other hand, it must be possible for providers to withdraw from the contract in cases where they have a serious reason for the termination of the contract.

Even without rigid regulations rest home contracts in New Zealand often contain detailed provisions under which the agreement may be terminated. ${ }^{424}$ However, without legal provisions the only protection for consumers is their confidence in the fairness and propriety of the provider. This confidence in voluntary concessions is not sufficient to protect consumers entirely. For this reason and to ensure that New Zealand's legislation meets the requirements of the aforementioned recommendations New Zealand should

\footnotetext{
${ }^{419}$ See National Contract for Age-related Residential Care, pt 2 s C 2.1.

${ }^{420}$ See for Australia Barnett and Hayes, above n 14, at 52.

${ }^{421}$ See Leventhal, above $n$ 102, at 54.

${ }^{422}$ For example trust and confidence are also inherent in an employment relationship; see Curtis $v$ RS Construction Ltd [2013] NZERA Auckland 139 at [21]; Campuzano v Western Bay Dental Care Ltd [2011] NZERA Auckland 198 at [22]; Morrow v Safeway Stores Plc [2001] WL 1135069 (Employment Appeal Tribunal) at 1 "It raises an interesting point relating to the implied term of trust and confidence, which exists in all contracts of employment.”

${ }^{423}$ For the German WBVG see Drucksachen des Deutschen Bundestages, above n 160, at [24].

${ }^{424}$ See for an example http://switzer.co.nz/uploads/file/007\%20Admission\%20Agreement.pdf.
} 
consider Australia's and Germany's regulations. Both countries' legislation has balanced the conflicting interests against each other and given preference to comprehensive consumer protection. On the one hand, consumers' legitimate expectations are met. On the other hand, Australia and Germany have also considered the economic interests of the providers, whereby Australia grants further termination rights to providers. This is why Australia's regulations appear more convincing. In Germany, providers generally have an obligation to adapt the contract if the consumers' needs change. Providers are able to exclude this obligation completely or partially only in a separate agreement at the moment the contract is concluded, ${ }^{425}$ whereas a suspension at a later date is not possible. ${ }^{426}$ The exclusion is only effective where the provider has a legitimate interest to exclude a contract adjustment in accordance with its service concept. ${ }^{427}$

In Australia, on the other hand, providers have more freedom. They have to adapt the rest home contract only, if they have agreed to provide care for the changing needs of the consumer. ${ }^{428}$ Therefore, providers in Australia do not need to exclude any of their services from the contract. The other reasons under Australian law for cancelling the contract, for example when consumers no longer need the care provided, do not pay their fees on time or the facility is closing, also guarantee sufficient economic margin for providers. Furthermore, the regulations give consumers under some circumstances a second chance, if they change their behaviour that led to the cancellation of the contract. $^{429}$ Overall, Australia focuses more on the providers' interests, but also meets the consumers' interests.

The Australian law is equally convincing in view of the cancellation period, because it ensures that consumers have a minimum of 14 days before they have to leave the facility, but can stay longer if no suitable alternative accommodation is available. ${ }^{430}$ Alternatively, consumers are able to terminate the contract on short notice. This ensures that elderly consumers do not have to continue receiving services, if they have lost trust and confidence in the provider's services. While it is true that providers can suffer economic

\footnotetext{
$\overline{425}$ Wohn- und Betreuungsvertragsgesetz 2009 (Germany), para 8(4)(1); Wolfgang Gitter, Jochem Schmitt and Irmgard Küfner-Schmitt (ed) WBVG - Heimrecht des Bundes und der Länder (looseleaf ed, Luchterhand) at para 8, note VI. 1. (translation: WBVG - The Federal and State Law Governing Homes for the Elderly).

${ }^{426}$ Weber, above n 116, at 341; Gitter, Schmitt and Küfner-Schmitt, above n 425, at para 8, note VI. 1.

${ }^{427}$ Wohn- und Betreuungsvertragsgesetz 2009 (Germany), para 8, sub-para 4(2).

${ }^{428}$ User Rights Principles 1997 (Cth), s 23.5(2)(b).

${ }^{429}$ Section 23.6(5).

${ }^{430}$ Section 23.6(2) and (3)
} 
harm because of this short cancellation period, they can include these costs in their general calculation. Lastly, New Zealand should also assume the formal requirements set out in s 23.6 of the User Rights Principles 1997. These requirements ensure that consumers receive a written notice showing the decision, the reasons for it, the time when consumers have to leave and their rights, so that they can fight the notice if they want to.

In conclusion, New Zealand should take the same path as Australia to ensure comprehensive protection for elderly consumers. To limit the providers' cancellation right is not a new approach to New Zealand. For example, the Code of Practice contains several regulations which influence the right to give notice of contract parties. Therefore, New Zealand can use some of the existing standards of the Code of Practice. ${ }^{431}$ While it is not convincing that the contract parties can negotiate the period of notice, ${ }^{432}$ the process for exercising the right to terminate the contract ${ }^{433}$ sets out strict rules for providers, including appropriate periods of notice, a dispute resolution process and, therefore, protects consumers' interests.

\section{B Providers' Obligations after the Termination of the Contract}

A further measure to protect elderly consumers is the creation of obligations for providers to assist consumers in cases of the contract termination.

\section{Existing Statutory Rules and Regulations in New Zealand, Australia and Germany}

In New Zealand, the law does not contain detailed obligations for the providers after the rest home contract has been cancelled. Only standard 3.10 of the NZS 8134.1.3:2008 Health and Disability Services (Core) Standards 2008 - Continuum of service delivery state that the service provider has to facilitate a planned and coordinated transition or exit from the provided services and, in addition, has to identify, document and minimise risks associated with each consumer's transition and exit. This general standard is explained more precisely in the guidance to the standard. The guidance for providers explains that the plan should at least ensure that the "discharge does not occur until arrangements for on-going follow-up are established" 434 and contact with the next service has been

\footnotetext{
${ }_{431}$ Retirement Villages Code of Practice 2008, s 46 to 54.

${ }^{432}$ Section 46(1).

${ }^{433}$ Section 49.

${ }^{434}$ NZS 8134.1.3:2008 Health and Disability Services (Core) Standards 2008 - Continuum of service delivery at $\mathrm{G}$ 3.10.2(a).
} 
established. ${ }^{435}$ However, the word "choice" suggests that the standard 3.10 gives providers a responsibility, but not a right for consumers. For this purpose, providers can still terminate to the consumers' detriment. Indeed, providers might be liable for damages under certain circumstances, ${ }^{436}$ but that does not ensure that consumers can stay in the rest home even if no other provider is available.

At the first glance, Australia's regulations do not clearly state obligations for providers after the cancellation of the contract. ${ }^{437}$ Only s 23.6(3) of the User Rights Principles 1997 (Cth) provides an indication that providers have further care responsibilities. The norm states that providers are able to take action to make consumers leave only if a suitable and affordable accommodation is available that meets the consumers' long-term needs. The choice of words leaves open whether this is an obligation for providers or only a measure to protect consumers ending up without any accommodation. However, a better description is find in the Residential Care Manual 2009 (Cth), ${ }^{438}$ which aims to help approved providers comply with their responsibilities under the Aged Care Act 1997 (Cth) and the User Rights Principles 1997 (Cth). The manual states that the provider should discuss with consumers, if they wish to find alternative accommodation on their own, but that "ultimately it is the approved provider's responsibility to ensure that accommodation is available for the resident, before the resident can be required to leave." 439 Therefore, the provider has to find suitable alternative accommodation, if consumers do not want to search on their own. The accommodation offered need not be the one the consumers prefer, but must be available and able to provide the required care. Furthermore, the new accommodation must be affordable for consumers. ${ }^{440}$

In Germany, the provider has to meet several duties after cancellation, as a result of the continuing duty of care. ${ }^{441}$ Clause 13 of the WBVG describes in detail various duties,

\footnotetext{
${ }_{435}$ At G 3.10.2(b).

${ }^{436}$ Consumers may be entitled to Accident Compensation Corporation (ACC) compensation, if they have suffered a personal injury. In limited cases damages are awarded to the consumer by the Human Rights Review Tribunal (HRRT), when the consumer's human rights have been violated. F

${ }^{437}$ Aged Care Act 1997 (Cth), s 56-1(e), for example, only states that the provider has to provide the security of tenure for the consumer.

${ }^{438}$ Residential Care Manual 2009 (Cth), at 176 - 178.

${ }^{439}$ At177.

${ }^{440}$ At 177. A hospital, for example, is not considered to be suitable alternate accommodation.

${ }^{441}$ Martell, above n 219, at 379; Edna Rasch Kommentar zum Wohn- und Betreuungsvertragsgesetz (Lambertus, Berlin, 2012), para 13, at 1 (translation: Commentary on the German Residential Care Contract Law).
} 
under which the obligations and responsibilities depend on the reason for cancellation. By request the provider has to provide consumers with an appropriate replacement for the services received and, in addition, has to pay for consumers' moving expenses if the provider is responsible for contract termination. ${ }^{442}$ The term "reasonable conditions" is not defined by law, but should be understood in a sense that the replacement corresponds with the previous standard and the consumers' needs. ${ }^{443}$ This means the new accommodation should be close to the previous one, so that consumers can maintain their social contacts. ${ }^{444}$ Consumers can demand the appropriate replacement, even if they have not yet cancelled the contract, but aim to do so. This is intended to guarantee that consumers do not end up without an adequate replacement of the services. ${ }^{445}$ Nevertheless, there is no obligation for consumers to make their claim; they can always waive it and search for new accommodation on their own. Although the German WBVG does not contain a fixed time for the duty to provide a replacement, the intent and purpose of the law requires that the proof is given in a timely manner, so that consumers can accept the offer and make the necessary preparations before the end of the notice period. ${ }^{446}$ To fulfil this duty, providers do not have to conclude a new contract on behalf of the consumer, but the new provider must be willing to conclude a similar contract with the consumer. ${ }^{447}$

These duties also apply if providers terminate the contract because they cease operating; significantly limiting their services or because a continuation of the contract would be an unreasonable hardship for them. ${ }^{448}$ In these cases providers are not necessarily responsible for the termination or the termination is not based on the fault of the providers. However, the duties are nevertheless justified, because the termination arises from the providers' sphere of action. ${ }^{449}$

\footnotetext{
$\overline{442}$ Wohn- und Betreuungsvertragsgesetz 2009 (Germany), para 13(1).

${ }^{443}$ Gitter, Schmitt and Küfner-Schmitt, above n 425, para 13, at note III. 1. a); Rasch, above n 441, para 13, at 7 .

${ }^{444}$ Weidenkaff, above n 225, para 13 WBVG, at 2.

${ }^{445}$ Drucksachen des Deutschen Bundestages, above n 160, at [28 - 29].

${ }^{446}$ See Martell, above n 219, at 380; similarly Weidenkaff, above n 225, para 13 WBVG, at 2.

${ }^{447}$ At 2.

${ }^{448}$ Wohn- und Betreuungsvertragsgesetz 2009 (Germany), para 13(2).

${ }^{449}$ Martell, above n 219, at 379.
} 
Even without the proof of an appropriate replacement the termination of the contract is effective, but the providers cannot enforce their eviction claim ${ }^{450}$ and, in addition, would make themselves liable for damages. This also applies if providers cease operating or have become insolvent.

\section{Evaluation and Criticism - Does New Zealand Need Further Obligations on Providers?}

The previous discussion has shown that New Zealand's providers, only to a limited extent, have obligations after the contract is terminated. This is no surprise considering New Zealand already granted more freedom to the contracting parties in regard to contract termination. However, that does not mean that the continuation of this tradition is appropriate.

The obligation to ensure that new accommodation is available is appropriate and necessary if one considers that elderly consumers due to their age and frailty are often unable to find an appropriate alternative accommodation on their own. Providers, on the contrary, often have a better overview of market conditions and local competitors. For this reason, it is often easier for providers to find appropriate replacement accommodation. ${ }^{451}$ This ensures a seamless transition of the services from one provider to the next.

It is true that in other areas of the law (for example the law of tenancy) consumers have to find substitute services on their own. Usually, providers have no further obligations after the termination of the contract. This, however, disregards the fact that the rest home contract of the parties is characterised by a special relationship of trust and proximity ${ }^{452}$ and that consumers are fundamentally dependent on a continuation of the services without interruption. Therefore, the situations are not directly comparable; elderly consumers have a special need for protection, which justifies intervention in their favour.

For the above reasons, New Zealand should introduce a stricter obligation on providers to help consumers to find new accommodation. The new regulation should ensure that

\footnotetext{
${ }^{450}$ See Federal Supreme Court (of Germany) [2004] III ZR 205/03, 28 October 2004, (2005) 58 NJW 147 at 149 .

${ }^{451}$ For Germany see Drucksachen des Deutschen Bundestages, above n 160, at [28].

452 See Leventhal, above n 102, at 54, 55.
} 
consumers have an enforceable right to receive an offer and that providers can make consumers leave only if they have fulfilled this obligation.

Another question is whether the providers' duty should, in accordance with the German legislation, be limited to cases in which they are responsible for the termination of the contract. This should be rejected. Due to their dependency and frailty, consumers are often unable to find another suitable service provider, no matter whether they are responsible for the termination. Furthermore, there should, in contrast to the German law, be no obligation to pay for consumers' moving expenses. In Germany this duty must be read in conjunction with the official justification of the law ${ }^{453}$ and the other duties stated in the WBVG. Both aim to ensure that consumers can stay in the rest home without exception. It is therefore only subsequently that providers have to pay the moving expenses if they caused the cancellation. However, in New Zealand and Australia the law does not contain such far-reaching obligations. The providers' economic freedom is not limited to the same extent. In New Zealand such a broad obligation would, therefore, go beyond the scope of a consistent piece of legislation.

Overall, it can be said that New Zealand should introduce a regulation similar to the Australian one. The duty to provide suitable, available and affordable accommodation ensures that the providers' economic freedom remains guaranteed. They are able to cancel the contract, but it is also ensured that consumers do not have to leave the rest home until a new service provider is available.

\section{Granting of a Cooling-off Period}

Another widespread tool to protect consumers and their independence and autonomy is a cooling-off period. ${ }^{454}$ “A cooling-off period is a specified period of time, within which the consumer has the right to withdraw from a concluded contract," 455 without giving any reason. In the last decade, these withdrawal rights have mushroomed around the world. ${ }^{456}$ These rights could be used to give elderly consumers the chance to rethink their decision and would allow them to move to another rest home if they are not satisfied with the services offered.

\footnotetext{
$\overline{453}$ Drucksachen des Deutschen Bundestages, above n 160.

${ }^{454}$ For New Zealand see regarding the Door to Door Sales Act 1967 Tokeley, above n 77, at 248; Bevan, Dugan and Grainer, above n 106, at 5.24; for Europe see Haupt, above n 25, at 1147.

${ }^{455}$ Rekaiti and Van den Bergh, above n 70, at 371.

456 Jan M Smits "Rethinking the Usefulness of Mandatory Rights of Withdrawal in Consumer Contract Law: The Right to Change Your Mind?” (2010-2011) 29 Penn St Intl L Rev 671 at 672.
} 


\section{Existing Statutory Rules and Regulations}

New Zealand does not provide a cooling-off period for consumers after signing the rest home contract. Neither the Code of Rights nor the Health and Disability Services (Core) Standards 2008 - Consumer Rights includes a right for consumers to terminate the contract within a certain time after the conclusion of the contract. Under the Age Related Residential Care Services Agreement and the Admission Agreement, an individual contract between the provider and the consumer, based on the mandatory provisions of the Age Related Residential Care Services Agreement, does not grant the consumer a cooling-off period. However, s 28(1)(a) of the RVA gives residents of a retirement village the right to cancel the agreement without having to give any reason within 15 working days after the agreement was signed.

In contrast to New Zealand's legislation, Australia grants their elderly consumers a cooling-off period after signing a rest home contract. The User Rights Principles 1997 (Cth), which lay down the essential content of a resident's agreement, determine in $\mathrm{s}$ 23.85(b)(i) that the agreement becomes void if consumers or their representatives tell the provider, in writing, within 14 days after signing, that they wish to withdraw from the agreement. In this case, consumers are liable for the fees and charges the services that have already been carried out, ${ }^{457}$ while "the provider is liable to refund any other amount paid by the care recipient under the agreement." can revoke their declaration of will within 14 days in Australia. In some federal states regulations exist that govern the contents of the contract more precisely. ${ }^{459}$ However, these regulations contain no cooling-off period.

In Germany, para 11(2) of the WBVG grants consumers de facto the right to try out the providers' rest home for two weeks. Within this period consumers can terminate the contract without a notice or giving a reason. With this regulation the German government intends to ensure that consumers can review without any risk, if the facility corresponds their expectations. ${ }^{460}$ The two weeks deadline does not start at the moment of signing the contract, but only when the provider has released the living space to the consumer. This is because consumers make use of the providers' services only after they move into the rest home. ${ }^{461}$ Furthermore, in contrast to para $11(2)$ of the WBVG, the deadline is extended if

\footnotetext{
${ }^{457}$ User Rights Principles 1997 (Cth), s 23.85(b)(ii).

458 Section 23.85(b)(iii).

459 See for example Residential Services (Accommodation) Act 2002 (Qld), ss 11-17, 83-86.

${ }^{460}$ Drucksachen des Deutschen Bundestages, above n 160, at [25].

${ }^{461}$ Weidenkaff, above n 225, para 11 WBVG, at 3.
} 
the provider does not hand over a copy of the contract terms to the consumer before the consumer settles into the rest home. In this case, the period begins with the handing over of a copy of the contract. This deadline extension is appropriate because the contract terms are the most likely chance for consumers to become aware of their right to test the rest home. Without this knowledge, however, consumers can merely judge if they like the facility but will not consider a termination. This, however, would counter the ratio legis. $^{462}$

\section{Justification of Cooling-off Periods as a Measure to Protect the Consumer}

Cooling-off periods are often used as a tool to protect consumers, not only but especially in the European Community. ${ }^{463}$ They serve several different purposes.

First, a "regret contingency" 464 tackles some insights of the research in consumer behaviour, ${ }^{465}$ especially the fact that consumers tend to behave irrationally when they are emotionally involved or have to decide on the spot. ${ }^{466}$ A cooling-off period would allow consumers to reframe their decision without being in an emotionally "hot" state. ${ }^{467}$ It would give consumers the opportunity to reconsider when they can act more rationally and without pressure or the influence of the provider or another third party. ${ }^{468}$ This permits consumers to overcome the influence of the impulsive and often irrational choice. ${ }^{469}$ Consumers may not be content with their choices and can then make a correct judgement based on their long-term preferences. ${ }^{470}$ This justification is particularly relevant in situations where consumers are especially vulnerable because they are taken by surprise and not aware about their rights. They often do not have stable preferences and show less bargaining power. ${ }^{471}$ This is, for example, the case in door to door sales ${ }^{472}$

\footnotetext{
462 Martell, above n 219, at 353.

${ }^{463}$ Haupt, above n 25, at 1147; see for the regulation in the United States of America Smits, above n 456, at 671.

464 This term was first used by Charles J Goetz and Robert E Scott "Enforcing Promises: An Examination of the Basis of Contract” (1980) 89 Yale L J 1261 at 1271.

465 On this subject see above page 43; see also Joseph P Mulholland "Behavioral Economics and the Federal Trade Commission” (12 December 2007) Social Science Research Network <www.ssrn.com> at 17.

${ }^{466}$ Rekaiti and Van den Bergh, above n 70, at 377.

${ }^{467}$ Rischkowsky and Döring, above $\mathrm{n} 37$, at 307.

468 Mulholland, above n 465, at 17; Rischkowsky and Döring, above n 37, at 307.

469 At 17; Haupt, above n 25, at 1147.

470 Similarly Rekaiti and Van den Bergh, above n 70, at 377.

${ }^{471}$ Tokeley, above n 77, at 376.
} 
and lay by sales; ${ }^{473}$ in other words: when aggressive sales techniques are used to force the consumers to enter into the contract. ${ }^{474}$

However, the situation when consumers enter into a rest home contract is not to the same extent characterised by psychological superiority, ${ }^{475}$ emotionally "hot" states or other pressures of the provider. Often emotions are involved and sometimes, due to a pressure of time, ${ }^{476}$ the contract is signed immediately after the first contact. However, in most cases consumers or their relatives have enough time to reconsider their decision.

Another justification for cooling-off periods is - once more - the inequality of effective information. ${ }^{477}$ Although this justification also aims at high pressure situations, it goes even further. Information asymmetries not only occur in particular circumstances, but are also connected with credence goods where the effects or the quality of the goods and services can only be assessed after consumers have experienced them on their own. ${ }^{478}$ In the case of the rest home contracts examined here consumers have no opportunity to check the goods and especially services in advance and might, therefore, realise later for the first time that the quality of the services is lower than expected. ${ }^{479}$ In addition, a cooling-off period could act as a "sword of Damocles", which would give providers the incentive to ensure a high service standard from the beginning.

On the other hand, some authors ${ }^{480}$ claim that the introduction of cooling-off periods has drawbacks. These authors state that consumers could be tempted to abuse their right. In the worst case, consumers could use their right again and again to receive a product or

\footnotetext{
472 In New Zealand door to door sales are governed in the Door to Door Sales Act 1967; see regarding the cooling-off period in New Zealand Tokeley, above $n$ 77, at 248; see for history about cooling-off periods and door to door sales Rodolpho Sandoval “A Critical Analysis of the Cooling-off Period for Door to Door Sales” (1976) 3 Chicano L Rev 110 at 112 - 114; for the pros and cons of a cooling-off period in door to door sales see Byron D Sher “The "Cooling-off" Period in Door-to-door Sales” (1967-1968) 15 UCLA L Rev 717 at 721.

${ }^{473}$ Layby sales are regulated in the Layby Sales Act 1971.

474 See Smits, above n 456, at 676.

${ }^{475}$ For details see Scott and Black, above 22, at 428.

${ }^{476}$ For an example see above page 47.

${ }^{477}$ O’Shea and Rickett, above n 32, at 146; see above page 14.

${ }^{478}$ See Rekaiti and Van den Bergh, above n 70, at 379; Haupt, above n 25, at 1148.

${ }^{479}$ Similarly but more generally at 380 .

${ }^{480}$ For the disadvantages see at 381 - 384; Haupt, above n 25, at 1148 - 1149; see also Scott and Black, above n 22, at 434 .
} 
service without paying for it. ${ }^{481}$ Other authors argue that the granting of a cooling-off period would lead to temporary delay and uncertainty regarding the validity of the contract. ${ }^{482}$ The principle that "agreements must be kept" ${ }^{483}$ is limited until the expiration of the cooling-off period. In terms of a cost-benefit analysis it can be argued that the provision of a cooling-off period and the uncertainty that goes with this would be costly for providers and that they would pass on these costs to consumers. ${ }^{484}$ Therefore, the introduction of a cooling-off period is often linked with substantial costs, which may outweigh the benefits for consumers. For this reason, Rekaiti and Van den Bergh ${ }^{485}$ conclude "mandatory disclosure of information could in this respect be a better instrument; while it also preserves and enhances consumer choice, it does not entail costs like the ones just mentioned.”

In addition, it is questionable to what extent consumers make use of a cooling-off period. Assuming that consumers become aware of the bad service quality of the provider within the cooling-off period, they, nevertheless, sometimes do not use the chance to withdraw their consent, because they do not want to admit that they made a mistake while entering into the contract. ${ }^{486}$ Lastly, it should be noted that generally there is a gap in knowledge about how consumers respond to cooling-off periods, because little research has been carried out. ${ }^{487}$ However, it has been stated that residents in retirement villages in New Zealand like the cooling-off period, because it gives them the chance to get additional advice and ensures that the resident is not being pressured into a hasty decision by the provider or relatives. ${ }^{488}$

This criticism cannot totally be dismissed, but is mainly irrelevant in relation to rest homes. Elderly consumers are often frail and reliant on health care services. It is hard to imagine that they would use a cooling-off period to receive unfair advantages. Often they are unable to move from one rest home to the next. So, it is unlikely that elderly consumers will exert the considerable amount of effort of moving into a rest home more than once. Therefore, they would make use of their regret contingency only if they are truly dissatisfied with the health care services, the facility or their accommodation.

\footnotetext{
${ }^{481}$ Rekaiti and Van den Bergh, above n 70, at 382.

${ }^{482}$ See Sher, above n 472, at 732.

483 English translation of the Latin principle pacta sunt servanda.

${ }^{484}$ Rekaiti and Van den Bergh, above n 70, at 383.

485 At 383.

${ }^{486}$ See Haupt, above n 25, at 1149.

${ }^{487}$ Mulholland, above n 465, at 17; Smits, above n 456, at 672 .

${ }^{488}$ See Retirement Commissioner, above n 74, at 3.3.
} 
Furthermore, information duties would not guarantee the same level of protection, because they are of little help in case of credence goods. ${ }^{489}$ This is because even mandatory information cannot replace the necessary personal experience of the goods and services. Often there is a major difference between the information consumers have received and the goods and services they have experienced in reality.

Some might argue that the cancellation rates are relatively low and that, therefore, there is no obvious need for cooling-off periods. ${ }^{490}$ However, the relatively small number of cancellations does not necessarily mean that consumers do not need or appreciate a cooling-off period. There may also be a lack of knowledge regarding the "regret contingency". The results of the investigations carried out so far state that only a few consumers make use of a cooling-off period, but do not explain the reasons why.

Overall, a cooling-off period could be an important tile in the mosaic of the protection of elderly consumers in rest homes. It would allow consumers to test provider's services without being bound to a long-term contract from the outset.

\section{Structuring a Cooling-off Period in New Zealand}

An optimal cooling-off period should be long enough for consumers to experience most of the services offered, but not too long, because a long period of uncertainty leads to higher transaction costs that may exceed the benefits of an asymmetric distribution of information. In Germany and Australia a deadline of two weeks had been tried and tested. The RVA contains a period of 15 working days. ${ }^{491}$ Both options are appropriate to judge providers' facilities and services without any pressure of time and, moreover, leave enough time for consumers to carefully judge their decision. In order to assure equal treatment between consumers in rest homes and retirement villages the cancellation period should be 15 working days. Moreover, the further details of s 28 of the RVA should also be used to improve the legal position of elderly consumers in rest homes. The adoption of s 28 would have the effect that consumers in rest homes could cancel the contract without a reason, in writing and in a form that indicates the intention to cancel the contract. $^{492}$ Providers, on the other hand, would be entitled to reasonable

\footnotetext{
$\overline{489}$ To this issue see already above page 49.

${ }^{490}$ See Mulholland, above n 465, at 18.

491 Retirement Village Act 2003, s 28(1)(a); for details see also John Greenwood and Simon Marks Retirement Villages (New Zealand Law Society, 2004) at 24.

${ }^{492}$ Retirement Village Act 2003, s 28(1)(a) and (2)(a).
} 
compensation for services provided, ${ }^{493}$ but could not derogate from this regulation in a manner which is detrimental to consumers. ${ }^{494}$ However, one important difference needs to be made. Elderly consumers in rest homes are often frail and have difficulties writing a notice. For this reason, elderly consumers should, in accordance with the German legislation, be able to exercise their right orally. This measure would further reduce the psychological hurdle in exercising the regret contingency and would allow elderly consumers to withdraw from the contract easily before they settle down and get accustomed to the facility completely.

To ensure the effectiveness of the cooling-off period several other measures should be introduced. The provision is rendered useless if the existence of the cooling-off period is buried in voluminous documents, ${ }^{495}$ so that consumers are hardly able to know fully about their right. Therefore, an obligation for the provider to highlight the regret contingency in the rest home contract should be introduced by legislation. ${ }^{496}$ To guarantee the best possible level of consumer protection it is also worthwhile to introduce a commitment that the provider has to inform the consumer about the right not only in a highlighted form but also on a separate sheet, which the consumer has to sign as the same time as signing the contract. ${ }^{497}$ This would ensure that consumers have all necessary information about their right. Otherwise providers could undermine the measure simply by not giving adequate responses to consumers' information requests within the coolingoff period. ${ }^{498}$ These measures would go further than the existing rights in the Code of Rights and the Health and Disability Services (Core) Standards 2008 - Consumer Rights, because they directly regulate how the information must be given to consumers.

In accordance with the German law and in contrast to Australian law the period should start only after consumers have moved into the rest home and received the services. This would ensure that all consumers have the chance to decide whether or not they want to stay in the facility after the service provision has started. Otherwise consumers who sign the contract, but move in later, would be needlessly disadvantaged.

\footnotetext{
493 Section 28(4).

${ }^{494}$ Section 28(5).

495 O'Shea and Rickett, above n 32, at 147.

${ }^{496}$ For details see below page 123.

497 See Sandoval, above n 472, at 125.

498 See O’Shea and Rickett, above n 32, at 147.
} 


\section{Conclusion}

The protection of consumers at the time of the termination of the rest home contract is insufficiently developed. To enhance consumer protection, New Zealand should limit the provider's right to give notice. Australia's strict regulation and some of the existing standards of the Code of Practice could serve as a good example to improve the consumers' legal position. Furthermore, New Zealand should expand providers' obligations after the contract has been terminated. Providers should have, similarly to the Australian law, the duty to help consumers to find new suitable, available and affordable accommodation. Lastly, the introduction of a cooling-off period would enhance the consumers' protection. Providers should also inform consumers about the right in a highlighted form on a separate sheet. 


\section{Access to Justice for Elderly Consumers in Rest Homes}

Even the best legislation in favour of elderly consumers cannot ensure that providers will always fulfil all their obligations. Sometimes elderly consumers will be dissatisfied with the quality of the services provided or, in case of elder abuse, basic rights of the consumer will be violated by the provider or its staff. This leads to the question how New Zealand, Australia and Germany provide comprehensive access to justice for elderly consumers. Access to justice is one of the most important components of consumer protection $^{499}$ and its effectiveness relies on three important factors: ${ }^{500}$

the degree of statutory protection for consumers; the extent to which consumers know about this statutory protection; and finally the ease with which consumers can enforce their statutory rights against suppliers.

The previous chapters have mainly focused on the first factor: the degree of the protection of elderly consumers in rest homes. It has been shown that New Zealand tries to ensure a certain degree of protection, but nevertheless significant gaps exist. The following chapter focuses on the remaining two factors and examines the question of whether elderly consumers know about their rights and whether they can easily assert their rights against rest home providers. Do consumers have ready access to appropriate redress when providers do not fulfil their duties? ${ }^{501}$ How can they exercise these rights? Consumer protection is effective only if the legislation not only gives consumers rights but also assists them in enforcing their rights. Otherwise consumer rights would be little more than a toothless tiger. ${ }^{502}$ In this context, it will be necessary to distinguish between whether and how consumers can enforce their rights. It is not only important that consumers have opportunities to seek justice but also that these opportunities can be used effectively.

It should also be borne in mind that consumers often have a tangle of motives and reasons why they decide to seek for access to justice. ${ }^{503}$ According to Bismark and Bauer the consumers' motivation can be divided into four different categories: ${ }^{.04}$

\footnotetext{
${ }^{499}$ Ramsay, above $\mathrm{n} 26$, at 27.

${ }^{500}$ Bevan, Dugan and Grainer, above n 106, at 1.1; similarly L’Heureux, above n 94, at 445.

${ }^{501}$ Similarly Ministry of Consumer Affairs, above n 19, at 12.

${ }^{502}$ Similarly Colleen M Flood and Kathryn May "A patient charter of rights: how to avoid a toothless tiger and achieve system improvement” (2012) 185 CMAJ 1583 at 1583.

${ }^{503}$ See Marie Bismark and Edward A Dauer "Motivation for Medico-Legal Action - Lessons from New Zealand” (2006) 27 J Leg Med 55; Marie Bismark, Edward Dauer, Ron Paterson and David Studdert "Accountability sought by patients following adverse events from medical care: the New Zealand
} 
Restoration, including financial compensation or some other intervention to "make the patient whole again": correction, such as a system change or competence review to protect future patients; communication, which may include an explanation, expression of responsibility, or apology; and satisfaction, including professional discipline or some other form of punitive action.

Consumers often do not seek for compensation alone, but also have a need for explanation, apology and the protection of other consumers. ${ }^{505}$ They want to understand why something went wrong and ensure that a similar incident does not happen to others in the future. ${ }^{506}$ Therefore, comprehensive access to justice requires allowing consumers to pursue all their different motivations for taking action.

This chapter does not present all the different enforcement remedies, but focuses on consumers' access to justice alone. Therefore, administrative and criminal enforcement remedies are not covered. These remedies can also help to ensure that providers comply with statutory consumer rights, but they do not help consumers to enforce their own statutory rights.

\section{A The New Zealand Approach}

In New Zealand, elderly consumers in rest homes have several opportunities in seeking access to justice.

\section{Internal Complaints Resolution Processes}

It has been shown above that the Code of Rights is one major source of consumers' rights and providers' obligations. ${ }^{507}$ However, the existence of those statutory rights does not ensure that every provider will comply with its obligations. It is therefore necessary for

experience” (2006) 175 CMAJ 889 at 890; Frank A Sloan, Penny B Githens, Ellen Wright Clayton, Gerald B Hickson, Douglas A Gentile and David F Partlett Suing for Medical Malpractice (University of Chicago Press, Chicago, 1993); Charles Vincent, Magi Young, Angela Phillips "Why do people sue doctors? A study of patients and relatives taking legal action” (1994) 343 The Lancet 1609.

${ }^{504}$ Bismark and Dauer, above n 503, at 55; see also Joanna Manning "New Zealand's remedial response to adverse events in healthcare" (2008) 16 TLJ 120 at 120; Joanna Manning "Access to justice for New Zealand health consumers" (24 March 2010) Health and Disability Commissioner <www.hdc.org.nz> at 2.

${ }^{505}$ See for research in New Zealand: Bismark, Dauer, Paterson and Studdert, above n 503, at 889 - 894; Manning, above n 504, at 120.

${ }^{506}$ Bismark and Dauer, above n 503, at 57; Manning, above n 504, at 2.

${ }^{507}$ See above page 27. 
an effective consumer protection that consumers have access to justice to enforce their rights.

The first option for elderly consumers to seek for access to justice is the right to complain, which is laid down in right 10(1) of the Code of Rights. It states that "[e]very consumer has the right to complain about a provider in any form appropriate to the consumer." 508 This definition includes the opportunity to complain directly to the service provider. ${ }^{509}$ The right to complain also places an obligation on providers to "facilitate the fair, simple, speedy, and efficient resolution of complaints." 510 The further sections of right 10 regulate in detail the requirements of the provider's complaints procedure and the time lines within which they must operate. ${ }^{511}$ The provider must, among other things, inform the consumer about the existing external complaints procedures ${ }^{512}$ and the availability of the Commissioner. After the provider's decision the consumer has to be informed about the reasons for the decision, any actions the provider proposes to take and any appeal procedure the provider has in place.

However, some consumers may call the independence of the internal complaint resolution process into question, because providers might protect their own reputation and their employees first and foremost. ${ }^{513}$ Consequently, it is important for a comprehensive access to justice that consumers have an opportunity to have recourse to an adjudicative body that they consider to be impartial. ${ }^{514}$ This ensures that consumers can obtain an independent decision if they do not want to complain to the provider directly or if they are unhappy with the complaint resolution within the rest home, even though most consumers' complaints are resolved on a low-level without being referred to an adjudicative body. ${ }^{515}$

\section{The Health and Disability Commissioner}

In 1994, New Zealand has established a Health and Disability Commissioner. The Commissioner has the tasks to help resolving problems between consumers and providers

\footnotetext{
${ }^{508}$ Code of Health and Disability Services Consumers’ Rights 1996, right 10(1).

${ }^{509}$ Right 10(2)(a).

${ }^{510}$ Right 10(3).

511 Skegg, above n 328, at 242.

512 For details regarding the external complaints procedures see below page 92.

513 Flood and May, above n 502, at 1585.

514 At 1585.

${ }^{515}$ Skegg, above n 328, at 243.
} 
and to promote and protect the rights of consumers who receive health and disability services. ${ }^{516}$ Generally, the Commissioner's tasks also apply to elderly consumers in rest homes, because these consumers usually receive health and disability services.

To help consumers resolve their problems with providers and to ensure that providers respect the rights of consumers the Commissioner acts as an adjudicative body and an independent complaint scheme that can investigate possible breaches of the Code of Rights. Section 31 of the HDCA allows any person, not only the affected consumer, to complain orally or in writing to an advocate or to the Commissioner. ${ }^{517}$ In the year ended 30 June 2012 the Commissioner received 1,564 new complaints and closed 1,380 complaints. ${ }^{518}$ However, only 106 of the new complaints were about rest homes. ${ }^{519}$

When dealing with consumers' complaints the Commissioner has several options, both formal and less formal. ${ }^{520}$ Generally, the focus lies on resolving complaints directly between the provider and the complainant ${ }^{521}$ or, if that is not possible, at the lowest appropriate level. ${ }^{522}$ In the year ended 30 June 2012 the Commissioner decided in half of the 1,380 cases to take no (further) action. ${ }^{523}$ The Commissioner can choose this option if he or she is of the opinion that (further) action is "unnecessary or inappropriate"; ${ }^{524}$ for example if the provider has adequately addressed the issues, further enquiry will not help resolve it or is has already been ensured that the shortcoming will not happen again. ${ }^{525}$ In 80 cases the Commissioner referred the complaint to one or more agencies, ${ }^{526}$ for example, the ACC, the Director-General of Health, the provider involved and the Chief Ombudsman. Another 140 complaints were closed by referral to a consumer advocate who then tried to resolve the matter by agreement between the parties. ${ }^{527} 203$ complaints

\footnotetext{
$\overline{516}$ Code of Health and Disability Services Consumers’ Rights 1996; Health and Disability Commissioner Act 1994, s 6.

517 Section 31.

518 Health and Disability Commissioner “Annual Report for the year ended 30 June 2012” (31 October 2012) Health and Disability Commissioner <www.hdc.org.nz> at 15.

519 At 15 and 16.

520 See Health and Disability Commissioner Act 1994, s 35; Manning, above n 504, at 4.

521 Nicola Sladden and Sarah Graydon "Liability for Medical Malpractice - Recent New Zealand Developments” (2009) 28 Med Law 301 at 305.

522 Paterson, above $n$ 327, at 51.

${ }^{523}$ Health and Disability Commissioner Act 1994, s 38.

524 Section 38.

525 See Health and Disability Commissioner, above n 518, at 17.

526 See Health and Disability Commissioner Act 1994, ss 34 and 36.

${ }^{527}$ Section 37; for details about the advocacy service see below page 96 .
} 
were resolved by referral (back) to provider. The Commissioner's option to call a mediation conference of the parties was used in two cases only. ${ }^{528}$ Lastly, in the most serious cases the Commissioner can decide to conduct formal investigations. ${ }^{529}$ When undertaking an investigation the Commissioner is not limited to single or discrete incidents, but can also investigate generic system issues if they are or appear to be in breach of the Code of Rights. ${ }^{530}$ The number of complaints that have led to a formal investigation has constantly dropped over the last decade. ${ }^{531}$ Consequently, only a small minority of complaints, which often involving major breaches of the Code of Rights, are investigated by the Commissioner. ${ }^{532}$ In the year ended 30 June 201244 investigations were completed. In 29 cases it was found that the consumer's rights had been breached. ${ }^{533}$ Unfortunately, the statistics do not show specific numbers for rest homes. However, the Commissioner's website lists seven decisions after investigations since the beginning of $2011 .^{534}$ In all of these seven cases the Commissioner came to the decision that services have not been carried out with reasonable care and skill and held the rest home accountable for this breach of the Code of Rights in six of these cases. ${ }^{535}$

If the Commissioner is, after an investigation, of the opinion that there was a breach of the Code of Rights, several measures can be taken. ${ }^{536}$ For example, in the Decision 10HDC01231 the Commissioner recommended that the provider should apologise to the consumer's family for its breaches of the Code of Rights and made several recommendations to ensure that the provider will comply with the Code of Rights. ${ }^{537}$ The

\footnotetext{
${ }^{528}$ Section 61(1).

529 Section 40.

${ }^{530}$ Nicholls $v$ Health and Disability Commissioner [1997] NZAR 351; Health and Disability Commissioner Decision 03HDC14692 (14 October 2005); Tokeley, above n 77, at 163.

${ }^{531}$ Skegg, above n 328, at 246.

532 Manning, above n 504, at 4.

533 Health and Disability Commissioner, above n 518, at 16.

${ }^{534}$ Health and Disability Commissioner Decision 10HDC01231 (23 April 2013); Health and Disability Commissioner Decision $10 H D C 00308$ (29 June 2012); Health and Disability Commissioner Decision 09HDC01641 (21 June 2012); Health and Disability Commissioner Decision 09HDC01974 (21 June 2012); Health and Disability Commissioner Decision 09HDC02110 (2 March 2012); Health and Disability Commissioner Decision 09HDC02159 (27 January 2012); Health and Disability Commissioner Decision 09HDC01783 (28 March 2011).

535 Only in Health and Disability Commissioner Decision 09HDC02110 (2 March 2012) the Health and Disability Commissioner decided that the rest home did not breach the Code of Health and Disability Services Consumers’ Rights 1996.

536 See for details Health and Disability Commissioner Act 1994, s 45(2).

537 See Health and Disability Commissioner Decision 10HDC01231 (23 April 2013) at 172 and 173.
} 
Commissioner can also report a case to the independent Director of Proceedings (hereinafter: the Director). ${ }^{538}$ After reviewing the entire case the Director has to decide whether to institute proceedings before the Human Rights Review Tribunal (hereinafter: the Tribunal), ${ }^{539}$ disciplinary proceedings before the Health Practitioners Disciplinary Tribunal (hereinafter: the HPDT), ${ }^{540}$ or both to publicly redress serious breaches. Under the provisions of s 57 of the HDCA the Tribunal has the power to award punitive damages. ${ }^{541}$ However, in the year ended 30 June 20128 cases were referred to the Director and only one case was related to rest homes. ${ }^{542}$ Therefore, rest home related cases are found only rarely in the jurisdiction of the Director and the Tribunal over the past years. $^{543}$

The opportunity to initiate civil proceedings before the Tribunal is particularly relevant for non-registered providers, because the disciplinary tribunal has no jurisdiction over them. ${ }^{544}$ The aggrieved persons themselves can bring the proceedings before the Tribunal if either the Commissioner, although a breach of the Code of Rights was found, does not refer the complaint to the Director, or the Director does not seek to take proceedings. ${ }^{545}$ However, this opportunity is very limited in practice, because consumers cannot seek damages arising directly or indirectly out of a personal injury covered by the $\mathrm{ACA}^{546}$ and would have to fund such proceedings on their own. ${ }^{547}$

\footnotetext{
${ }^{538}$ Health and Disability Commissioner Act 1994, s 45(2)(f).

539 Section 50.

540 Section 49(1)(a).

541 Section 57(1); for details about the jurisdiction of the Human Rights Review Tribunal see Royden Hindle "Putting it Right? Monetary Remedies for Breaches of Patients' Rights” Royden Hindle $<$ www.roydenhindle.co.nz>.

${ }^{542}$ Health and Disability Commissioner, above n 518, at 24 and 27.

543 For examples of rest home related Human Rights Review Tribunal cases see Director of Proceedings under the Health and Disability Commissioner Act 1994 v Norfolk Court Rest Home Limited [2011] NZHRRT 12 (12 May 2011); Director of Proceedings under the Health and Disability Commissioner Act 1994 v Norfolk Court Rest Home Limited [2011] NZHRRT 13 (12 May 2011); Director of Proceedings v Emms [2013] NZHRRT 5 (16 November 2012).

544 Manning, above $n$ 504, at 5.

545 Health and Disability Commissioner Act 1994, s 51.

546 Section 52(2); Joanna Manning “Informed Consent to Medical Treatment: The Common Law and New Zealand's Code of Patients’ Rights” (2004) 12 Med L Rev 181 at 185. The opportunity is also limited due to the interpretation of s 57(1)(c) of the Health and Disability Commissioner Act 1994 in Marks v Director of Health and Disability Proceedings [2009] 3 NZLR 108 (CA).

547 Skegg, above n 328, at 252.
} 


\section{The Advocacy Service}

Elderly consumers can also try to enforce their rights with the help of the Health and Disability Advocacy. The advocacy service performs many different functions ranging from making sure that providers respect their rights and help consumers to resolve complaints about health or disability services. ${ }^{548}$ Therefore, the advocacy service do not only focuses on the law enforcement but also tries to give elderly consumers the necessary information to ensure that they know about their existing rights. The advocacy service received nearly 11,000 enquiries in the year ended 30 June $2012 .{ }^{549} 98 \%$ of these enquiries were closed within two days and $99 \%$ within five days. ${ }^{550}$ Furthermore, the advocates received 3,025 new complaints over the same period. 341 of these complaints were related to rest homes. ${ }^{551}$ Generally, the advocacy service was able to partially or fully resolve $90 \%$ of the received complaints. If the complaint cannot be resolved, the advocate must refer it to the Commissioner. ${ }^{552}$ The advocacy service received two-thirds of the complaints directly from consumers, whereas nearly one-third was made by a third party such as family members or referred by the Commissioner. ${ }^{553}$

\section{Complain to the District Health Boards}

Another agency that can investigate complaints about rest homes are the DHBs. A consumer or another person on behalf of the consumer can complain to the DHBs if they are dissatisfied with the services they have received by a publicly funded rest home. ${ }^{554}$ The DHBs are entitled to act on complaints and can investigate the rest home to ensure that the services are carried out to an appropriate standard. The complaint procedures vary between the DHBs, but all of them try to respond to consumer complaints in a fair and timely manner. ${ }^{555}$

\footnotetext{
$\overline{548}$ Ron Paterson “The Patients’ Complaints System in New Zealand” (2002) 21 Health Affairs 70 at 73; Health and Disability Commissioner Act 1994, s 30.

${ }^{549}$ Health and Disability Commissioner, above n 518, at 20.

${ }^{550}$ At 20.

551 At 20.

552 Health and Disability Commissioner Act 1994, s 31(3)(a).

553 Health and Disability Commissioner, above n 518, at 21.

554 Wilson, above n 11, at 28.

555 See for example: West Coast District Health Board, http:/www.westcoastdhb.org.nz/publications/ policies_n_procedures/policies_n_procedures_docs/general/ConsumerComplaintsProcedure.pdf; Capital and Coast District Health Board, http://www.ccdhb.org.nz/complaints.htm.
} 


\section{Complain to the Ministry of Health}

A further option for elderly consumers is to complain directly to the Ministry of Health. The Health and Disability Services (Safety) Act 2001 gives the ministry and authorised persons the right to inspect a rest home, especially to find out whether services being provided are meeting all relevant service standards and / or are being provided in a safe and satisfactory manner. ${ }^{556}$

\section{The Accident Compensation Corporation (ACC)}

Another opportunity for elderly consumers to seek for access to justice is provided by the Accident Compensation Corporation (hereinafter: the ACC). The ACC is an option only if elderly consumers seek restoration and compensation where they have suffered a personal injury in a rest home in New Zealand. ${ }^{557}$ The ACC provides government funded, no-fault personal injury cover. Introduced over thirty-five years ago, on 1 April 1974, the scheme is based on a social contract between the people and the government. ${ }^{558}$ The people gave up their common law right to sue for damages for personal injury covered by the scheme in return for cover and access to statutory entitlements under the scheme. ${ }^{559}$

The term personal injury is defined in ss 20, 26 of the Accident Compensation Act 2001 (hereinafter: the ACA) and includes, among other things, accidents and treatment injuries. ${ }^{560}$ In rest homes accidents that cause a personal injury happen quite frequently. For example, more than every second consumer in a rest home who is older than 80 years old suffers a slip, trip and fall once a year. ${ }^{561}$ Many of these accidents result in a personal injury. Treatment injury, ${ }^{562}$ as a particular type of personal injury, which was introduced in July 2005 to relax the qualifying criteria significantly, to simplify the claim process, to improve the cooperation and participation of the health practitioners, to avoid a blaming

\footnotetext{
${ }^{556}$ Health and Disability Services (Safety) Act 2001, s 40(1).

${ }^{557}$ For the definition of New Zealand see Accident Compensation Act 2001, s 16.

${ }^{558}$ Manning, above n 504, at 13. See also Accident Compensation Act 2001, s 3 that mentions the "social contract represented by the first accident compensation scheme”; Queenstown Lakes District Council v Palmer [1999] 1 NZLR 549.

559 Accident Compensation Act 2001, s 317; Sladden and Graydon, above n 521, at 302; Manning, above n 504, at 13 .

${ }^{560}$ For a definition of these terms see Accident Compensation Act 2001, s 20(2)(a) and (b).

561 The Accident Compensation Corporation states on their website: "In 2007/08 falls were the cause of 446 deaths and 48,417 injuries. New Zealanders aged over 65 have a one in three chance of having a fall each year; once they're 80 that increases to one in two, or even higher if they live in a rest home.”

562 Accident Compensation Act 2001, ss 20(2)(b) - (d), 32, 33; see for details regarding the cover Stephen Todd “Treatment Injury in New Zealand” (2011) 86 Chi Kent L Rev 1169 at 1188 - 1189.
} 
culture and to provide a true no-fault compensation, ${ }^{563}$ includes treatments carried out in rest homes by one or more registered health professionals. ${ }^{564}$ The definition of registered health professionals in s 6 of the ACA includes, for example, nurses and physiotherapist but not untrained staff. The term "treatment” includes, among other things, physical and cognitive rehabilitation. ${ }^{565}$ Treatments in rest homes are often carried out in cases in which consumers have suffered an injury whether or not they have already been in the rest home. For example, a consumer might fall at home and suffer a brain injury or a hip fracture. After the treatment in the hospital the elderly consumer is transferred into a rest home, where especially physiotherapists try to improve the cognitive and physical abilities of the consumer. In such a case consumers can seek for remedy via ACC if they suffer an injury during treatment. ${ }^{566}$

However, the details of the scheme are not discussed here. ${ }^{567}$ On one hand, the scheme is not about enforcing statutory rights of consumers against providers in a strict sense. The ACA does not refer to any consumer protection statutes or rights, but generally provides compensation in case of a personal injury. On the other hand, in many cases where consumers seek access to justice they have not suffered a personal injury. For example, not every poor performance of services or treatment leads to personal injury. An inadequately cleaned room, meals of poor quality or even care services of an inappropriate standard often do not have a personal injury as a consequence.

\footnotetext{
${ }^{563}$ See Injury Prevention, Rehabilitation and Compensation Amendment Act (No 2) 2005, s 13; see also Ken Oliphant "Beyond Misadventure: Compensation for Medical Injuries in New Zealand" (2007) 15 Med L Rev 357 at 369 - 371; Stephen Todd "Accident Compensation and the Common Law" in Stephen Todd (ed) The Law of Torts in New Zealand (6th ed, Thomson Reuters, Wellington, 2013) 21 at 51; for a historical overview see Petra Butler “A Brief Introduction to Medical Misadventure” (2004) 35 VUWLR 811 at $815-820$.

${ }^{564}$ Accident Compensation Act 2001, s 32(1)(a)(i).

${ }^{565}$ Section 6.

${ }^{566}$ The Treatment Injury Claim form of the Accident Compensation Corporation when lodging a claim for injuries which occur in the context of treatment also includes rest homes as one option where a treatment can be provided.

${ }^{567}$ For a comprehensive presentation of the accident compensation scheme's history see Bill Atkin and Geoff McLay Torts in New Zealand: cases and materials (5th ed, Oxford University Press, Oxford, 2012); Todd, above n 563, at 23. Petra Butler Medical Misadventure im neuseeländischen Accident Compensation Scheme (Peter Lang, Frankfurt am Main, 1999) (translation: Medical Misadventure in New Zealand's Accident Compensation Scheme); Ian B Campell Compensation for personal injury in New Zealand (Auckland University Press, Auckland, 1996) at 42; Oliphant, above 563, at 357.
} 
Overall, it can be said that ACC helps elderly consumers in rest homes to claim for compensation if they have suffered a personal injury, but does not focus on strengthening the law enforcement of special consumer rights. However, even if elderly consumers can lodge a claim in certain cases only, the ACC fulfils an important task. It provides a simply designed and clearly structured no-fault compensation process and, in addition, very extensive cover. ${ }^{568}$ This is supported by the Court of Appeal, which held a "generous, unniggardly interpretation" in keeping with the government's policy of universal coverage under the accident compensation scheme. ${ }^{569}$ The access to this remedy is further secured by a well-structured review and appeal process. ${ }^{570}$ Moreover, it avoids elderly consumers going to court to get redress, which is a rather unrealistic option. However, sometimes it can be difficult for consumers to lodge their claim successfully, because they have to proof that the treatment has caused the injury, not just the risk of injury. ${ }^{571}$

It is also important to note that the ACA limits consumers' access to justice in certain cases. Section 317(1) of the ACA contains a bar on actions for damages, whether founded on tort, contract, equity or statute, ${ }^{572}$ if the claim is covered by the Act. The bar applies even if a consumer chooses not to lodge a claim or is not entitled for compensation. ${ }^{573}$

However, the bar does not prevent any person from bringing common law proceedings in any court in New Zealand for exemplary damages. ${ }^{574}$ This is because exemplary damages do not pursue the same objective and, therefore, are outside of the scope of the ACA. Exemplary damages do not try to compensate the claimant, but rather try to punish the

\footnotetext{
${ }^{568}$ Sladden and Graydon, above n 521, at 302.

${ }^{569}$ Harrild v Director of Proceedings [2003] 3 NZLR 289 (CA) at 39, 80, 130; Accident Compensation Corporation $v$ Mitchell [1992] 2 NZLR 436 (CA) at $438-439$.

${ }^{570}$ See for details Accident Compensation Act 2001, ss 134, 138, 149, 162, 163.

${ }^{571}$ Atkinson v Accident Rehabilitation Compensation and Insurance Corporation [2002] 1 NZLR 374 at [24]; Ambros v Accident Compensation Corporation HC Auckland CIV 2004-404-3261, 21 March 2005; Accident Compensation Corporation (ACC) v Ambros [2007] NZCA 304; see also Todd, above n 562, at 1190 - 1197.

572 Accident Compensation Act 2001, s 317(1); Wilding v Attorney-General [2003] 3 NZLR 787 (CA) at 791; for details see Todd, above n 563, at 34; for exclusions from the bar see Accident Compensation Act 2001, s 317(2).

573 Marie Bismark and Ron Paterson "No-Fault Compensation In New Zealand: Harmonizing Injury Compensation, Provider Accountability, And Patient Safety” (2006) 25 Health Affairs 278 at 279: see also Green v Matheson [1989] 3 NZLR 564 (CA).

${ }^{574}$ Couch v Attorney-General (No 2) [2010] 3 NZLR 149 (SC) at 4; Sladden and Graydon, above n 521, at 303.
} 
defendant. ${ }^{575}$ Even so, such damages have only been awarded in exceptional cases of intentional acting or subjective and outrageous recklessness. ${ }^{576}$ Therefore, this option is limited to rare cases of serious elder abuse. In addition, common law damages are also possible where the damage is not covered by the ACA, for example mental injury without a physical injury. ${ }^{577}$

\section{Civil Law Proceedings and Disputes Tribunal}

Elderly consumers can bring their claim to court if the statutory bar of s 317(1) of the ACA does not apply. For example, elderly consumers might claim for compensation if a public rest home fails to comply with the provisions of the New Zealand Bill of Rights Act $1990 .{ }^{578}$ Another example are cases in which the provider was negligently in breach of the rest home contract or in case of a breach of s 28 of the CGA aged consumers can initiate legal proceedings. ${ }^{579}$ Generally, the CGA is self-enforcing and elderly consumers have to seek redress directly from the provider. Considering the fact that s 28 of the CGA and right 4(1) of the Code of Rights contain a similar obligation for providers, elderly consumers can often use the internal complaint process to seek redress. If no agreement can be reached consumers can take their matters to the court. ${ }^{50}$ The different statutory rights and remedies available to the consumer have already been shown above. ${ }^{581}$ However, legal proceedings are linked with high costs for elderly consumers and, therefore, this option is rarely used. ${ }^{582}$

A further, less expensive opportunity for consumers is to resolve the dispute with the help of a Disputes Tribunal. ${ }^{583}$ These tribunals try to resolve many civil disputes quickly and informally. The tribunals do not act like formal courts. A Principal Disputes Referee who

\footnotetext{
${ }^{575}$ Donselaar v Donselaar [1982] 1 NZLR 97 (CA).

${ }^{576}$ Couch v Attorney-General (No 2) [2010] 3 NZLR 149 (SC) at 3; departed from A v Bottrill [2003] 2 NZLR 721 at [24].

577 Sladden and Graydon, above n 521, at 304; Manning, above n 504, at 148 - 149; Director of Proceedings v O'Neil [2001] NZAR 59 (HC); for further examples see Todd, above n 562, at 1207 - 1210.

578 Section 3(b) of the New Zealand Bill of Rights Act 1990 states that the act only applies to "any person or body in the performance of any public function, power, or duty conferred or imposed on that person or body by or pursuant to law.” Therefore, private rest homes are not covered by the Act.

${ }^{579}$ See generally Tokeley, above n 77, at 165.

${ }^{580}$ Consumer Guarantee Act 1993, s 47.

${ }^{581}$ See above page 67.

${ }^{582}$ Ministry of Consumer Affairs, above 19, at 12.

583 Consumer Guarantee Act 1993, ss 47(3) to (6), 51 and 52; Disputes Tribunals Act 1988, sch 1.
} 
has been trained hears the dispute. ${ }^{584}$ Nevertheless, the rulings they make are binding for the parties involved ${ }^{585}$ and can be enforced by the courts. ${ }^{586}$

\section{Summary}

Elderly consumers in New Zealand have several different options when seeking access to justice. The selection of the right option often crucially depends on the question which statutory right the elderly consumer want to assert.

\section{B The Australian Approach}

Australia's system is somewhat similar to the New Zealand's system, because it also provides several opportunities for consumers to seek access to justice. However, there are great variations in the design of the legal redress opportunities. The presentation will focus on the main opportunities, because a detailed presentation of the different state laws goes beyond the scope of this dissertation. ${ }^{587}$

\section{Australia's Complaint Scheme}

In Australia, elderly consumers can seek access to justice via an internal and the external complaint scheme. Sections 56-1(i) and 56-4 of the Aged Care Act 1997 (Cth) oblige every provider to establish a complaints resolution mechanism for their aged care service. The internal complaint mechanism must be used to address any complaints, comply with any requirement made under the Complaints Principles 2011 (Cth) and provided for in the resident agreements. ${ }^{588}$ The Complaints Principles 2011 (Cth) ${ }^{589}$ came into force on the basis of an enabling clause in s 96-1 of the Aged Care Act 1997 (Cth).

The general baselines for the external complaint scheme are set out in the Aged Care Act 1997 (Cth). ${ }^{590}$ Nevertheless, the Complaints Principles 2011 (Cth) ${ }^{591}$ contain detailed

\footnotetext{
${ }^{584}$ Section 6A.

${ }^{585}$ Section 23.

${ }^{586}$ Section 47.

${ }^{587}$ For example this dissertation will not present the Commonwealth funded advocacy services in all States and Territories, although they help consumers to understand and assert their rights.

${ }^{588}$ Aged Care Act 1997 (Cth), s 56-4(1)(2).

589 Regarding the history of the complaint scheme in Australia see Complaints Principles 2011 (Cth) explanatory statement, at 1.

${ }^{590}$ Aged Care Act 1997 (Cth), s 94A-1.
} 
procedures regarding the operation of the scheme. The Principles regulate how to make, deal with and solve a complaint. They replaced the Investigation Principles 2007 (Cth) and shifted the focus from "investigations" to a more flexible approach. ${ }^{592}$ To ensure easy access to the complaint scheme s 23.19 of the User Rights Principles 1997 (Cth) states an obligation for providers to allow the access necessary to investigate and assist in the resolution of the complaint. The Complaint Principles 2011 (Cth) entitle every person to make a complaint, anonymously if desired, orally or in writing to the Secretary of the Department of Health and Ageing (hereinafter: the Secretary), if the person is of the opinion that a provider violated its obligations under the Aged Care Act 1997 (Cth) or one of the principles made under s $96-1$ of the Act. ${ }^{593}$

The Secretary has delegated the responsibilities under the Complaint Principles 2011 (Cth) to the nominated officers within the Department's Office of Aged Care Quality and Compliance. This Department runs the Aged Care Complaints Scheme (hereinafter: the Scheme), which therefore carries out the Secretary's responsibilities under pt 2 through 6 of the Complaint Principles 2011 (Cth). Thus, the use of "the Scheme" in this dissertation has to be seen in connection with the Secretary's delegation of the responsibilities.

Similarly to New Zealand, the Scheme has several options after receiving a complaint. ${ }^{594}$ It can decide to take no further action under certain circumstances ${ }^{595}$ or it can quickly resolve the issue to the satisfaction of the complainant; ${ }^{596}$ for example by helping consumers to understand their rights, so that they are confident enough to raise the complaint directly with the provider. Lastly, if none of the other options applies, the Scheme can undertake a more formal resolution process, which is described in pt 3 of the Complaints Principles 2011 (Cth). However, it is possible that the Scheme undertakes a resolution process on own motion when it receives information from another source, for example a doctor, that a provider may have breached its responsibilities. ${ }^{597}$

Generally, when undertaking the resolution process the Scheme can freely choose between one or more of four different options. The Scheme can request the provider to

\footnotetext{
${ }^{591}$ Regarding the history of the complaint scheme in Australia see Complaints Principles 2011 (Cth) explanatory statement, at 1 .

${ }^{592}$ Explanatory statement, at 1.

${ }^{593}$ Complaints Principles 2011 (Cth), s 13A.5.

${ }^{594}$ See Section 13A.6.

${ }^{595}$ Section 13A.7(a) and (g).

${ }^{596}$ Section 13A.6(b).

${ }^{597}$ Section 13A.8.
} 
examine and attempt to resolve the complaint, ask the parties to participate in a conciliation process, undertake an investigation or refer the issue to mediation. ${ }^{598}$ The different approaches can be adopted during the process and can involve different activities. Furthermore, the Scheme has the right to analyse and review documents, visit the provider's location, discuss the issue with the parties or any other person or request information from any person. ${ }^{599}$

The Scheme can decide to end a resolution process for many different reasons, ${ }^{600}$ but most importantly when the issue has been resolved, the Scheme has initiated a sanction in accordance with pt 4.4 of the Aged Care Act 1997 (Cth), ${ }^{601}$ the continuation of the process is not warranted or the Scheme gave directions to the provider to ensure that the provider will comply with its responsibilities. The procedure for the latter option is regulated in detail in s 13A.14 of the Complaints Principles 2011 (Cth) and requires, among other things, that the Scheme gives the provider a written notice of intention, ${ }^{602}$ except prompt action is required. ${ }^{603}$ The provider has to comply with the given directions, otherwise the Scheme can initiate action under pt 4.4 of the Aged Care Act 1997 (Cth).

Under certain circumstances the complainant and the provider can apply for reconsideration by the Scheme. ${ }^{604}$ In some cases is also possible for the complainant and the provider to apply, orally or in writing and within 28 days, to the Aged Care Commissioner for examination of the Scheme's decision. ${ }^{605}$ However, even if the Aged Care Commissioner recommends the Scheme to undertake a new resolution process, ${ }^{606}$ the Scheme can freely decide whether or not a new resolution process will follow. ${ }^{607}$ This shows that the Aged Care Commissioner has no power to overturn a Scheme's decision, but rather the Scheme maintains complete control of the process. ${ }^{608}$

\footnotetext{
${ }^{598}$ Section 13A.9(1)(a) - (d).

599 Section 13A.9(2)(a) - (d).

${ }^{600}$ Section 13A.13.

${ }^{601}$ See also Section 13A.20.

${ }^{602}$ Section 13A.14(3).

603 Section 13A.14(4).

${ }^{604}$ See for details Section 13A.21(1) and (2).

605 Section 13A.23.

${ }^{606}$ Section 13A.25(2).

${ }^{607}$ Section 13A.26.

${ }^{608}$ Lewis, above n 346.
} 


\section{Common Law Proceedings}

Where elderly consumers suffer an injury or damage, because the provider fails to deliver an appropriate standard of care, ${ }^{609}$ although there is a pre-existing duty of care to the consumer, ${ }^{610}$ consumers can assert a common law claim. Without a doubt, providers and its staff owe a duty of care to elderly consumers in rest homes, ${ }^{611}$ because several statutory provisions determine a certain care standard ${ }^{612}$ and in any case care services are an integral part of rest home contracts. ${ }^{613}$ Negligence is presumed if the care provided to consumers is below the required standard of reasonableness, and results in foreseeable harm to them. ${ }^{614}$

The consumer as the plaintiff has the burden of proving all elements of the cause of action in order to succeed. ${ }^{615}$ This means the consumer "will have to show that it is more likely than not that the [provider] was negligent and that the negligence caused the [consumer's] loss." ${ }^{616}$ Therefore, a successful claim requires that the consumer can prove that the provider's failure caused actual damage in breach of the duty. ${ }^{617}$ If the consumer can prove these elements, the court has to decide the amount of compensation awarded as a result of the defendant's negligence. ${ }^{618}$ The guiding principle to the assessment of

\footnotetext{
${ }^{609}$ See above page 63.

${ }^{610}$ Lewis, above n 346; see for details Jaensch v Coffey (1984) 155 CLR 549 (HCA) at 585-586.

${ }^{611}$ In other cases the question of whether the provider owes a duty of care is a complex question of law. See Rogers $v$ Whitaker (1992) 175 CLR 479 (HCA) at 483.

${ }^{612}$ See in detail above page 63.

${ }^{613}$ A contract between the parties indicates that there is a duty of care, see Bryan $v$ Maloney (1995) 182 CLR 609 (HCA) at 621.

${ }^{614}$ Aged Rights Advocacy Service "Duty of Care” Aged Rights Advocacy Service South Australia $<$ www.sa.agedrights.asn.au>; Donoghue v Stevenson [1932] AC 562 (HL); Stephen Walmsley, Alister Abadee and Ben Zipser Professional Liability in Australia (2nd ed, Lawbook Co, Sydney, 2007) at [1.210]; see also more generally Chapman v Hearse (1961) 106 CLR 112 (HCA); for statutory definitions in all Australian jurisdictions see: Civil Liability Act 2002 (NSW), s 5B; Civil Liability Act 2003 (Old), s 9; Civil Liability Act 2002 (Tas), s 11; Civil Liability Act 2002 (WA), s 5B; Civil Liability Act 1936 (SA), s 32; Civil Law (Wrongs) Act 2002 (ACT), s 43; Wrongs Act 1958 (Vic), s 48.

${ }^{615}$ Pam Stewart and Anita Stuhmcke Australian Principles of Tort Law (3rd ed, The Federation Press, Sydney, 2012) at 219; see also Civil Liability Act 2002 (NSW), s 5E; Civil Liability Act 2003 (Qld), s 12; Civil Liability Act 2002 (Tas), s 14; Civil Liability Act 2002 (WA), s 5D; Civil Liability Act 1936 (SA), s 35; Civil Law (Wrongs) Act 2002 (ACT), s 46; Wrongs Act 1958 (Vic), s 52.

${ }^{616}$ Stewart and Stuhmcke, above n 615, at 282; see also R P Balkin and J L R Davis Law of Torts (4th ed, LexisNexis, Chatswood, 2009) at 7.4.

${ }^{617}$ Scarcella v Lettice (2000) 51 NSWLR 302 (NSWCA) at 306; Stewart and Stuhmcke, above n 615, at 152.

${ }^{618}$ At 583; Cattanach v Melchior (2003) 215 CLR 1 (HCA).
} 
damages is that damages for the consequences of mere negligence are compensatory, but not punitive. ${ }^{619}$ With the compensation the consumer is placed in the position he or she would have been in if there had not been the defendant's negligence behaviour that caused damage. $^{620}$

However, as stated above ${ }^{621}$ to bring a claim to court is often linked with significant risks and high costs for consumers. Therefore, comprehensive access to justice should provide easier opportunities for consumers to assert their rights.

\section{Enforcement of Obligations Stated in the Australian Consumer Law (ACL)}

In view of the obligations stated in the ACL several different ways of law enforcement exist. On one hand, contravention of a consumer protection provision can be pursued by means of public enforcement. ${ }^{622}$ Several different agencies, for example the Australian Competition and Consumer Commission, have a range of civil, administrative and criminal enforcement remedies at their disposal ${ }^{623}$ to encourage and enforce compliance with the ACL. ${ }^{624}$ On the other hand, the ACL contains several private rights that consumers can enforce through Commonwealth, state and territory courts and tribunals. ${ }^{625}$ Private enforcement is possible if the provider does not fulfil its guarantees stated in the ACL and, as a result of this flawed conduct of services, the consumer suffers loss or damage. ${ }^{626}$ This claim is similar to a common law claim, but must be made to a special tribunal that can be identified in every State or Territory. ${ }^{627}$

\section{Summary}

In Australia, elderly consumers have several accesses to remedies, which are well distinguished from one another. Consumers do not always have to initiate common law proceedings but also have easier opportunities to enforce their rights.

\footnotetext{
${ }^{619}$ Skelton $v$ Collins (1966) 115 CLR 94 (HCA) at 128.

${ }^{620}$ Livingstone v Rawyards Coal Co (1880) 5 App Cas 25 (HL) at 39.

${ }^{621}$ See above page 100.

622 Corones, above n 66, at 13.05 .

${ }^{623}$ Competition and Consumer Act 2010, chapter 5.

${ }^{624}$ For details see Commonwealth of Australia "Compliance and enforcement - How regulators enforce the Australian Consumer Law” (2010) Australian Consumer Law <www.consumerlaw.gov.au> at 6.

${ }^{625}$ Commonwealth of Australia, above n 624, at 6.

${ }^{626}$ Corones, above n 66, at 13.05 and chapter 14.

627 See for example the Consumer, Trader and Tenancy Tribunal (CTTT) of New South Wales $<$ www.cttt.nsw.gov.au>.
} 


\section{The German Approach}

The German system is significantly different from the systems in New Zealand and Australia.

\section{Civil Law Proceedings}

Elderly consumers in Germany can always bring their claim to court to assert their rights. They can claim a proper performance of the obligations ensuing from the rest home contract, compensation for damages instead of or in addition to the service provision, ${ }^{628}$ compensation for expenses, ${ }^{629}$ or compensation in case of a negligent conduct. ${ }^{630}$ The legal proceedings are based on the regulations of the German Code of Civil Procedure. ${ }^{631}$ The question whether consumers are entitled to receive compensation is often linked with the question whether the services were provided in accordance with the generally accepted state of professional specified knowledge. ${ }^{632}$

\section{Out-of-Court Opportunities for Resolving Disputes in Germany}

The German regulations do not contain a comprehensive complaint scheme to facilitate the legal enforcement of consumer rights. For example, the WBVG only states consumer rights but does not simplify consumers' access to justice. However, that does not mean that consumers generally cannot complain about providers. They can complain directly to the rest home provider. Often providers welcome it when consumers draw attention to abuses in the rest home and try to solve the problem. This may be due to the fact that consumers always have the opportunity to reduce their fees, if there is a legitimate reason to complain or it may be because providers fear negative publicity. Furthermore, consumers can contact the resident representatives in the rest home, ${ }^{633}$ to receive help with their complaint. However, no complaint procedure is described by law. Consumers always rely on the mechanism established in the rest home but cannot expect a certain procedure.

A further contact point for consumer complaints are the rest home supervisory authorities in the federal states. These authorities assess the compliance of providers with the federal

\footnotetext{
${ }^{628}$ Bürgerliches Gesetzbuch 2002 (Germany), paras 280 to 283.

${ }^{629}$ Paragraph 284.

${ }^{630}$ Paragraph 823.

${ }^{631}$ See Zivilprozessordnung 2005 (Germany).

632 See above page 64.

${ }^{633}$ See for example for Lower Saxony: Niedersächsisches Heimgesetz (NHeimG), para 4.
} 
state law governing homes for the elderly. They take complaints as an occasion to review the proper operation of the rest home. Where a deficiency has been found, the rest home supervisory authorities will first give the rest home advice about how to eliminate the defect $^{634}$ and a reasonable period of time to correct the defect. If the provider does not fix the deficit the authorities can prescribe any necessary measures ${ }^{635}$ and, at worst, prohibit the operation of the rest home. ${ }^{636}$

Furthermore, in 2004 a federal government commissioner for patient issues was established. ${ }^{637}$ Contrary to New Zealand, the commissioner is not a contact point for individual complaints, but has the tasks of providing patients with information and ensuring that patients' issues are considered. ${ }^{638}$ However, although older people frequently contact the commissioner, ${ }^{639}$ the commissioner does not specifically focus on rest home related problems, but rather tries to improve the patients’ rights.

\section{Summary}

Overall, it can be said that Germany has many contact points for consumers but no comprehensive complaint scheme that helps them to assert their rights, especially if they seek remedy for non-compensatory reasons.

\section{Advantages and Disadvantages of New Zealand's Approach}

Consumers' access to justice in New Zealand, Australia and Germany differ greatly. The advantages of the existing system are now discussed. Then the weaknesses of the existing system provide an opportunity to make some proposals for improvements to the system for elderly consumers in rest homes. All this is done taking into consideration the strengths of the Australian and the German approach. Patientenbeauftragten der Bundesregierung ältere Menschen an?“ (2007) 40 Z Gerontol Geriat 275 at 279 (translation: Does the Offer to Consult the Federal Government Commissioner for Patient Issues Address Older People?).
} 


\section{Advantages of New Zealand's Approach}

New Zealand's system has the advantage that it offers elderly consumers several opportunities to assert their rights.

The Commissioner promotes and protects the rights of consumers. Complaints are resolved at the lowest appropriate level within an efficient resolution process. This allows consumers to seek access to corrective justice. The complaint scheme also puts an emphasis on "resolution, not retribution" and "learning, not lynching". ${ }^{640}$ For this reason, individual providers are rarely named in the public. ${ }^{641}$ Providers have largely been receptive to the Commissioner's decisions and recommendations with a compliance rate of 99,2 per cent in the year ended 30 June $2012^{642}$ and weight them similar to court decisions. $^{643}$

A further advantage for elderly consumers is the advocacy service, which makes a significant contribution to solve consumer complaints adequately. It was shown above ${ }^{644}$ that the advocacy service resolves many consumer enquiries within a few days. The beneficial role of the advocacy service is supported by the fact that nearly all providers, if they have agreed to take action to resolve the complaint, completed these actions within the agreed timeframe. ${ }^{645}$ This shows that providers often try to resolve the complaint at an early stage.

The ACC gives consumers access to justice if they seek compensation for personal injuries from their treatment. It has the advantage that it puts an emphasis on injury prevention, open disclosure and learning. ${ }^{646}$ Consumers do not need to prove fault or negligence by the rest home's staff, ${ }^{647}$ as the personal liability of individual persons is irrelevant for the compensation claim. Consequently, the ACC has no reporting obligation to the relevant professional body or the Commissioner, but only to the authority responsible for patient safety if the ACC believes from the information

\footnotetext{
${ }^{640}$ Paterson, above n 327, at 51.

641 See Health and Disability Commissioner "Policy Document - Naming Providers in Public HDC Reports” (1 July 2008) Health and Disability Commissioner <www.hdc.org.nz> at $4-5$.

${ }^{642}$ See also the Health and Disability Commissioner, above n 518, at 16.

643 Flood and May, above n 502, at 1585; Sladden and Graydon, above n 521, at 313; see also the Health and Disability Commissioner, above n 518, at 6.

${ }^{644}$ See above page 96.

${ }^{645}$ Health and Disability Commissioner, above n 518, at 20.

${ }^{646}$ Oliphant, above 563, at 388.

${ }^{647}$ Marie M Bismark “Compensation and complaints in New Zealand” (2006) 332 BMJ 1095 at 1095.
} 
collected that there is a risk of harm to the public. ${ }^{648}$ In other words, the focus is generally on improving the quality of the whole system instead of attributing individual blame. ${ }^{649}$ This is a great advantage in comparison with the systems of Australia and Germany, because New Zealand's system can overcome a blaming culture, which induces silence and bitterness, rather than honesty, ${ }^{650}$ to enhance consumers' safety, ${ }^{651}$

In addition, the existing compensation scheme has the advantage for elderly consumers that there is no need for lawyers, that the administrative and legal fees are low in comparison with countries with malpractice systems ${ }^{652}$ and that that the length of the process is short in comparison with fault-based schemes. ${ }^{653}$

Furthermore, New Zealand's system has the advantage that consumers can enforce their statutory rights under the CGA with the help of Disputes Tribunals. Therefore, elderly consumers do not necessarily have to bring their claims to court but can use a quicker and more informal process to assert their rights.

Overall, it can be said that New Zealand's system has the advantage that it provides several different opportunities for consumers to enforce their statutory rights. Therefore, New Zealand not only provides a certain degree of statutory protection for elderly consumer in rest homes, but also tries to ensure that consumers are able to assert these rights. Another strength is that the existing system shifted away from a blaming culture, opened lines of communication and focuses on improvements of the whole health system. Moreover, only in the minority of cases are lawyers involved, ${ }^{654}$ because legal representation is not compulsory for consumers. This makes it easier for consumers to seek for access to justice, especially because if one considers that the cost of financial litigation is one major barrier for consumers’ access to justice. ${ }^{655}$

\footnotetext{
${ }^{648}$ Accident Compensation Act 2001, s 284; Todd, above n 562, at 1204.

${ }^{649}$ Paterson, above n 327, at 52.

650 See Natalie Gray "Reforming the relationship between medicine and the law of tort" (2004) 11 JLM 324.

${ }^{651}$ Paterson, above n 327, at 52.

652 Bismark and Paterson, above n 573, at 281; Randall R Bovbjerg, Frank A Sloan and Peter J Rankin “Administrative Performance of 'No-Fault' Compensation for Medical Injury” (1997) 60 Law and Contemp Probs 71; Todd, above n 562, at 1212; for further references see Kirsten Armstrong and Daniel Tess “Fault versus No fault - Reviewing the International Evidence” (November 2008) Actuaries Institute $<$ www.actuaries.asn.au $>$ at $13-16$.

653 Armstrong and Tess, above n 652, at 19.

654 Ron Paterson “Complaints and quality: handle with care!” (2004) 117 NZMJ 970.

${ }^{655}$ See above page 22.
} 


\section{Proposals to Improve Consumers' Access to Justice}

All that glitters is not gold and there are several reasons why the current system can be criticised. Australia's and Germany's systems have their own strengths, which can be used to improve the existing legislation in New Zealand.

\section{a. Establishment of a New Commissioner}

A first problem arises if one considers that consumers can complain not only to the Commissioner but also to the Ministry of Health and the DHBs. Consumers can choose freely between these options and could also complain to all of these agencies. This entails the risk that elderly consumers are confused and discouraged from using the existing options. For this reason, the existing system is too cumbersome to provide easy access to a complaint scheme for elderly consumers in rest homes.

To improve the existing system the Australian model could be a useful guide. ${ }^{656}$ In Australia, the Office of Aged Care Quality and Compliance manages the Scheme, which acts as a central contact point to anyone who has a complaint or concern about government subsidised aged care services. Elderly consumers in Australia do not have to choose between different agencies. They always have the same contact point that deals with their complaints. The Scheme handles aged care related cases only. It has a complete overview of the sector, which helps to find and tackle systematic issues. Aged care services often face different problems, because the focus is not so much on health services carried out by a health professional, but on care and support services provided by nurses and care-givers. In addition, a central agency would also streamline administration costs and simplify educating consumers.

A further model could be New Zealand's Children's Commissioner Act 2003 (hereinafter: the CCA) and the Children's Commissioner who acts under this specific piece of legislation. With the Children's Commissioner New Zealand has already proven that it is possible to establish a Commissioner who advocates the interests of a specific group of persons. Describing the tasks of the Children's Commissioner the website of the Commissioner states that the "Act enables the Children's Commissioner and his staff to promote the rights, health, welfare, and well-being of children and young people between the ages of 0 and 18 years." Section 12 of the CCA describes several functions of the Commissioner, for example to undertake and promote research into any matter that

${ }^{656}$ Wilson, above n 11, at 28. 
relates to the welfare of children, ${ }^{657}$ which could be used to a great extent to describe the tasks and powers of a Commissioner for aged consumers. For the above reasons, New Zealand should establish a central agency and a Commissioner for aged consumers, who tries to enhance the statutory care and protection of elderly consumers. The Commissioner could also be granted further powers to set out and enforce standards, for example mandatory staffing requirements, ${ }^{658}$ to protect consumers. ${ }^{659}$ This is necessary because elderly consumers in rest homes often have severe difficulties exercising their rights ${ }^{660}$ and therefore rely on good statutory protection.

This leads to the question where to establish a central agency in New Zealand? Currently, the Commissioner and advocacy service receive the vast majority of consumer complaints. ${ }^{661}$ The advocacy service is unsuitable as a central agency, because it serves other purposes. ${ }^{662}$ Consequently, an obvious choice is to establish the Commissioner as the only contact point for consumer complaints. However, the Commissioner could only use the existing complaint scheme, which is not tailored for aged care services alone. Therefore, it would be preferable to put a new Commissioner and a new office in place, trained to solve all different problems that can occur within a rest home and which can work under a specific rest home related complaint scheme. A new Commissioner and its office could also more easily detect systematic failures within the rest home sector and handle complaints with the necessary particular sensitivity. In addition, a new Commissioner could address the specific issues of rest homes and try to improve the legal position of elderly consumers. To introduce these changes New Zealand should enact a new piece of legislation designed for rest homes. ${ }^{663}$

\section{b. Introduction of a New Complaint Scheme}

The introduction of a new Commissioner and its staff as a central agency for aged consumers would solve the problem that the existing system is too cumbersome. However, some problems remain unsolved. Firstly, neither the existing complaint scheme nor the Code of Rights are specifically tailored to aged care services, but generally apply

\footnotetext{
${ }^{657}$ Children's Commissioner Act 2003, s 12(1)(e).

658 See above page 65.

${ }^{659}$ For details see page 123.

${ }^{660}$ See above page 22.

${ }^{661}$ In the year ended 30 June 2012 the Commissioner has received 1,564 new complaints. 106 of these complaints were about rest homes.

${ }^{662}$ See above page 96.

${ }^{663}$ For details see below page 123.
} 
to all consumers who receive health and disability services. Secondly, the Commissioner can only act if there was a breach of the Code of Rights. This is not always the case when elderly consumers are concerned. For example, a complaint to the Commissioner is not possible if the contract parties dispute over the right to terminate the contract. To avoid these problems and to achieve better protection for elderly consumers in rest homes it is necessary to introduce a new complaint scheme.

The new scheme should be managed by the new Commissioner and its staff and should be available to anyone who has a concern or complaint about rest home related services. This means that the new scheme should not be limited to health and disability services but include all services carried out in rest homes. This recommendation corresponds with the existing Australian legislation. The Complaint Principles 2011 include all relevant obligations of providers, without being limited to health and disability services alone. Similarly to the Australian approach, ${ }^{664}$ guidelines should be developed to assist with implementing the changes to the existing scheme. Moreover, the new scheme could also include further consumer rights. It has been shown above ${ }^{665}$ that some parts of the Code of Rights are not specifically tailored for rest home care and, therefore, must be supplemented. The introduction of a new scheme could ensure that consumers can complain if providers do not comply with these new obligations.

However, this does not mean that the new scheme cannot use the existing scheme as a basis. To use the existing scheme as a template would have the benefit that many advantages of the existing system could be preserved. For example, New Zealand made a great effort to promote the existing system and to inform consumers about their rights. The Code of Rights and the right to complain are well publicised in every rest home. ${ }^{666}$ Moreover, several brochures exist, which aim to explain to consumers their rights in simple terms and consumers who struggle to find the contact point can seek support from free, independent advocates. ${ }^{667}$ All these measures try to ensure that consumers know about their existing rights. This is supported by the providers' obligation to inform consumers about the availability of any relevant internal and external complaints procedures, which increases the likelihood of providers responding appropriately to

\footnotetext{
${ }^{664}$ See Office of Aged Care Quality and Compliance "Guidelines for the Aged Care Complaints Scheme" (September 2011) Department of Health and Ageing <www.health.gov.au>.

665 See above page 54 .

${ }^{666}$ Similarly Skegg, above n 328, at 242 and 266.

${ }^{667}$ Bismark and Dauer, above n 503, at 60.
} 
complaints. ${ }^{668}$ Nevertheless, some of the efforts already made will be vain. The establishment of a new Commissioner and new consumer rights will necessarily have the consequence that consumers have to learn about the new system and their new rights. However, these disadvantages will be outweighed by the improved protection of elderly consumers in rest homes. To promote the new system the Commissioner should establish a new programme that aims to inform consumers about their rights. ${ }^{669}$

The introduction of a system adapted to rest home care could also be used to avoid some of the disadvantages of the existing system. Therefore, some proposals for further improvements follow.

\section{c. Streamlining of the New Complaint Scheme}

Some authors point out that in serious cases the existing complaint process is too attenuated, because of time delays and multiple investigations. ${ }^{670}$ Although in 2003 several improvements were made to streamline the complaints process and to give the Commissioner more flexibility, ${ }^{671}$ several problems remain. The Commissioner still does not have the flexibility to refer serious complaints, which obviously raise public health risks, directly to the Director for urgent action, including suspension where appropriate. $^{672}$ Therefore, especially in cases where urgent action seems to be appropriate, repeated inquiries are necessary with the consequence that the investigation process often takes longer than one year. ${ }^{673}$ This should be changed by giving the new office, the right to forward serious complaints directly to the Director. Furthermore, as under the Australian law, the Commissioner should be able to give directions to the provider, if it is necessary to do so because prompt action is required to protect the consumers' health. Consequently, New Zealand should adopt a regulation similarly to s 13.A14(4) of the Complaints Principles 2011 (Cth).

\footnotetext{
${ }^{668}$ Code of Health and Disability Services Consumers’ Rights 1996, right 10(6)(b); Skegg, above n 328, at 242.

669 See below page 118.

670 Manning, above n 504, at 133; Wendy Brandon “Complaints Against Medical Practitioners” [2001] NZLJ 249 at 252.

${ }^{671}$ Health and Disability Commissioner Amendment Act 2003, s 9, which restructured ss 31 - 45 of the Health and Disability Commissioner Act 1994.

672 Helen Cull "Review of Processes Concerning Adverse Medical Events” (March 2001) Ministry of Health <www.moh.govt.nz> at 43 - 44; Manning, above n 504, at 133.

${ }^{673}$ At 133.
} 


\section{d. Dramatic Decline in Disciplinary Proceedings}

Some authors argue that it is a matter of concern that the accountability of health professionals is much diminished. ${ }^{674}$ The number of disciplinary charges before the HPDT, which is the single disciplinary tribunal for 12 different health professions, has dramatically declined since the introduction of the Code of Rights and the Commissioner's complaint system in 1996. While in the three years before the Code was enacted, the relevant professional body received annual average of 84 charges, by 2010 the average dropped to $8 .{ }^{675}$ In Brandon's opinion consumers already "have a much reduced jurisdiction for complaint compared to health care consumers in other jurisdictions, in any event. ${ }^{„ 676}$ In addition, with a gatekeeping role of the Commissioner or the unwillingness of the disciplinary body to prosecute complaints, consumers can hardly receive any acknowledgement of harm suffered and the psychological healing becomes considerably more difficult. ${ }^{677}$

Nonetheless, this situation should not change under the new complaint scheme. For the area of rest home providers it has to be considered that the HPDT's jurisdiction only includes nurses but not caregivers or the rest home provider itself. Therefore, the HPDT's power is limited from the beginning. In addition, often there is no need for disciplinary proceedings to address performance issues, because the health practitioner's competence can be reviewed without disciplinary proceedings. ${ }^{678}$ Furthermore, the function of psychological healing is assured by the independent investigation of the consumer's complaint. ${ }^{679}$ The complaint process includes determining whether there was a breach of the Code of Rights and consumers have the chance to "tell their story". ${ }^{680}$ This ensures that consumers are not alone with their grief and anger. Lastly, the decline is a consequence of the non-punitive philosophy that only major breaches, for example serious competence concerns, or unethical practice, should lead to disciplinary proceedings. ${ }^{681}$

\footnotetext{
${ }^{674}$ Brandon, above $\mathrm{n} 670$, at 251.

${ }^{675}$ Flood and May, above n 502, at 1584; Manning, above n 504, at 131; Paterson, above n 327, at 59.

${ }^{676}$ Brandon, above n 670, at 251.

${ }^{677}$ At 252.

${ }^{678}$ See Health Practitioners Competence Assurance Act 2003, pt 3; Skegg, above n 328, at 256; Flood and May, above n 502, at 1584.

${ }^{679}$ Skegg, above n 328, at 256.

${ }^{680}$ Brandon, above n 670, at 252.

${ }^{681}$ See Manning, above n 504, at 131.
} 


\section{e. Right to Appeal}

Another disadvantage of the existing scheme is the lack of a right to appeal for providers and consumers against the Commissioner's opinion. ${ }^{62}$ The parties are not entitled to challenge the Commissioner's assessment whether there was a breach of the Code of Rights or the decision to refer the complaint to the Director or the HRRT. ${ }^{683}$ Hence, consumers can bring civil proceedings before the HRRT, but, for reasons already discussed, this option is rarely used. ${ }^{684}$ At the first glance, there are some good reasons why there is no right to appeal. A right to appeal would contradict the idea of a low-level resolution, because parties often exercise an appeal right, especially if the costs are covered by insurance. Furthermore, the complaint process would often be extended with the consequence that it would take longer to provide legal certainty. This would also contradict the aim to ensure a simple, speedy and efficient resolution process. ${ }^{685}$ In addition, the absence of a right to appeal is probably one reason why the Commissioner's opinion is very significant for the parties involved. ${ }^{686}$ Without the right to appeal and the seeming authority of the decision, the parties often count it for at least as much as a court decision. ${ }^{687}$ The risk of unfairness is therefore a conscious choice and "is outweighed by the attraction of the low-level nature of the process as a whole.”688

It is certainly true that a general right to appeal would be of little advantage, because the process could not be resolved quickly. On the other hand, Australia's existing complaint system shows that a well-functioning system can include a right to appeal. It allows both parties to seek for reconsideration and examination of decisions. Indeed, the Scheme maintains complete control of the process, ${ }^{689}$ but consumers and providers can get a second opinion. However, the pathways for review and appeal have been criticized as "bewildering to anyone who is not well versed in interpreting and understanding Commonwealth legislative instruments." 690 A general right to appeal would therefore contradict the main aim to simplify the existing complaint system. For this reason, New Zealand should not fully adopt Australia's way. However, there are single cases in which

\footnotetext{
${ }^{682}$ At 131; under the Accident Compensation Act 2001 the parties have a right to appeal. See Accident Compensation Act 2001, pt 5.

${ }^{683}$ Manning, above $\mathrm{n}$ 504, at 131.

${ }^{684}$ See for details Skegg, above n 328, at $249-252$.

${ }^{685}$ Health and Disability Commissioner Act 1994, title.

${ }^{686}$ Skegg, above n 328, at 258.

${ }^{687}$ At 258.

${ }^{688}$ Manning, above n 504, at 132.

${ }^{689}$ Lewis, above n 346.

${ }^{690}$ Lewis, above n 346.
} 
it seems to be harsh that neither party have a right to appeal. This refers in particular to serious cases with potentially major breaches of the Code of Rights, for example when a consumer died or in case of sexual allegations. It is unlikely that the parties take the Commissioner's decision in these cases with equanimity. ${ }^{691}$ Especially in the light of normal legal proceedings, which can go through several instances, even in cases in which less serious legal interests are involved, it is not appropriate that neither party can appeal. It should also be considered that the Commissioner's investigations are often less fair judicial proceedings, because consumers can very rarely put their case in person to the Commissioner and the Commissioner's decision will often rely on evidence gathered by others. $^{692}$

For these reasons, the scheme should give the parties the right to appeal in certain cases. The Director could act as an independent authority for appeals that examines the Commissioner's decision and thereafter makes its own decision. The Director already deals with the most serious cases and has to review the entire case, if a matter is referred to the Director. Therefore, the Director is competent enough to deal with appeals. Furthermore, existing structures could be utilised and the intervention in the existing system would be comparatively small. The right to appeal should also be limited to serious cases. Obviously, this term is vague. To specify the term the new scheme could contain an enabling clause for the Minister of Health to define the cases in which an appeal is possible. This would ensure that further adaptations could be made quickly.

\section{f. Lessons from the Retirement Village Act 2003 (RVA)}

One essential element of consumers' access to justice is the ease with which consumers can enforce their rights. ${ }^{693}$ New Zealand provides several different options, for example the existing complaint scheme, the ACC and the Dispute Tribunals, to facilitate access to justice for elderly consumers.

Nonetheless, it could be useful to cast a glance at the regulations of the RVA. The RVA provides for two different types of dispute procedures, a complaints facility and dispute resolution. ${ }^{694}$ Every provider must have an internal facility for dealing with complaints by

\footnotetext{
${ }^{691}$ Manning, above n 504, at 131.

${ }^{692}$ Skegg, above n 328, at 247.

${ }^{693}$ Bevan, Dugan and Grainer, above n 106, at 1.1.

${ }^{694}$ Retirement Village Act 2003, s 50; see also Retirement Villages Code of Practice 2008, ss 32 to 36; for details see Burke and Greenwood, above n 306, at 53 to 63.
} 
consumers $^{695}$ and, if the complaint cannot be resolved within 20 working days, both parties can give the other party a dispute notice. ${ }^{696}$ This notice initiate a comprehensive dispute resolution process including the appointment of a disputes panel to resolve the dispute. ${ }^{697}$ Only in certain cases consumers can give a dispute notice, most importantly relating to an alleged breach of the Code of Residents' Rights or the Code of Practice. ${ }^{698}$ However, this dispute resolution process does not override other consumers' rights or the existing complaint scheme. Consumers are not entitled to give a dispute notice concerning any health or disability service. ${ }^{699}$ In other words, a dispute resolution is not possible if consumers can complain to the Commissioner. The disputes panel has, among others, ${ }^{700}$ the power to order a payment or refund, where the dispute involves liability for a payment. ${ }^{701}$ The panel's decision is binding for both parties and enforceable. ${ }^{702}$ The provider is responsible for the costs incurred by the disputes panel. ${ }^{703}$ Both parties have a right to appeal, ${ }^{704}$ but a further appeal after is not possible. ${ }^{705}$

At the first glance, it is difficult to find a reason why consumers in rest homes should not have the same entitlements. A similar dispute procedure could ensure that consumers in rest homes could complain about all problems that can occur in rest home and not only if they are concerned with the health and disability services. Furthermore, the existing protection of elderly consumers would be supported and it would be ensured that the aged consumer could use a complaint scheme to enforce their rights even if there is no breach of the Code of Rights or no personal injury. However, it has already been proposed ${ }^{706}$ to introduce a new scheme that allows elderly consumers to complain about all their concerns and about all services received. Therefore, there is no need for a disputes panel, which would further complicate the different options of consumers' access to justice.

\footnotetext{
${ }^{695}$ Retirement Village Act 2003, s 51.

696 Section 52.

${ }^{697}$ See for details Sections 58 and 59; Bevan, Dugan and Grainer, above n 106, at 13.16.

698 Section 53(1).

${ }^{699}$ Section 53(2).

700 Section 69.

${ }^{701}$ Section 69(1)(c).

702 Section 72.

${ }^{703}$ Section 74(1).

${ }^{704}$ Section 75(2).

${ }^{705}$ Section 75(6).

${ }^{706}$ See above page 111.
} 


\section{g. Remaining Communication Barriers}

A further area of concern is the limited communication between consumers and providers, especially in case of an adverse event. Although open disclosure of harm is accepted as the right thing to do, ${ }^{707}$ a professional duty for medical practitioners ${ }^{708}$ provides an environment that enables health practitioners to learn in an educational manner from openly discussed mistakes, ${ }^{709}$ a requirement of the Health and Disability Service Standards and a right of consumers under the Code of Rights, ${ }^{710}$ only the minority of health practitioners were likely to disclose a mistake or error. ${ }^{711}$ Indeed, in comparison to health practitioners in Germany (83\% of the patients were not told about the mistake) and Australia (70 \% were not told), New Zealand health practitioners were most likely to disclose a mistake (61 \% were not told). The higher numbers in Germany and Australia may be a result of the fear of litigation, which is a known barrier to open disclosure, ${ }^{712}$ whereas the lower number in New Zealand's no-fault environment seemed to be a factor for disclosure and discussion of mistakes. ${ }^{713}$ However, although New Zealand's health practitioners do not have to fear litigation, the number of practitioners who do not disclose a mistake is still high. This is because other reasons, for example complaints and disciplinary processes and loss of reputation, are also likely to be main barriers to open disclosure. ${ }^{714}$ As Malcolm and Barnett stress "disclosure may still be

\footnotetext{
${ }^{707}$ For hospital doctors see Farzad Soleimani "Learning from mistakes in New Zealand hospitals: what else do we need besides “no-fault”?” (2006) 119 NZMJ U2099.

${ }^{708}$ Medical Council of New Zealand “Disclosure of harm following an adverse event” (December 2010) Medical Council of New Zealand <www.mcnz.org.nz>.

709 At 1.

${ }^{710}$ Code of Health and Disability Services Consumers’ Rights 1996, rights 5(2) and 6(1); Ron Paterson and Marie van Wyk “Candour and the Code” (2002) 4 O \& G 100 at 100.

711 Cathy Schoen, Robin Osborn, Phuong Trang Huynh, Michelle Doty, Kinga Zapert, Jordon Peugh and Karen Davis “Taking The Pulse Of Health Care Systems: Experiences Of Patients With Health Problems In Six Countries” (2005) 24 Health Affairs 509 at 513 - 514.

712 Manning, above n 504, at 125; Rae M Lamb, David M Studdert, Richard M J Bohmer, Donald M Berwick, Troyen A Brennan “Hospital disclosure practices: Results of a national survey” (2003) 22 Health Affairs 73.

713 Schoen, Osborn, Huynh, Doty, Zapert, Peugh and Davis, above n 711, at 522; Laurence Malcolm and Pauline Barnett “Disclosure of treatment injury in New Zealand's no-fault compensation system” (2007) 31 Aust Health Rev 116 at 121; Peter Davis, Roy Lay-Yee, Julie Fitzjohn, Phil Hider, Robin Briant and Stephan Schug “Compensation for Medical Injury in New Zealand: Does “No-Fault” Increase the Level of Claims Making and Reduce Social and Clinical Selectivity?” (2002) 27 J Health Pol, Pol'y \& L 833 at 833 : "little evidence".

${ }^{714}$ Manning, above n 504, at 125.
} 
seen as leading to a highly professionally damaging complaints system." ${ }^{\text {,715 }}$ Moreover, although practitioners strongly support society's right to complain, they are often threatened by the complaints process, feel that the different disciplinary and complaints procedures provide "death by a thousand arrows"716 and they are by no means sure that current complaints system will improve the health system as a whole. ${ }^{717}$

The non-disclosure of adverse events is linked with further impacts. Generally, consumers often do not seek compensation, although they are entitled to do so, but many more may be unaware of their right, because without open disclosure they are not aware that they suffered an adverse event. ${ }^{718}$ Consequently, the ratio of successful claims to potentially compensatable events is still low. ${ }^{719}$ This is somewhat surprising, given the absence of financial and legal barriers. ${ }^{720}$

Although the previous research primarily refers to doctors and not to rest home providers, it can be assumed that the situation and the behaviour of rest home providers are similar, because the motivations and interests of providers are comparable with those of doctors. Providers also fear a loss of reputation, an unfair complaint process and disciplinary procedures. It is therefore to be expected that open disclosure of adverse events is not common practice in rest homes. This applies not only to possible compensation claims but generally to all cases in which providers do not perform their services adequately.

Some authors may state that it is not necessary to improve the communication between consumers and providers, because the existing system provides adequate incentives for providers to disclose their errors. They outline that open disclosure would reduce the risk that consumers seek redress and reduce the risk of consumer complaints. ${ }^{721}$ However, these assumptions are still unproven; ${ }^{722}$ the research on these issues is ambivalent. ${ }^{723}$

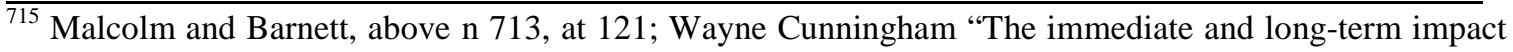
on New Zealand doctors who receive patient complaints” (2004) 117 NZMJ U972.

716 Wayne Cunningham “The medical complaints and disciplinary process in New Zealand: doctors' suggestions for change” (2004) 117 NZMJ U974.

${ }^{717}$ Wayne Cunningham "New Zealand doctors' attitudes towards the complaints and disciplinary process" (2004) 117 NZMJ U973.

${ }^{718}$ Bismark and Paterson, above n 573, at 281.

719 Davis, Lay-Yee, Fitzjohn, Hider, Briant and Schug, above n 713, at 834 and 850.

720 At 850.

721 Soleimani, above n 707; in contrast to this assumption David M Studdert, Michelle M Mello, Atul A Gawande, Troyen A Brennan and Y Claire Wang "Disclosure Of Medical Injury To Patients: An Improbable Risk Management Strategy” (2007) 26 Health Affairs 215 at 224.

${ }^{722}$ Manning, above n 504, at 126.
} 
Therefore, a link between open disclosure and advantages for providers cannot be established beyond all doubt. Furthermore, even if such a connection can be found, other barriers remain. Often providers fear not only medico-legal consequences, but also media exposure, a loss of reputation, the consequences of other consumers, and maybe guilt, shame and loss of self-esteem. ${ }^{724}$ Moreover, it is acknowledged that discussing mistakes with consumers is often stressful and difficult. ${ }^{725}$

To ensure effective communication, improvements would, therefore, have to aim to break down all barriers that prevent providers from disclosing a mistake. This aim cannot be achieved by stricter regulations. The existing regulations already set out several duties of disclosure for providers. Thus, to enhance the communication and open disclosure of mistakes a change regarding the perception of consequences is necessary. New Zealand has successfully shifted away from a blaming culture, but still the myth remains that New Zealand is one of the most hostile medico-legal environments. ${ }^{726}$ To change the providers' view it is essential to show them the benefits of an honest and open interaction with consumers. For example, in a complaint process the fact that the provider has freely disclosed the error and already apologised is a great advantage. ${ }^{727}$ It can encourage the Commissioner to take no further action or to resolve the complaint on a lower level, because the Commissioner acknowledges that (remedial) actions have already been taking lace. ${ }^{728}$

To overcome the existing biases the Commissioner, the District Health Boards and New Zealand's government could perform an awareness-raising campaign. On one hand, the campaign should address providers and explain the advantages of the current system and state that open disclosure would help to increase transparency, to review processes and to create a safer health environment. Moreover, the campaign should point out that a supportive culture already exists and providers can seek for professional support ${ }^{729}$ and, furthermore, state that many consumers do not seek compensation but only feel the need

\footnotetext{
${ }^{723}$ Malcolm and Barnett, above n 713, at 121.

${ }^{724}$ Manning, above n 504, at 126; Malcolm and Barnett, above n 713, at 121; Cunningham, above n 717; Soleimani, above $\mathrm{n} 707$.

${ }^{725}$ Medical Council of New Zealand, above n 708, at 3.

726 John Hickey "Summary Report and Accounts 2004” (May 2005) The Medical Protection Society <www.medicalprotection.org> at 9; for further arguments see Skegg, above n 328, at 259 - 262; Paterson and van Wyk, above n 710, at 36.

${ }^{727}$ Bismark and Dauer, above n 503, at 63.

${ }^{728}$ Manning, above n 504, at 126.

${ }^{729}$ For doctors see Medical Council of New Zealand, above n 708, at 3.
} 
to be heard. ${ }^{730}$ On the other hand, it should also include consumers and clarify that to err is human and errors occur as an inevitable consequence even in the best organisations. ${ }^{731}$ The reality of treatment is that there will always be mistakes, but blaming a single person will not help to improve the whole system or building in barriers and defences. ${ }^{732}$ Therefore, the campaign should highlight that the existing system is not about blaming individuals. Lastly, the campaign should also focus on educating consumers about their rights in a simple and understandable way. ${ }^{733}$ It should explain to consumers that the system is cheap with little financial and legal barriers and that their claims can help to improve the health system as a whole. Furthermore, the campaign should explain the new complaint scheme and inform consumers about the new Commissioner for rest home care. This programme could be supported by the Office for Senior Citizens ${ }^{734}$ that investigates the outcomes of the new complaint scheme.

Overall, it can be said that improving the communication skills of providers and explaining the advantages of the existing system to both parties will be the key to take down the existing barriers and will close the gap between theory and practice. ${ }^{735}$

\section{Summary}

The existing regulations in New Zealand offer some advantages for consumers in rest homes. Consumers can pursue their different interests in most cases in a speedy, less costly and not blame-orientated manner. For elderly consumers it is particularly advantageous that they can enforce their rights without the help of lawyers and that their claims are often resolved within weeks or months. Therefore, in terms of consumer protection New Zealand's system is largely a fortunate experiment.

However, the existing system is far from perfect and there is still a long way to go to fully achieve all targets. Although many barriers of consumers' access to justice have been

\footnotetext{
${ }^{730}$ See above page 90.

${ }^{731}$ Linda T Kohn, Janet M Carrigan and Molla S Donaldson To Err is Human: Building a Safer Health System (National Academy Press, Washington, 2000); Manning, above n 504, at 127.

${ }^{732}$ Manning, above n 504, at 136.

${ }^{733}$ Similarly Eric M Carlson “Negotiating for Resident-Centered Care” (2008-2009) 10 Marq Elder’s Advisor 21 at 52.

${ }^{734}$ For details about the Office for Senior Citizens, which is an office within the within the Ministry of Social Development see www.osc.govt.nz.

${ }^{735}$ Similarly Malcolm and Barnett, above n 713, at 121; Manning, above n 504, at 127.
} 
removed, the complaint and claim rates are still low. ${ }^{736}$ To take down the remaining barriers and to improve the access to justice for elderly consumers in rest homes, several - minor and major - changes are necessary: New Zealand should establish a Commissioner who deals with rest home related complaints and concerns, and introduce a new complaint scheme for rest home related issues, which is based on the existing complaint scheme. Furthermore, the complaint process should be streamlined and a limited right to appeal should be introduced. All of these changes should be part of a new Act that is specifically targeted at elderly consumers in rest homes. ${ }^{737}$ Lastly, an awareness-raising campaign should be undertaken by the new commissioner to promote the communication between the parties and the open disclosure of mistakes.

\footnotetext{
$\overline{736}$ Armstrong and Tess, above n 652, at 11 state that this is perhaps because consumers who suffered a treatment injury receive additional treatments often free-of-charge and, thus, see no need to file a claim. ${ }^{737}$ See below page 123.
} 


\section{Implementation of the Different Measures}

The previous chapters have shown that the protection of elderly consumers in rest homes is imperfect at best and only partially existent at worst. There is a lack of a co-ordinated approach that covers all major aspects of rest home care. ${ }^{738}$ However, so far, the question of how to implement the proposed measures to improve the legal position of elderly consumers has been largely excluded from discussion. This is now addressed.

To improve the protection of aged consumers in rest homes two fundamentally different options come into consideration. On one hand, the existing measures to protect consumers could be reformed and tailored specifically for elderly consumers. This would require several amendments to existing legislation. On the other hand, New Zealand could introduce a new piece of legislation that focuses on elderly consumers in rest homes alone. This statute could refer to existing legislation but could also introduce new measures where necessary and appropriate.

The first option faces serious problems, because it would be difficult to incorporate the changes into the existing system consistently. For example, the proposed introduction of a new complaint scheme ${ }^{739}$ and tailored information obligations ${ }^{740}$ would require profound changes of the HDCA and the Health and Disability Services (Safety) Act 2001. Such far-reaching changes entail the risk that the existing system would be substantially affected. Furthermore, this option would be no more than a patchwork solution that would complicate the existing system rather than developing comprehensive protection. The second option, however, could more appropriately deal with the unique issues and needs of elderly consumers in rest homes. It could thoughtfully address the delicate problems and the different needs of aged consumers and could be part of a whole strategy to improve their protection. Furthermore, a new piece of legislation would have the advantage that New Zealand could respond to changes in the future more quickly.

For this reason, New Zealand should develop a long term strategy and implement this strategy through a new Act, which ensures that elderly consumers in rest homes receive the best protection possible. The Education (Early Childhood Services) Regulations 2008, the CCA, the RVA and the complementary Code of Practice show that it is not alien to New Zealand to establish a piece of legislation for a specific consumer group. In the present case, some parts of each of the existing Acts could serve as a model to establish a

\footnotetext{
${ }_{738}$ Similarly for Australia Barnett and Hayes, above n 14, at 76.

${ }^{739}$ See above page 110 .

${ }^{740}$ See above page 54.
} 
specific piece of legislation. ${ }^{741}$ The existing regulations show that it is possible to enhance the protection of a single consumer group without changing the existing system completely. The new statute could take a similar approach. It could build on the existing consumer protection measures but also improve them and introduce new measures to tackle the issues of elderly consumers. For example, the new Act should establish a new Commissioner and contain an independent complaint procedure. ${ }^{742}$ In accordance with the CCA the new piece of legislation should grant the Commissioner several rights to strengthen the legal position of elderly consumers in general. This is especially important in cases in which consumers are not capable of initiating any kind of process to enforce their rights. Therefore, the new Commissioner should act as an advocate for elderly people's interests, rights, and welfare generally ${ }^{743}$ with the power to put protective measures such as minimum standards and staff ratios in place. Similarly to the RVA and the complementary Code of Practice the new piece of legislation should describe the rights of the elderly consumers. It could use the existing Code of Rights as a basis and refer to it but also state further rights, which are specifically tailored for elderly consumers in rest homes. This applies in particular to the proposed new information obligations, ${ }^{744}$ cancellation rights, ${ }^{745}$ the cooling-off period ${ }^{746}$ and the providers' obligations after contract termination. ${ }^{747}$

However, not all of the protection measures should be laid down in the new piece of legislation. It would be impractical and inflexible to regulate every detail of the proposed information sheets ${ }^{748}$ in the legislation, because conditions and requirements are likely to change over time. To preserve flexibility the statute should not only contain general baselines of the information sheets but also have an enabling clause that allows the Ministry of Health to regulate the details of the content. Section 13 of the Health and Disability Services (Safety) Act 2001 and s 89 of the RVA could serve as examples. To ensure that the interests of elderly consumers are sufficiently taken into account participation by the new Commissioner should be included.

\footnotetext{
$\overline{{ }^{741} \text { However, the Retirement Village Act } 2003 \text { and the Retirement Village Code of Practice } 2008 \text { are not a }}$ perfect approach. See for details Retirement Commissioner, above n 74 .

${ }^{742}$ See above page 110.

${ }^{743}$ See Children's Commissioner Act 2003, s 12(1)(f).

${ }^{744}$ See above page 54.

${ }^{745}$ See above page 72 .

${ }^{746}$ See above page 87.

${ }^{747}$ See above page 81.

${ }^{748}$ See above page 56 and 57.
} 
In order to ensure comprehensive protection of aged consumers in rest homes, the new Act should also pave the way for a comprehensive code of practice. The code of practice could set out minimum requirements that providers of rest homes must carry out to fulfil their duties under the new Act. It could also give providers advice so that they will better know how to respect the consumers' rights. In other words, the code of practice would put the more abstract new statute in concrete terms and implement some of the proposed changes.

The introduction of a new statute specifically for rest homes would not make other legislation in favour of consumers superfluous. For example, the CGA and the Code of Rights will also support the legal position of aged consumers in rest homes. The new legislation and the code of practice will only ensure that elderly consumers in rest homes have a stronger legal position and would better coordinate the different protection measures.

Overall, New Zealand should develop and introduce a specific piece of legislation for rest home care to ensure a comprehensive and more targeted protection of aged consumers; one of the most vulnerable consumer groups. 


\section{Conclusion}

The population of people who are 65 years and older will increase dramatically over the next decades. This will lead, on one hand, to a greater demand for rest home care services and, on the other hand, to a greater demand for appropriate regulation of this area of law. Several horror stories about inadequate care, neglect and abuse indicate that the current system does not ensure comprehensive protection of elderly consumers. This is unfortunate, because elderly consumers have special vulnerabilities and can suffer various detriments at the time of signing, implementation and termination of a rest home contract. $^{749}$ It is therefore essential to have comprehensive legal protection to strengthen the legal position of this consumer group. ${ }^{750}$

However, currently no legislation exists that is specifically tailored for aged consumers in rest homes. ${ }^{751}$ Measures to protect rest home consumers are spread over a number of different acts and their regulations often apply to health and disability services in general $^{752}$ or even to all different kind of service provision. ${ }^{753}$ Therefore, the existing measures are often inappropriate to ensure full protection of elderly consumers. Furthermore, the existing approach has some gaps and misses out necessary measures to guarantee the best protection possible.

To place the protection of aged consumers in rest homes on a new footing is, therefore, essential in order to strengthen the legal position of elderly consumers. New Zealand should develop a long term strategy that includes introducing a new Act that establishes a new Commissioner who protects consumers in rest homes and that contains all the different measure specifically tailored for aged consumers. In addition, a code of practice should set out detailed minimum requirements for providers in order to safeguard the practiced implementation of the legislation.

\footnotetext{
${ }^{749}$ See above page 12.

${ }^{750}$ See above page 26.

${ }^{751}$ See above page 27.

${ }^{752}$ See for example Code of Health and Disability Services Consumers’ Rights 1996.

${ }^{753}$ For example Consumer Guarantees Act 1993, s 28.
} 


\section{$X$ Bibliography}

\section{A Cases}

1 New Zealand

A v Bottrill [2003] 2 NZLR 721.

Accident Compensation Corporation (ACC) v Ambros [2007] NZCA 304, [2008] 1 NZLR 340.

Ambros v Accident Compensation Corporation HC Auckland CIV 2004-404-3261, 21 March 2005.

Cooper v Ashley \& Johnson Motors Ltd (1997) 6 NZBLC 102, 108, (1996) 7 TCLR 407, [1997] DCR 170.

Atkinson v Accident Rehabilitation Compensation and Insurance Corporation [2002] 1 NZLR 374.

Campuzano v Western Bay Dental Care Ltd [2011] NZERA Auckland 198.

Curtis v RS Construction Ltd [2013] NZERA Auckland 139.

Cooper v Accident Compensation Corporation HC Dunedin AP 9/02, 13 September 2002.

Couch v Attorney-General (No 2) [2010] 3 NZLR 149 (SC).

Director of Proceedings under the Health and Disability Commissioner Act $1994 \mathrm{v}$ Norfolk Court Rest Home Limited [2011] NZHRRT 12 (12 May 2011).

Director of Proceedings under the Health and Disability Commissioner Act $1994 \mathrm{v}$ Norfolk Court Rest Home Limited [2011] NZHRRT 13 (12 May 2011).

Director of Proceedings v Emms [2013] NZHRRT 5 (16 November 2012).

Director of Proceedings v O'Neil [2001] NZAR 59 (HC).

Donselaar v Donselaar [1982] 1 NZLR 97 (CA).

Green v Matheson [1989] 3 NZLR 564 (CA).

Health and Disability Commissioner Decision 03HDC14692 (14 October 2005).

Health and Disability Commissioner Decision 06HDC06457 (20 August 2009).

Health and Disability Commissioner Decision 08HDC20957 (3 November 2010).

Health and Disability Commissioner Decision 09HDC01641 (21 June 2012).

Health and Disability Commissioner Decision 09HDC01783 (28 March 2011).

Health and Disability Commissioner Decision 09HDC01974 (21 June 2012). 
Health and Disability Commissioner Decision 09HDC02110 (2 March 2012).

Health and Disability Commissioner Decision 09HDC02159 (27 January 2012).

Health and Disability Commissioner Decision 10HDC00308 (29 June 2012).

Health and Disability Commissioner Decision 10HDC01231 (23 April 2013).

Marks v Director of Health and Disability Proceedings [2009] 3 NZLR 108 (CA).

McLaren Maycroft \& Co Ltd v Fletcher Development Ltd [1973] 2 NZLR 100 (CA).

Queenstown Lakes District Council v Palmer [1999] 1 NZLR 549.

Smith v Auckland Hospital Board [1964] NZLR 241.

Sulco Limited v E S Redit and Company Limited and Another [1959] NZLR 45 (SC).

Wilding v Attorney-General [2003] 3 NZLR 787 (CA).

\section{Australia}

Bryan v Maloney (1995) 182 CLR 609 (HCA).

Cattanach v Melchior (2003) 215 CLR 1 (HCA).

Chapman v Hearse (1961) 106 CLR 112 (HCA).

Donoghue v Stevenson [1932] AC 562 (HL).

Jaensch v Coffey (1984) 155 CLR 549 (HCA).

Rogers $v$ Whitaker (1992) 175 CLR 479 (HCA).

Scarcella v Lettice (2000) 51 NSWLR 302 (NSWCA).

Skelton v Collins (1966) 115 CLR 94 (HCA).

\section{United Kingdom}

Le Lievre v Gould [1893] 1 QB 491 at 497.

Lister v Hesley Hall Ltd [2002] 1 AC 215.

Livingstone v Rawyards Coal Co (1880) 5 App Cas 25 (HL).

Morrow v Safeway Stores Plc [2001] WL 1135069 (Employment Appeal Tribunal).

\section{Europe}

Case 178/84 Commission v Germany [1987] ECR 1227.

Case C-210/96 Gut Springenheide GmbH and Rudolf Tusky v Oberkreisdirektor des Kreises Steinfurt - Amt für Lebensmittelüberwachung [1998] ECR I-4657. 
Case C-362/88 GB-INNO-BM v Confédération du commerce luxembourgeois [1990] ECR I-667.

\section{Germany}

Federal Supreme Court (of Germany) [2001] III ZR 14/01, 8 November 2001, (2002) 55 NJW 507.

Federal Supreme Court (of Germany) [2004] III ZR 205/03, 28 October 2004, (2005) 58 NJW 147.

Federal Supreme Court (of Germany), [2004] III ZR 399/04, 28 April 2005, (2005) 58 NJW 1937.

Federal Supreme Court (of Germany) [2005] VIII ZR 347/04, 20 July 2005, (2005) 58 NJW 2773.

Higher Regional Court München [2008] 20 U 3322/08, 12 November 2008, (2009) 13 PflR 142.

Higher Regional Court Naumburg [2003] 1 U 97/03, 14 September 2004, (2005) 23 MedR 232.

\section{B Legislation}

1 New Zealand

Accident Compensation Act 2001.

Auditor Regulation Act 2011.

Children’s Commissioner Act 2003.

Code of Health and Disability Services Consumers’ Rights 1996.

Consumer Guarantees Act 1993.

Consumer Law Reform Bill 2011.

Contractual Remedies Act 1979.

Disputes Tribunals Act 1988.

Education (Early Childhood Services) Regulations 2008.

Health Practitioners Competence Assurance Act 2003.

Health and Disability Commissioner Act 1994.

Health and Disability Commissioner Amendment Act 2003.

Health and Disability Services (Core) Standards 2008. 
Health and Disability Services (General) Standard 2008.

Health and Disability Services (Safety) Act 2001.

Injury Prevention, Rehabilitation and Compensation Amendment Act (No 2) 2005.

New Zealand Bill of Rights Act 1990.

New Zealand Public Health and Disability Act 2000.

Retirement Village Act 2003.

Retirement Villages Code of Practice 2008.

Social Security Act 1964.

\section{Australia}

Aged Care Act 1997 (Cth).

Aged Care (Consequential Provisions) Act 1997 (Cth).

Allocation Principles 1997 (Cth).

Approval of Care Recipients Principles 1997 (Cth).

Charter of Residents’ Rights and Responsibilities (Cth).

Civil Law (Wrongs) Act 2002 (ACT).

Civil Liability Act 2002 (NSW).

Civil Liability Act 2003 (Old).

Civil Liability Act 1936 (SA).

Civil Liability Act 2002 (Tas).

Civil Liability Act 2002 (WA).

Classification Principles 1997 (Cth).

Competition and Consumer Act 2010 (Cth).

Complaint Principles 2011 (Cth).

Complaint Principles 2011 - explanatory statement (Cth).

Information Principles 1997 (Cth).

Quality of Care Principles 1997 (Cth).

Residential Care Manual 2009 (Cth).

Residential Care Subsidy Principles 1997 (Cth).

Residential Services (Accommodation) Act 2002 (Qld).

User Rights Principles 1997 (Cth). 
Wrongs Act 1958 (Vic).

\section{Europe}

Bürgerliches Gesetzbuch 2002 (Germany).

Drucksachen des Deutschen Bundestages "Gesetzentwurf eines Gesetzes zur Neuregelung der zivilrechtlichen Vorschriften des Heimgesetzes nach der Föderalismusreform“ (24 March 2009) BT-Dr 16/12409 (translation: Bill of a Revision of the Civil Law Rules of the Amended Nursing Home Act (HeimG) after the Reform of the Federal System).

Drucksachen des Deutschen Bundestages “Entwurf eines Gesetzes zur Absicherung des Risikos der Pflegebedürftigkeit“ (24 June 1993) BT-Dr 12/5262 (translation: Bill of a Law Against the Risk of Requiring Long-Term Nursing Care).

Niedersächsisches Heimgesetz (NHeimG).

Sozialgesetzbuch V 1988 (Germany).

Sozialgesetzbuch XI 1994 (Germany).

Sozialgesetzbuch XII 2003(Germany).

Zivilprozessordnung 2005 (Germany).

Wohn- und Betreuungsvertragsgesetz 2009 (Germany).

\section{Books and Chapters in Books}

Bill Atkin, and Geoff McLay Torts in New Zealand: Cases and Materials (5th ed, Oxford University Press, Oxford, 2012).

R P Balkin and J L R Davis Law of Torts (4th ed, LexisNexis, Chatswood, 2009).

Bill Bevan, Bob Dugan, Virginia Grainer Consumer Law (LexisNexis NZ, Wellington, 2009).

Petra Butler Medical Misadventure im neuseeländischen Accident Compensation Scheme (Peter Lang, Frankfurt am Main, 1999) (translation: Medical Misadventure in New Zealand's Accident Compensation Scheme).

Michelle Burke and John Greenwood Retirement Villages - the full impact of the Act (New Zealand Law Society, 2007).

Ian B Campell Compensation for personal injury in New Zealand (Auckland University Press, Auckland, 1996).

Stephen G Corones The Australian Consumer Law (ThomsonReuters, Sydney, 2011). 
Gerhard Dalichau Pflegeversicherung, Kommentar und Rechtssammlung (looseleaf ed, Luchterhand) (translation: Nursing Care Insurance, Commentary and Collection of Laws).

Horst Eidenmüller Effizienz als Rechtsprinzip (Mohr Siebeck, Tübingen, 2005) (translation: Efficiency as an Essential Principle of Law).

Stephen Goldberg, Eric Green and Frank Sander Dispute Resolution (Little Brown, Boston, 1985).

John Goldring, Laurence W Maher and Jill McKeough Consumer Protection Law (4th ed, The Federation Press, Sydney, 1993).

John Greenwood and Simon Marks Retirement Villages (New Zealand Law Society, 2004).

Stefan Grundmann and Wolfgang Kerber "Information Intermediaries and Party Autonomy - The Example of Securities and Insurance Markets” in Stefan Grundmann, Wolfgang Kerber and Stephen Weatherill Party Autonomy and the Role of Information in the Internal Market (De Gruyter, Berlin, 2001).

Brian W Harvey and Deborah L Parry The Law of Consumer Protection and Fair Trading (6th ed, Butterworths, London, 2000).

Eike von Hippel Verbraucherschutz (3rd ed, Mohr, Tübingen, 1986) (translation: Consumer Protection).

Rainer Kemper Verbraucherschutzinstrumente (Nomos, Baden-Baden, 1994) (translation: Consumer Protection Measures).

Sandra Kind Die Grenzen des Verbraucherschutzes durch Information (Duncker \& Humblot, Berlin, 1998) (translation: The Limits of Consumer Protection by Information).

Linda T Kohn, Janet M Carrigan and Molla S Donaldson To Err is Human: Building a Safer Health System (National Academy Press, Washington, 2000).

Frederik Martell Der Schutz des Verbrauchers im Heimrecht (Dr. Kovač, Hamburg, 2012) (translation: The Protection of the Consumer in the Area of Law Governing Homes for the Elderly).

Organisation for Economic Co-operation and Development Ageing, Housing and Urban Development (OECD, 2003).

Robert Prichard Liability and Compensation in Health Care (University of Toronto Press, Toronto, 1990).

Iain Ramsay Consumer Protection (Weidenfeld and Nicholson, London, 1989). 
Markus Rehberg Der Versicherungsabschluss als Informationsproblem (Nomos Verlag, Baden-Baden, 2003) (translation: The Conclusion of an Insurance Contract as a Problem of Information).

Mark Daniel Schweizer Kognitive Täuschungen vor Gericht (Dissertation, Zürich, 2005) (translation: Cognitive Illusions before a Court).

Colin Scott and Julia Black Cranston's Consumers and the Law (3rd ed, Butterworths, London, 2000).

Herbert Simon Models of man (Wiley, New York, 1957).

Frank A Sloan, Penny B Githens, Ellen Wright Clayton, Gerald B Hickson, Douglas A Gentile and David F Partlett Suing for Medical Malpractice (University Of Chicago Press, Chicago, 1993).

Pam Stewart and Anita Stuhmcke Australian Principles of Tort Law (3rd, The Federation Press, Sydney, 2012).

Stephen Todd “Accident Compensation and the Common Law" in Stephen Todd (ed) The Law of Torts in New Zealand (6th ed, Thomson Reuters, Wellington, 2013).

Kate Tokeley Consumer Law in New Zealand (Butterworths, Wellington, 2000).

Standards New Zealand New Zealand Handbook: Indicators for Safe Aged-care and Dementia-care for Consumers (NZ Standards Council, Wellington, 2005).

Stephen Walmsley, Alister Abadee and Ben Zipser Professional Liability in Australia (2nd ed, Lawbook Co, Sydney, 2007).

Chris Willett “Autonomy and Fairness: The Case of Public Statements” in Geraint G Howells, Andre Janssen and Reiner Schulze (ed) Information Rights and Obligations - A Challenge for Party Autonomy and Transactional Fairness (Ashgate, Aldershot, 2005).

\section{Commentaries}

Otto Dahlem, Dieter Giese and Gerhard Igl Heimrecht des Bundes und der Länder (looseleaf ed, Wolters Kluwer) (translation: The Federal and State Law Governing Homes for the Elderly).

Wolfgang Gitter, Jochem Schmitt and Irmgard Küfner-Schmitt (ed) WBVG - Heimrecht des Bundes und der Länder (looseleaf ed, Luchterhand) (translation: WBVG - The Federal and State Law Governing Homes for the Elderly).

Sascha Iffland and Markus Düncher Kommentar zum Wohn- und Betreuungsvertragsgesetz (Vincentz, Hannover, 2011) (translation: Commentary on the Residential Care Contract Law). 
Edna Rasch Kommentar zum Wohn- und Betreuungsvertragsgesetz (Lambertus , Berlin, 2012) (translation: Commentary on the German Residential Care Contract Law).

Walter Weidenkaff in Otto Palandt Kommentar zum Bürgerliches Gesetzbuch (71 ed, CH Beck, München, 2012) (translation: Commentary on the German Civil Code.)

\section{E Journal Articles}

Sharon Andrews-Hall, Anna Howe and Andrew Robinson "The dynamics of residential aged care in Australia: 8-year trends in admission, separations and dependency" (2007) 31 Australian Health Review 611.

Rabeea Assy "Can the Law Speak Directly to its Subjects? The Limitation of Plain Language” (2011) 38 Brit J Law \& Soc 376.

Alan Baddeley “The Magical Number Seven: Still Magic After All These Years?” (1994) 101 Psychological Rev 353.

Derek E Bambauer "Shopping Badly: Cognitive Biases, Communications, and the Fallacy of the Marketplace of Ideas” (2006) 77 U Colo L Rev 649.

Jeffrey Barnes "When 'Plain Language' legislation is Ambiguous - Sources of Doubt and Lessons for the Plain Language Movement” (2010) 34 Melb U L Rev 671.

Michael Barnett and Robert Hayes "Not seen and not heard: Protecting elder human rights in aged care” (2010) 14 UWSLR 45.

Linda Bauld, John Chesterman and Ken Judge "Measuring satisfaction with social care amongst older service users: issues from the literature" (2000) 8 Health Soc Care Community 316.

David Bawden, Clive Holtham and Nigel Courtney "Perspectives on information overload” (1999) 51 Aslib Proceedings 249.

Howard Beales, Richard Craswell and Steven C Salop "The Efficient Regulation of Consumer Information” (1981) 24 J L Econ 491.

Marie M Bismark "Compensation and complaints in New Zealand” (2006) 332 BMJ 1095.

Marie Bismark and Edward A Dauer "Motivation for Medico-Legal Action - Lessons from New Zealand” (2006) 27 J Leg Med 55.

Marie Bismark, Edward Dauer, Ron Paterson and David Studdert "Accountability sought by patients following adverse events from medical care: the New Zealand experience" (2006) 175 CMAJ 889. 
Marie Magdaleen Bismark, Troyen A Brennan, David M Studdert, Ronald J Paterson and Peter B Davis "Relationship between complaints and quality of care in New Zealand: a descriptive analysis of complaints and non-complaints following adverse events” (2006) 15 QSHC 17.

Marie Bismark and Ron Paterson "No-Fault Compensation In New Zealand: Harmonizing Injury Compensation, Provider Accountability, And Patient Safety” (2006) 25 Health Affairs 278.

Julia Black "Decentring Regulation: Understanding the Role and Regulation and SelfRegulation in a 'Post-Regulatory’ World” (2001) 54 CLP 103.

Randall R Bovbjerg, Frank A Sloan and Peter J Rankin “Administrative Performance of 'No-Fault' Compensation for Medical Injury” (1997) 60 Law and Contemp Probs 71.

Wendy Brandon “Complaints Against Medical Practitioners” [2001] NZLJ 249.

Petra Butler “A Brief Introduction to Medical Misadventure” (2004) 35 VUWLR 811.

Eric M Carlson “Negotiating for Resident-Centered Care” (2008-2009) 10 Marq Elder’s Advisor 21.

Michael Calnan, Stephen Almond and Nick Smith "Ageing and public satisfaction with the health service: an analysis of recent trends” (2003) 57 Soc Sci Med 757.

James Cockayne "Roger v Whitaker: still crazy after all these years?” (2007) 36 HIMJ 30.

Jules L Coleman “The Rational Choice Approach to Legal Rules” (1989) 65 Chi L Kent Rev 177.

Wayne Cunningham "New Zealand doctors' attitudes towards the complaints and disciplinary process” (2004) 117 NZMJ U973.

Wayne Cunningham "The immediate and long-term impact on New Zealand doctors who receive patient complaints” (2004) 117 NZMJ U972.

Wayne Cunningham "The medical complaints and disciplinary process in New Zealand: doctors' suggestions for change” (2004) 117 NZMJ U974.

Synneve Dahlin-Ivanoff, Gunilla Gosman-Hedström, Anna-Karin Edberg, Katarina Wilhelmson, Kajsa Eklund, Anna Duner, Lena Ziden, Anna-Karin Welmer and Sten Landahl "Elderly persons in the risk zone. Design of a multidimensional, healthpromoting, randomised three-armed controlled trial for "prefrail" people of $80+$ years living at home” (2010) 10 BMC Geriatr 27.

Edward A Dauer and Leonard J Marcus “Adapting Mediation to Link Resolution of Medical Malpractice Disputes with Health Care Quality Improvement" (1997) 60 Law and Contemp Probs 185. 
Peter Davis, Roy Lay-Yee, Julie Fitzjohn, Phil Hider, Robin Briant and Stephan Schug "Compensation for Medical Injury in New Zealand: Does "No-Fault” Increase the Level of Claims Making and Reduce Social and Clinical Selectivity?” (2002) 27 J Health Pol, Pol'y \& L 833.

Israel Doron, Iddo Gal, Maya Shavit and Pnina Weisberg-Yosub "Unheard voices: complaint patterns of older persons in the health care system” (2011) 8 Eur J Ageing 63.

Thomas A Durkin “Credit Card Disclosures, Solicitations, and Privacy Notices: Survey Results of Consumer Knowledge and Behavior” (2006) 92 Fed Res Bull 355.

Cowan Ertine "Consumer Redress for Misleading and Aggressive Practices” (2011) 15 EdinLR 448.

Phil Evans “Accessing Consumer Detriment” (2007) 28 ECLR 26.

Colleen M Flood and Kathryn May “A patient charter of rights: how to avoid a toothless tiger and achieve system improvement” (2012) 185 CMAJ 1583.

Audrey S Garfield “Elder Abuse and the States’ Adult Protective Service Response: Time for a Change in California” (1990-1991) 42 Hastings LJ 859.

Charles J Goetz and Robert E Scott "Enforcing Promises: An Examination of the Basis of Contract” (1980) 89 Yale L J 1261.

Ingrid Gottschalk and Iris Schneider “The Intelligibility of Supplier Information” (1983) 6 JcP 161.

Natalie Gray "Reforming the relationship between medicine and the law of tort" (2004) 11 JLM 324.

Barbara Grunewald “Aufklärungspflichten ohne Grenzen?” (1990) 190 AcP 609 (translation: Duty to Give Information without Borders?).

Gillian K Hadfield, Robert Howse und Michael J Trebilcock “Information-Based Principles for Rethinking Consumer Protection Policy” (1998) 21 JCP 131.

Stefan Haupt “An Economic Analysis of Consumer Protection in Contract Law” (2003) 4 German L J 1137.

Kathryn Hensiak “Abuse in Nursing Homes: Consumers Are Being Left in The Dark” (2002-2003) 4 Elder’s Advisor 73.

Geraint Howells “The Potential and Limits of Consumer Empowerment by Information” (2005) 32 BritJ Law \& Soc 349.

Geraint Howells and Christian Twigg-Flesner "What sort of Europe do consumers want" (2005) 15 CPR 169. 
Rossella Incardona and Cristina Poncibò "The average consumer, the unfair commercial practices directive, and the cognitive revolution” (2007) 30 JCP 21.

Jacob Jacoby “Perspectives on information overload” (1984) 10 J Consum Res 432.

Christine Jolls, Cass R. Sunstein and Richard Thaler “A Behavioral Approach to Law and Economics” (1998) 50 Stan L Rev 1471.

Daniel Kahnemann and Amos Tversky “Choices, Values, and Frames” (1984) 39 Am Psychologist 341.

Daniel Kahnemann and Amos Tversky "Prospect Theory: An Analysis of Decision und Risk” (1979) 47 Econometrica 263.

Emmett B Keeler, Robert L Kane and David H Solomon "Short- and Long-Term Residents of Nursing Homes” (1981) 19 Medical Care 363.

Duncan Kennedy "Distributive and paternalist motives in contract and tort law, with special reference to compulsory terms and unequal bargaining power” (1982) $41 \mathrm{Md} \mathrm{L}$ Rev 563.

Johannes Köndgen “Grund und Grenzen des Transparenzgebots im AGB-Recht“ (1994) 42 NJW 943 (translation: Reason and Limitations of the Requirements of Transparency in Law on the General Terms of Business).

Lewis A Kornhauser “On Justifying Cost-benefit Analysis” (2000) 29 JLS 1037.

Russell Korobkin "Bounded Rationality, Standard Form Contracts, and Unconscionability” (2003) 70 U Chi L Rev 1203.

Mary Ann Kupeli "Tort Law = No Fault Compensation: An Unrealistic Elixir to the Medical Malpractice Ailment” (1995-1996) 19 Suffolk Transnational L Rev 559.

Rae M Lamb, David M Studdert, Richard M J Bohmer, Donald M Berwick, Troyen A Brennan "Hospital disclosure practices: Results of a national survey” (2003) 22 Health Affairs 73.

Ann G Lawthers, A Russell Localio, Nan M Laird, Stuart Lipsitz, Liesi Hebert, Troyen A Brennan "Physicians' Perceptions of the Risk of Being Sued” (1992) 17 J Health Pol, Pol'y \& L 463.

Leib Leventhal “The role of understanding customer expectations in aged care” (2006) 21 IJHCQA 50.

George Loewenstein “Out of Control: Visceral Influences on Behavior” (1996) 65 Organizational Behavior and Human Decision Processes 272.

Charles G Lord, Lee Ross and Mark R Lepper "Biased Assimilation and Attitude Polarization: The Effects of Prior Theories on Subsequently Considered Evidence” (1979) 37 J of Personality and Social Psychology 2098. 
Nicolas L’Heureux “Effective Consumer Access to Justice: Class Actions” (1992) 15 JCP 445.

Laurence Malcolm and Pauline Barnett “Disclosure of treatment injury in New Zealand's no-fault compensation system” (2007) 31 Aust Health Rev 116.

Joanna Manning “Informed Consent to Medical Treatment: The Common Law and New Zealand’s Code of Patients’ Rights” (2004) 12 Med L Rev 181.

Joanna Manning “New Zealand's remedial response to adverse events in healthcare” (2008) 16 TLJ 120.

Sandra McCullough "Aged Care - A Victorian perspective on complaints handling and the enforcement of consumer rights” (2002) 27 Alternative LJ 57.

Dragan Miljkovic "Rational choice and irrational individuals or simply an irrational theory: A critical review of the hypothesis of perfect rationality” (2005) 34 J Socio-Econ 621.

George A Miller “The Magical Number Seven, Plus or Minus Two: Some Limits on Our Capacity for Processing Information” (1956) 63 Psychological Rev 81.

Vincent Mor, Victoria Wilcox, William Rakowski, and Jeffrey Hiris "Functional Transitions among the Elderly: Patterns, Predictors, and Related Hospital Use” (1994) 84 Am J Public Health 1274.

Phillip Nelson “Advertising as Information” (1974) 82 J Pol Econ 729.

Phillip Nelson “Information and Consumer Behaviour” (1970) 78 J Pol Econ 311.

Ken Oliphant "Beyond Misadventure: Compensation for Medical Injuries in New Zealand” (2007) 15 Med L Rev 357.

Clodagh O’Dwyer and Desmond O’Neill “Developing Strategies for the Prevention, Detection and Management of Elder Abuse: The Irish Experience” (2008) $20 \mathrm{~J}$ Elder Abuse \& Neglect 169.

Paul O'Shea and Charles Rickett “In Defence of Consumer Law: The Resolution of Consumer Disputes” (2006) 28 Sydney L Rev 139.

Ellie Palmer "Current Developments - Residential care: rights of the elderly and the Contracts (Right of Third Parties) Act 1999” (2000) 22 J Soc Wel \& Fam L 461.

Ron Paterson “Complaints and quality: handle with care!” (2004) 117 NZMJ 970.

Ron Paterson “Protecting Patients’ Rights in New Zealand” (2005) 24 Med Law 51.

Ron Paterson “The Health and Disability Commissioner” [2001] NZLJ 224.

Ron Paterson “The Patients' Complaints System in New Zealand” (2002) 21 Health Affairs 70. 
Ron Paterson and Marie van Wyk "Candour and the Code” (2002) 4 O \& G 100.

John A Pearce II, John J O’Brien and Derek A Rapisarda "Protecting Nursing Home Residents From Attacks on Their Ability to Recover Damages” (2008-2009) 61 Rutgers L Rev 705.

Richard A Posner "Rational choice, behavioral economics, and the law” (1998) 50 Stan L Rev 1551.

Matthew Rabin "Psychology and Economics” (1998) J of Economic Literature 11.

Iain Ramsay “Consumer Law, Regulatory Capitalism and the 'New Learning' in Regulation” (2006) 28 Sydney L Rev 9.

Pamatia Rekaiti and Roger Van den Bergh “Cooling-off Periods in the Consumer Laws of the EC Member States” (2000) 23 JCP 371.

Franziska Rischkowsky and Thomas Döring “Consumer Policy in a Market Economy: Considerations from the Perspective of the Economics of Information, the New Institutional Economics as well as Behavioural Economics” (2006) 31 JCP 285.

Lee Ross, Mark R Lepper and Michael Hubbard "Perseverance in Self-Perception and Social Perception: Biased Attributional Processes in the Debriefing Paradigm” (1975) 32 J of Personality and Social Psychology 880.

Markus Roth "Die Rechtsgeschäftslehre im demographischen Wandel, Stärkung der Autonomie sowie Schutzkonzepte bei Älteren und Minderjährigen” (2008) 208 AcP 451 (translation: The Legal Doctrine in Demographic Change, Strengthening of the Autonomy and Protection Concepts for Elders and Minors).

Rodolpho Sandoval “A Critical Analysis of the Cooling-off Period for Door to Door Sales” (1976) 3 Chicano L Rev 110.

Nils Schneider, Marie-Luise Dierks, Gabriele Seidel and Friedrich W Schwartz “The federal government commissioner for patient issues in Germany: initial analysis of the user inquiries” (2007) 7 BMC Health Serv Res 24.

Nils Schneider, Gabriele Seidel and Marie-Luise Dierks „Spricht das Angebot einer Patientenbeauftragten der Bundesregierung ältere Menschen an?““ (2007) 40 Z Gerontol Geriat 275 (translation: Does the offer to consult the federal government commissioner for patient issues address older people?).

Cathy Schoen, Robin Osborn, Phuong Trang Huynh, Michelle Doty, Kinga Zapert, Jordon Peugh and Karen Davis “Taking The Pulse Of Health Care Systems: Experiences Of Patients With Health Problems In Six Countries” (2005) 24 Health Affairs 509.

Byron D Sher "The "Cooling-off" Period in Door-to-door Sales” (1967-1968) 15 UCLA L Rev 717. 
Itamar Simonson "Choice Based on Reasons: The Case of Attraction and Compromise Effects” (1989) $16 \mathrm{~J}$ of Consumer Research 158.

Peter Skegg “A Fortunate Experiment? New Zealand's Experience with a Legislated Code of Patients’ Rights” (2011) 19 Med L Rev 235.

Nicola Sladden and Sarah Graydon "Liability for Medical Malpractice - Recent New Zealand Developments” (2009) 28 Med Law 301.

Vernon L Smith "Behavioral economics research and the foundations of economics" (2005) 34 J Socio-Econ 135.

Jan M Smits "Rethinking the Usefulness of Mandatory Rights of Withdrawal in Consumer Contract Law: The Right to Change Your Mind?” (2010-2011) 29 Penn St Intl L Rev 671.

Farzad Soleimani "Learning from mistakes in New Zealand hospitals: what else do we need besides “no-fault”?” (2006) 119 NZMJ U2099.

George J Stigler “The Economics of Information” (1961) 69 J Pol Econ 213.

Deborah Stone “Shopping for Long-Term Care” (2004) 23 Health Affairs 191.

David M Studdert, Michelle M Mello, Atul A Gawande, Troyen A Brennan and Y Claire Wang "Disclosure Of Medical Injury To Patients: An Improbable Risk Management Strategy” (2007) 26 Health Affairs 215.

Cass R Sunstein “Behavioral analysis of law” (1997) 64 U Chi L R 1175.

Ümit Taş, Ewout W Steyerberg, Sita MA Bierma-Zeinstra, Albert Hofman, Bart W Koes and Arianne P Verhagen "Age, gender and disability predict future disability in older people: the Rotterdam Study” (2011) 11 BMC Geriatrics 22.

Ümit Taş, Arianne P Verhagen, Sita MA Bierma-Zeinstra, Albert Hofman, Else Odding, Huib AP Pols and Bart W Koes "Incidence and risk factors of disability in the elderly: The Rotterdam Study” (2007) 44 Preventive Medicine 272.

Ümit Taş, Arianne P Verhagen, Sita MA Bierma-Zeinstra, Else Odding and BartW Koes "Prognostic factors of disability in older people: a systematic review" (2007) 57 Br J Gen Pract 319.

Richard Thaler “Toward a Positive Theory of Consumer Choice” (1980) 1 J Econ Behav \& Org 39.

Klaus Theuerkauf “Zivilrechtliche Verbindlichkeit von Expertenstandards in der Pflege” (2011) 29 MedR 72 (translation: Civil Liability of Expert Standards in the Care Sector).

Karen Tickner “Rogers v Whitaker - Giving Patients a Meaningful Choice” (1995) 15 OJLS 109. 
Stephen Todd “Treatment Injury in New Zealand” (2011) 86 Chi Kent L Rev 1169.

Kate Tokeley "Introducing a Prohibition on Unfair Contractual Terms Into New Zealand Law: Justifications and Suggestions for Reform” (2009) 23 NZULR 419.

Kate Tokeley "Late Departures: Consumers' Rights Under the Consumer Guarantees Act 1993” (2001-2004) 10 Otago L Rev 411 at 417 - 419.

Amos Tversky and Daniel Kahnemann "Rational Choice and the Framing of Decisions" (1986) 59 J Bus 251.

Neil Vidmar "Seeking Justice: An Empirical Map of Consumer Problems and Consumer Responses in Canada” (1988) 26 Osgoode Hall LJ 757.

Charles Vincent, Magi Young, Angela Phillips "Why do people sue doctors? A study of patients and relatives taking legal action” (1994) 343 The Lancet 1609.

W Kip Viscusi "Individual Rationality, Hazard Warnings and the Foundations of Tort Law” (1996) 48 Rutgers L Rev 625.

Ernest J Weinrib “Corrective Justice in a Nutshell” (2002) 52 UTLJ 349.

Sebastian Weber "Verbraucherschutz bei Verträgen über Wohnraum in Verbindung mit Pflege- und Betreuungsdienstleistungen” (2010) 13 NZM 337 (translation: Protection of Consumers in Contracts for Living Space in Conjunction with Nursing and Care Services).

Alan M White “Behavior and Contract” (2009) 27 Law \& Ineq J 135.

Solveig Wikström "Bringing Consumer Information Systems Down to Earth, Experiences from a Swedish Experiment” (1984) 7 JcP 13.

Chris Willett "The functions of transparency in regulating contract terms: UK and Australian approaches” (2011) 60 ICLQ 355.

Barry Williams ”Cost-benefit analysis” (2008) 2 ELMR 67.

Qi Zhou “What Can Contract Lawyers Learn from Law and Economics?” (2011) 30 U Tas LR 157.

Jacob S Ziegel “The Future of Canadian Consumerism” (1973) 51 Can Bar Rev 191.

\section{F Parliamentary and Government Materials}

Ministry of Consumer Affairs Consumer Law Reform: A Discussion Paper (Wellington, 2010).

Ministry of Consumer Affairs Consumer Law Reform Additional Paper - Unfair Contract Terms (Wellington, 2010). 


\section{G Reports}

The Royal Commission of Inquiry Compensation for Personal Injury in New Zealand (Woodhouse Report, December 1967).

\section{H Internet Resources}

Aged Care Crisis “Elder Abuse” (10 February 2008) Aged Care Crisis $<$ www.agedcarecrisis.com>.

Aged Care Crisis “Staffing issues" (18 December 2012) Aged Care Crisis $<$ www.agedcarecrisis.com>.

Age Concern "Respect Not Threats - Information about elder psychological abuse for resthome carers and managers” (2011) Age Concern New Zealand $<$ www.ageconcern.org.nz>.

Aged Rights Advocacy Service “Duty of Care” Aged Rights Advocacy Service South Australia <www.sa.agedrights.asn.au>.

Kirsten Armstrong and Daniel Tess "Fault versus No fault - Reviewing the International Evidence” (November 2008) Actuaries Institute <www.actuaries.asn.au>.

Australian Government Department of Health and Ageing “Aged Care Complaints” Department of Health and Ageing <www.health.gov.au>.

Australian Government Department of Health and Ageing “The Charter of Residents' Rights and Responsibilities” Department of Health and Ageing < www.health.gov.au>.

Better Regulation Executive and the National Consumer Council "Warning: Too Much Information Can Harm” (November 2007) Department for Business Information \& Skills $<$ www.bis.gov.uk>.

Rachel Browne “Alarm at violence in aged care” (28 March 2010) The Age National $<$ www.theage.com.au>.

Ramil Burden "Vulnerable consumer groups: quantification and analysis" (April 1998) Office of Fair Trading <www.oft.gov.uk>.

Commonwealth of Australia "Compliance and enforcement - How regulators enforce the Australian Consumer Law” (2010) Australian Consumer Law $<$ www.consumerlaw.gov.au>.

Helen Cull "Review of Processes Concerning Adverse Medical Events” (March 2001) Ministry of Health <www.moh.govt.nz>. 
Geoff Cumming and Martin Johnston “Review: Rest home roulette” (11 August 2012) The New Zealand Herald <www.nzherald.co.nz>.

Judith Davey, Virginia de Joux, Ganesh Nana and Mathew Arcus “Accommodation Options for Older People in Aotearoa/New Zealand” (June 2004) Institute for Governance and Policy Studies <igps.victoria.ac.nz>.

Department of Trade and Industry "Extending Competitive Markets: Empowered Consumers, Successful Business” (July 2004) Department for Business Information \& Skills <www.bis.gov.uk>.

Department of Trade and Industry "Extending Competitive Markets: Empowered Consumers, Successful Business” (June 2005) Department for Business Information \& Skills <www.bis.gov.uk>.

Department of Trade and Industry “Comparative Report on Consumer Policy Regimes” (October 2003) Department for Business Information \& Skills < www.bis.gov.uk>.

Europe Economics “An analysis of the issue of consumer detriment and the most appropriate methodologies to estimate it" (July 2007) European Commission $<$ ec.europa.eu>.

Peter Hanks and Lisa de Ferrari "Regulation of Residential Aged Care. Review of Legislation: Commonwealth, State and Territory” (30 April 2003) Australian Government Department of Health and Ageing <www.health.gov.au>.

Health and Disability Commissioner “Annual Report for the year ended 30 June 2012” (31 October 2012) Health and Disability Commissioner <www.hdc.org.nz>.

Health and Disability Commissioner "Policy Document - Naming Providers in Public HDC Reports” (1 July 2008) Health and Disability Commissioner <www.hdc.org.nz>.

Health \& Disability Advocacy and Health and Disability Commissioner "Your rights when using a health or disability service in New Zealand and how to make a complaint" Health and Disability Commissioner <www.hdc.org.nz>.

John Hickey “Summary Report and Accounts 2004” (May 2005) The Medical Protection Society <www.medicalprotection.org>.

Marika Hill “Appalling plight of elderly revealed” (28 April 2013) Stuff $<$ www.stuff.co.nz>.

Royden Hindle "Putting it Right? Monetary Remedies for Breaches of Patients' Rights" Royden Hindle <www.roydenhindle.co.nz>.

Warren P Hogan "Review of Pricing Arrangements in Residential Aged Care” (2004) Australian Government Department of Health and Ageing <www.health.gov.au>. 
Lillian Jeter "Facts on Elder Abuse - Australia" (February 2011) Office of the High Commissioner for Human Rights <www.ohchr.org>.

Retirement Commissioner “Retirement Villages Act 2003 Monitoring Project Residents’ Perspectives” (July 2011) Commission for Financial Literacy and Retirement Income $<$ www.cflri.org.nz>.

Rodney Lewis “An alternative to the resolution of aged care disputes” (31 January 2013) Aged Care Crisis <www.agedcarecrisis.com>.

Joanna Manning “Access to justice for New Zealand health consumers” (24 March 2010) Health and Disability Commissioner <www.hdc.org.nz>.

Medical Council of New Zealand "Disclosure of harm following an adverse event" (December 2010) Medical Council of New Zealand <www.mcnz.org.nz>.

Ministry of Consumer Affairs "Consumer Law Reform Additional Paper - Consumer Information Standards” (February 2011) Consumer Affairs $<$ www.consumeraffairs.govt.nz $>$.

Ministry of Consumer Affairs "Regulatory Impact Statement Consumer Law Reform” (December 2010) Consumer Affairs <www.consumeraffairs.govt.nz>.

Ministry of Health “Medicines Care Guides for Residential Aged Care” (May 2011) Ministry of Health <www.health.govt.nz>.

Joseph P Mulholland "Behavioral Economics and the Federal Trade Commission" (12 December 2007) Social Science Research Network <www.ssrn.com>.

New Zealand Labour, Green Party of Aotearoa and Grey Power New Zealand “A Report into Aged Care: What does the future hold for Older New Zealanders?”(October 2010) Labour <www.labour.org.nz $>$.

New Zealand Nurses Organisation "Rest home "horror stories” will continue” (8 October 2009) New Zealand Nurses Organisation <www.nzno.org.nz>.

New Zealand Nurses Organisation "Submission to the Health Select Committee On the Report from the Controller and Auditor-General on the effectiveness of arrangements to check the standard of services provided by rest homes” (April 2010) New Zealand Parliament <www.parliament.nz>.

New Zealand Press Association "Nurse struck off for punching elderly man in mouth" (11 May 2010) The New Zealand Herald <www.nzherald.co.nz>.

Office of Aged Care Quality and Compliance "Guidelines for the Aged Care Complaints Scheme” (September 2011) Department of Health and Ageing <www.health.gov.au>.

Stefan Schneider “Homo economicus - or more like Homer Simpson?” (29 June 2010) DB Research <www.dbresearch.in>. 
David Schout “Staff cuts faulted in nursing home death" (6 August 2012) The Dandenong Journal <www.dandenongjournal.com.au>.

Statistics New Zealand “National Population Estimates: September 2012 quarter” (14 November 2012) Statistics New Zealand <www.stats.govt.nz>.

Statistisches Bundesamt “Ältere Menschen in Deutschland und der EU“ (June 2011) Statistisches Bundesamt <www.destatis.de> (translation: Aged People in Germany and the European Union).

Grant Thornton “Aged Residential Care Service Review” (September 2010) Grant Thornton <www.grantthornton.co.nz>.

Jessica Wilson “Rest home roulette” (August 2009) Consumer <www.consumer.org.nz>.

\section{Other Resources}

Shane Cowlishaw "Rest home tardy over referral to hospital” The Dominion Post (New Zealand, 20 September 2012). 